Portland State University

PDXScholar

\title{
Outsiders Within Inequality Regimes: a Sociological Framework to Advance the Lives of Women Veterans
}

Sarah Louise Aktepy

Portland State University

Follow this and additional works at: https://pdxscholar.library.pdx.edu/open_access_etds

Part of the Military and Veterans Studies Commons, and the Sociology Commons Let us know how access to this document benefits you.

\section{Recommended Citation}

Aktepy, Sarah Louise, "Outsiders Within Inequality Regimes: a Sociological Framework to Advance the Lives of Women Veterans" (2020). Dissertations and Theses. Paper 5611.

https://doi.org/10.15760/etd.7483

This Dissertation is brought to you for free and open access. It has been accepted for inclusion in Dissertations and Theses by an authorized administrator of PDXScholar. Please contact us if we can make this document more accessible: pdxscholar@pdx.edu. 
Outsiders Within Inequality Regimes:

A Sociological Framework to Advance the Lives of Women Veterans

\author{
by
}

Sarah Louise Aktepy

A dissertation submitted in partial fulfillment of the requirements for the degree of

\author{
Doctor of Philosophy \\ in \\ Sociology
}
Dissertation Committee:
Maura Kelly, Chair
Amy Lubitow
Dara Shifrer
Miriam Abelson

Portland State University 
(C) 2020 Sarah Louise Aktepy 


\begin{abstract}
This three-paper dissertation examines pervasive gender inequalities across two institutions: the US military and Department of Veterans Affairs (VA). The first paper, “'Don't Rock the Boat:' Experiences and Perceptions of Gender-Based Violence in the U.S. Military" uses qualitative interviews to better understand the experiences of gendered harassment and violence of women veterans in the US military. The second paper, "First Do No Harm: Assessing Veterans Affairs Screening for Military Sexual Abuse among our Nations Veterans" uses survey data and qualitative interviews to identify factors that contribute to inaccurate results of clinical screening for veterans with military sexual violence histories within the Veteran Health Administration. The third paper, "Battle for Benefits: Gender Bias and VA Disability Award" uses survey data to highlight gender disparities in access to VA benefits and entitlement associated with selfreported military duty hazardous exposures. In sum, this dissertation examines the ways in which women veterans are "outsiders within" the "inequality regimes" of these organizations, and concludes with a discussion of key findings across all three papers with an explicit call to action.
\end{abstract}




\section{DEDICATION}

To the Goddesses of wisdom, craft, and warfare, who syncretized their knowledge and courage in support of veteran feminism and this glorious victory-I praise and thank you. 


\section{ACKNOWLEDGEMENTS}

I would like to recognize the participants, without whom I would not have been able to complete this work; to my dissertation committee for their willingness to impart their

knowledge and support, especially Dr. Maura Kelly; and, to the sociology department for funding a portion of my degree. 


\section{TABLE OF CONTENTS}

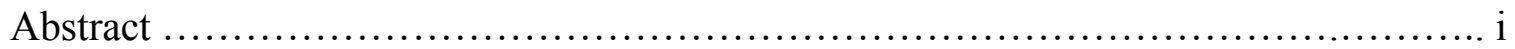

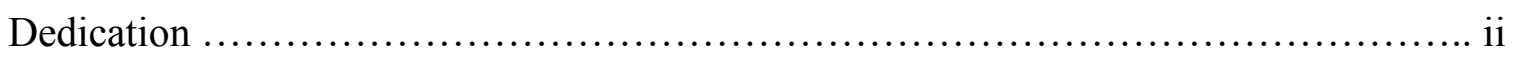

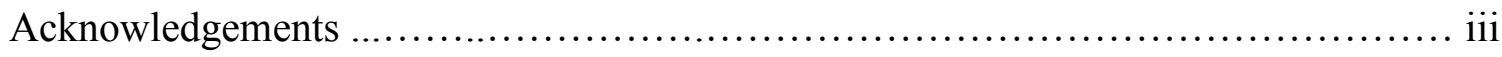

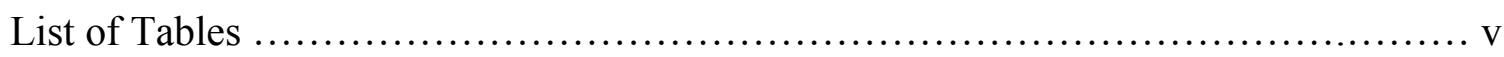

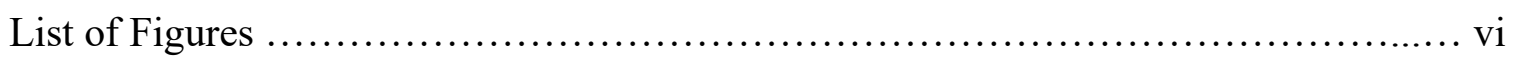

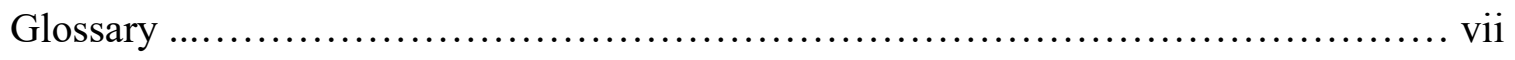

Chapter 1:

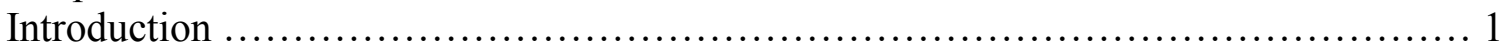

Chapter 2:

Literature Review ......................................................... 10

Chapter 3:

"Don't Rock the Boat": Experiences and Perceptions of Gender-Based Violence in the U.S. Military .......................................................... 18

Chapter 4:

First Do No Harm: Assessing Veterans Affairs Screening for Military Sexual Abuse

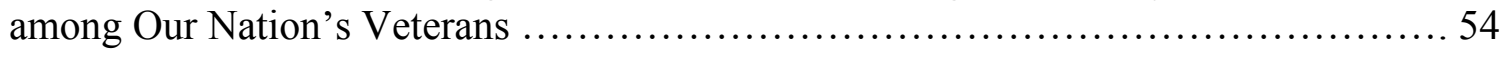

Chapter 5:

Combating Gender Bias in VA Disability Award ............................. 94

Chapter 6:

Discussion ......................................................... 122 


\section{LIST OF TABLES}

\section{Chapter 4 Tables}

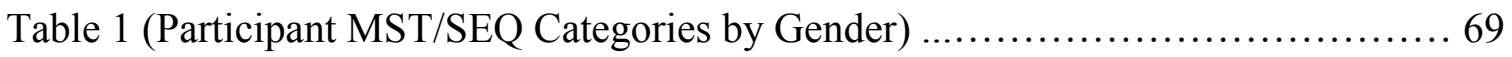

Table 2 (Local Rate of MST Screening by Gender) ............................ 72

\section{Chapter 5 Tables}

Table 1 (Descriptive Statistics Based on Weighted Data) ............................... 104

Table 2 (Log Odds from Logistic Regression Models Predicting VADC Award) .......109

Table 3 (Logistic Regression Models Predicting VA Disability Compensation 50\%-Or

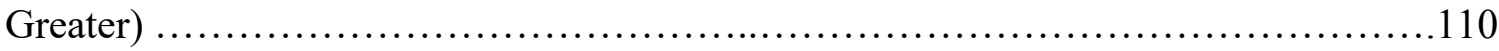

\section{Chapter 6 Tables}

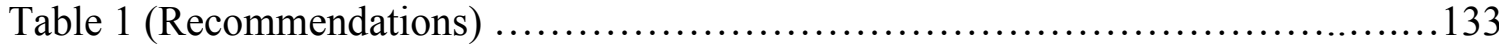




\section{LIST OF FIGURES}

Figure 1 (Gender Moderating Relationship between Military Exposures and VADC

Award and Rating) ................................................... 107 


\section{GLOSSARY}

United States Armed Forces. Also known as the US military consisting of the Army, Marine Corps, Navy, Air Force, Space Force, and Coast Guard. The president of the United States is the commander-in-chief of the Armed Forces and forms military policy with the Department of Defense (DoD) and Department of Homeland Security (DHS), both federal executive departments, acting as the principal organizations by which military policy is carried out.

Veteran. A person who served in the active military, naval, or air service and who was discharged or released under conditions other than dishonorable.

Active-duty service. Full-time duty 24 hours per day, 7 days a week, with the exclusion of leave (vacation) or pass (authorized time off). Active-duty members fall under the jurisdiction of the US Department of Defense (DOD) and can serve in the Army, Marine Corps, Navy, Air Force, Space Force, and Coast Guard.

Reservists. Performing duties one weekend per month, plus two weeks of training per year, members of the Reserves and National Guard are considered part-time, though, since the Gulf War in 1990, they've spent exponentially more time called to full-time active duty. Members are required to serve a minimum of 39 days on active-duty each year.

Department of Veterans Affairs (VA). The Veterans Administration was founded in 1930 and was formerly an independent government agency until 1989 when it became a US federal Cabinet-level agency with the title Department of Veterans Affairs. Today it is commonly referred to as "the VA" and provides healthcare services to eligible military veterans at VA medical centers and outpatient clinics located throughout the country; several non-healthcare benefits including disability compensation, vocational rehabilitation, education assistance, home loans, and life insurance; and provides burial and memorial benefits to eligible veterans and family members at 147 national cemeteries.

Veteran Health Administration (VHA). The largest of the three administrations that comprise VA and one of the largest health care systems in the world; providing health services to 9 million enrolled veterans each year at 144 VA Medical Center, 1,232 outpatient sites of care; provides training for America's medical, nursing, and allied health professionals; roughly 60 percent of all medical residents obtain a portion of their health training at VA hospitals; and VA medical research programs.

Veteran Benefits Administration (VBA). One of the three administrations of the VA responsible for administering programs that provide financial and other forms of assistance to veterans, their dependents, and survivors, such as disability compensation, insurance for service personnel and veterans, vocational rehabilitation for the disabled, 
and the VA home loan guarantee program.

National Cemetery System (NCA). One of the three administrations that comprise VA and is the system of 147 nationally important cemeteries in the United States for military burial places established during the American Civil War in an act passed by the US Congress on July 17, 1862; the national and state cemeteries contain the graves of US military personnel, veterans and their spouses, some important civilian leaders, and other national figures; the best known national cemetery is Arlington National Cemetery in Arlington County, Virginia, outside Washington, D.C.

Service-Connected Disabled Veteran: Also, known as VA disability compensation (VADC) is a veteran who is compensated monetarily each month and is eligible for health care for an injury that was caused or aggravated by military service.

MOS. Military occupational specialty.

Combat veteran: Any veteran deployed to a combat zone or area of war operations, such as Vietnam or Iraq.

Officer: Commissioned military personnel, usually known for planning military operations.

Enlisted: Military personnel that execute orders during military operations, a noncommissioned officer.

Mobilize: To move a military unit from state side to a military theatre of war.

PREMOB: Pre-mobilization is the act of assembling forces for active-duty in times of war or national emergency.

Theatre: Land, sea, subsurface, air, and space that may become or is involved in war operations.

Haze gray vessel: A US Navy ship.

Morale van: A military vehicle that operates on a US Armed Forces installation specifically for transporting military personnel to locations to enhance morale and welfare, such as a bowling alley or church.

EMR. Electronic medical record.

Gender-based violence (GBV). Any act of violence gender-based that results in, or is likely to result in physical, sexual, or psychological harm or suffering, including threats of such acts, coercion or arbitrary deprivations of liberty, whether occurring in public or 
private life. This can include: sexual harassment, sexual assault, rape, coercion, retaliation, and secondary traumatization, as well as the threat of such acts.

Secondary victimization. The victim-blaming attitudes, behaviors, and practices engaged in by service providers, which results in additional trauma for sexual assault survivors. This can include: shaming, threatening, revoking privileges, tarnishing personal records, and blaming the victim.

Sexual assault. Sexual assault is any type of sexual contact or behavior that occurs without the explicit consent of the recipient. Falling under the definition of sexual assault are sexual activities as forced sexual intercourse, forcible sodomy, child molestation, incest, fondling, and attempted rape.

Sexual harassment. Unwelcome sexual advances, requests for sexual favors, or other verbal or physical conduct of a sexual nature that occur in a work setting. Can include touching, feeling, groping, and/or repeated unpleasant, degrading and/or sexist remarks directed toward an employee, implying that employment status, promotion, or favorable treatment.

Rape. Any act of sexual intercourse or penetration of the vagina, anus, or mouth of another person, with or without force, by a sex organ, other body part, or foreign object, without consent.

Military sexual abuse. Any act of violence by a military member to another military member is gender-based and results in, or is likely to result in physical, sexual, or psychological harm or suffering, including threats of such acts, coercion or arbitrary deprivations of liberty, whether occurring in public or private life. This can include: sexual harassment, sexual assault, rape, coercion, retaliation, and secondary traumatization, as well as the threat of such acts.

Military sexual trauma (MST). The term adopted by the VHA; MST refers to both sexual harassment and sexual assault that occur in the US military. Both men and women can experience MST and the perpetrator can be of the same or of the opposite gender.

Sexual Experiences Questionnaire-Department of Defense version (SEQ-DOD). A published measure that documents experiences with sexual harassment and sexual assault in the military.

Command rape. The institutional retaliation experienced by military personnel and veterans when reporting military sexual abuse to military and VA authorities within these institutional contexts.

Fratricide. Defined as killing one's brother or sister, this term is used in the military to describe service member on service member killing. 
Institutional betrayal. Wrongdoing's perpetrated by an institution upon individuals dependent on that institution, including failure to prevent or respond supportively to wrongdoings by individuals committed within the context of the institution.

Total institution. A total institution termed by Erving Goffman is defined as a closed social system in which life is organized by strict norms, rules, and schedules, and what happens within it is determined by a single authority whose will is carried out by its members who enforce the rules; separated from wider society by distance, laws, and/or protections around their property and those who live within them are generally similar to each other in some way, examples include prisons, military, private boarding schools, and locked mental health facilities.

Inequality regimes. A concept developed by American sociologist, Joan Acker defined as interrelated practices, processes, actions, and meanings that result in and maintain class, gender, and racial inequalities within particular organizations.

Outsiders within. A term defined by Patricia Hill Collins (1986) as a person who has a particular knowledge/power relationship, one of gaining knowledge about or if a dominant group without gaining full power accorded to members of that group.

Veteran feminism. A term I introduce and define as veterans and allies who engage in various forms of individual and collective political activism across diverse organizational contexts, including local, state, and national levels to advance the lives of veterans. 


\section{CHAPTER 1: INTRODUCTION}

Women veterans are the fastest growing segment of the total veteran population, and account for two of the 22 million veterans living in the United States (Women Veterans Report, 2017). Women have a broad range of military and post- service experiences; however, they are often invisible to policymakers and the public (SWAN, 2018). Despite a large volume of public health literature on women veterans, little is understood about differing quality of life outcomes for women as a veteran group. Although many women reintegrate successfully to civilian life after serving in the US military, the majority of research suggests women veterans as more likely to be unemployed, uninsured, housing insecure, and diagnosed with post-traumatic stress disorder (PTSD) compared to all other veteran groups (Women Veterans Report, 2017); suicide rates among women veterans increased 63\% between 2000 and 2014, compared to 30\% among men (VA Office of Suicide Prevention, Veterans Affairs, 2016). Much of this research conceptualizes women veterans from a focus that has been centered on victimization of sexual assault in the military, an ongoing epidemic that has gained more recent attention, with growing awareness that support and post-service approaches for addressing health sequelae of military service are derived from 'traditional' approaches and prove insufficient for full recovery. A study conducted by Kimerling (2015) found it difficult for women veterans to remain engaged in health care, and half of women veterans who utilize VA health care report feeling unwelcome at these facilities (SWAN, 2018). Therefore, it is most certain a critical need to better understand the lived experiences of military women and women veterans if we are to advance the lives of women veterans. 


\section{Statement of the Problem}

Despite a large volume of public health literature on veterans, little is understood about differing quality of life outcomes for women veterans. Most studies about veterans do not report on women veterans as a sub-group. More than $50 \%$ of this research emphasizes mental health, post-deployment health, access to care and rural health, reproductive health, and other health conditions, with only $10 \%$ of research focused on other categories (VA, 2016). Nearly all of which draw on public health and psychological frameworks that emphasize military stressors, traumatization and/or pathology of military duty exposures, history of childhood sexual abuse, posttraumatic stress disorder (PTSD), substance abuse, and other physical and mental health diagnoses to explain gender differences in post-service outcomes. These studies conceptualize women veterans to be victims of military sexual violence, which is an ongoing epidemic that has gained more recent attention. But these approaches also, suggests women's poor health related to military service is the result of individual level factors that make them deficient for full recovery. While individual or proximate approaches allow for identifying immediate determinants of some acts of violence and risk factors, these research approaches do not help detect patterns embedded in and across structural systems that may better explain disparate health and other quality of life outcomes among women veterans (Dominguez, 2014).

\section{Research Positionality}

I identify as a queer, cis- woman veteran with multiple deployments in support of combat operations during Operation Enduring Freedom/Operation Iraqi Freedom. I have 
over 20 years of work and volunteer history within the US military, Department of Veterans Affairs (VA), and in the veteran non-profit sector. Over the years I have personally participated in, and observed a justice movement for veterans with a broad range of change efforts within and outside varying types of organizations. I have engaged in this justice movement by way of diverse media platforms, including several awareness campaigns, forging and dissolving professional relationships, coordinating with political allies, and engaging in representational political actions in national and international settings, including breweries, hospitals, classrooms, conferences, before members of Congress, and legal and policy reform initiatives at the Federal Circuit. Veteran feminism, a term I introduce and adopt to define veterans and allies who engage in various forms of individual and collective political activism to advance the lives of veterans regardless of gender across diverse organizational contexts, including local, state, and national levels. Veteran feminism is what inspired this dissertation and has been a key motivation of this work.

Black feminists produce "oppositional knowledge" to combat negative theoretical models based on racialized mischaracterizations and exploitation of inequalities (Collins 2016, Mullings 2000). Similarly, veteran feminism in this dissertation produces oppositional knowledge to combat negative medical and theoretical models based on institutional mischaracterizations and exploitation of systemic gender inequalities. The idea of pursuing academic veteran feminism by drawing on my own "insiderism" came about as a political act in my consciousness due to the emerging awareness of the importance for me in obtaining legitimate academic authority due to the alarming trends 
and gaps in most literature circulated about the lives of women veterans. Upon completion of the $\mathrm{PhD}$, I intend to re-emerge in the professional ranks of the veteran justice movement, and continue with this work dedicated to challenging existing limited and limiting approaches to justice for military women, women veterans, and other disadvantaged veteran groups.

\section{Learning from Black Feminist Thought: Women Veterans as Outsiders Within}

The medical model is a term coined by psychiatrist R. D. Laing in his The Politics of the Family and Other Essays (1971). It is defined as a "set of procedures in which all doctors are trained," whereby basic assumptions about medicine inform research and theory of physical and psychological difficulties. Mainstream research on women veterans is typically aligned with basic medical models, thus dominant public health discourse plays a role in reproducing active ignorance and maintaining systems of oppression by failing to acknowledge and critique distribution and social dimensions of the knowledge produced (Berenstain, 2016). Most of the literature positions women and other underrepresented veteran groups primarily or exclusively as: patients, victims, traumatized, or interpersonally resource deficient, pathologizing women veterans by medicalizing their responses to lived experiences, especially responses adaptive in military contexts which portrays them post- military service as "people needing to be managed" (Gomez, et.al, 2016; p.170).

In the article, "Learning from the Outsiders Within: The Sociological Significance of Black Feminist Thought” (1986), Collins suggests not only Black women can draw on key themes of Black feminist thought to generate a distinctive standpoint on existing 
paradigms. She argues that other marginal intellectuals can similarly draw on three sociological significant characteristics of Black feminist thought: "(1) self-definition and self-evaluation, (2) the interlocking nature of oppression, and (3) the importance of the Afro-Women's culture to highlight the tension experienced by any groups of less powerful outsiders encountering the paradigmatic thought of a more powerful insider community that previous excluded them" (p. 24). As marginal intellectuals, 'outsiders within' sociology, Collins (1986, p. 30) proposes that by placing greater trust in the creative potential of their own personal and cultural biographies, "they can move themselves and their discipline closer to the humanist vision implied in their work".

Women veterans have a unique perspective about their lived experiences and produce certain commonalties in their way of seeing as women veterans. Class, race, age, region, era of service, sexuality, and ability are examples of factors that create differing experiences and expressions among women veterans despite universal commonalties. Drawing from the literature on the special perspectives of Black women's experience as outsiders within, I am encouraged to focus attention on the duality of my own emerging creativity and power as a woman veteran within inequality regimes and as an 'outsider within sociology' (Collins, 1986), and the voices of women veterans as outsiders within these institutions. An "outsider within" is a person who has a particular knowledge/power relationship, a relationship in which gaining knowledge about, or if a dominant group, without gaining full power accorded to members of that group (Collins, 2016; Harrison, 2008). This task is significant, in part, as it is also a practice of creative potential and the production of oppositional knowledge to "combat negative" theoretical models based on 
mischaracterizations and exploitation of inequalities (Collins, 2016; Mullings, 2000). How are you applying this in your dissertation?

A substantial body of research on women veterans draws on public health and psychological frameworks that emphasize military stressors, traumatization and/or pathology of combat exposures, military sexual harassment and assault, abuse in childhood, posttraumatic stress disorder (PTSD), traumatic brain injury (TBI), depression, substance abuse, and other physical and mental health diagnoses, and suicide rates to argue for differences in post-service outcomes among women veterans. While individual or proximate approaches allow for identifying immediate determinants of some acts of violence and risk factors, these research approaches do not help detect patterns embedded in and across structural systems (Dominguez, 2014). Alternatively, in this project I adopt an "outsider within status" as a woman veteran to "stimulate a reexamination and identification" of my own standpoint as a sociologist and "generate a distinctive standpoint vis-à-vis existing paradigms" of women veterans as a group (Collins, 1986 p.16). Consistent with approaches advocated by intersectionalists (Collins, 2000; Crenshaw, 1991), this work embraces a state of perpetual transformation, the ongoing processing of new conceptualizations of private and public experiences, and my learning to trust them as significant and valid sources of knowledge. The ideas from outsider within inequality regimes produced in this dissertation demonstrate the important of social difference in academic endeavors by producing a distinctive analysis of gender and class inequality that has predominantly obscured research in this substantive area, providing clarity of women veteran's standpoint by embracing the three themes of Black 
feminist thought. In this sense, I draw on the duality of my own "insiderism" and "marginality, and that of the military women and veteran women community "to clarify a standpoint of and for women veterans" and highlight aspects of the culture within which women veterans live (p. 16). In addition, I aim to transcend pathologizing and limiting scholarship and demonstrate a critical posture as a "marginal intellectual" (Mannheim, 1936) to advance a "particular way of seeing reality" (White, 1984).

Consistent in Black feminist thought is the importance of adopting an intersectional approach to assess how systems of inequality operate on the basis of gender, race, class, and other systems of inequality observed in the context of organizations (Collins, 2000 \& Crenshaw, 1989). Therefore, this three-paper dissertation, I redirect focus on structural patterns and inequalities within broader contexts normally unrecognized as forms of violence and misrecognized disadvantaged social locations (Fieldmen, 1991). Across these three papers, I provide a distinctly sociological perspective which highlights structural factors and power relations that move beyond individual-level factors to reframe how we understand differing quality of life outcomes for women veterans as a group existing within broader organizational contexts. Here, characteristics and less evident manifestations of systematic disparities between participants in power and control over goals, resources, and outcomes, and other forms of institutional transfer that come from profound inequalities is analyzed and unveiled (Acker, 2009; Dominiguez, Menjivar, 2014). A critical posture and sociological approach is necessary to reveal the transferability of situational contexts and systematic forms of violence, including disadvantaged access and control of resources for survival across and 
distributed through the US military and VA. This work serves as a source to better understand the complexity of inequalities, the controls that prevent protest against them with the intention to advance the lives of women veterans, whilst embracing "the freedom both to be different and part of the solidarity of humanity" (Collins, 1986:30). State how this paragraph is relevant for your dissertation - maybe just move the second to last sentence to be the last sentence

Overview of the Dissertation

The primary goal of this dissertation project is to fill conceptual gaps in the literature by exploring experiences of women veterans in relation to social structures, institutions, bureaucracies, and in every day, ongoing practices across two specific organizations: the US military and VA. Much of the research that documents women veterans' lives focus primarily on individual or other proximate determinants of health. These approaches evade institutional responsibility within work organizations, and the relationship of disparate health outcomes for certain veteran groups. While the expansive literature about women veterans has gained intellectual attention in the last decade, it remains under-theorized across differing academic disciplines, with most research endeavors that ignore broader contexts and inequalities that create social conditions and maintain disadvantages. It is important to understand these factors, since they manifest in the lives of veterans, and have implications for clinical practice, and policy.

To achieve this goal, I employ multiple methods across three studies for the dissertation project. In the first chapter, I provide a brief history of women in the US military; a review of previous research on gender-based harassment, discrimination, and 
assault in the military; a discussion of the theoretical framework for the dissertation; an overview of my positionality as a researcher; and an overview of the dissertation chapters. In the first study, I conducted interviews and analyzed qualitative interview data from a total of 14 participants, seven Iraq and Afghanistan Era women veterans and seven providers from the same VA health care facility. The aim of the study was to explore: How do women veterans and their VA providers understand experiences of military gendered harassment and violence. The aim of this study was to assess: How does gender influence VA benefit award for women veterans? In the second paper, I analyzed qualitative interview data from a total of 76 men and women veterans to better understand: What veterans remember when asked to recall being screened for MST in the VA health care setting? In the third paper, I analyzed self-reported survey data on military hazards and DVA benefit award that I extracted from the 2010 National Survey of Veterans (NSV) designed to identify needs of veterans and inform distributional of costly resources The dissertation will conclude with a discussion of key findings across all three papers, as well as recommendations for shifting change efforts informed by 'outsiders within inequality regimes.' 


\section{CHAPTER 2: LITERATURE REVIEW}

Women in the U.S. Military

The position of women as outsiders in the U.S. military began with their limited access to the institution until relatively recently. Women officially could enlist in the US military during the last two years of World War I although it has been documented they have engaged the enemy on the battlefield since the American Revolution (Murdoch, 2013).

Initially, women could not serve in certain military jobs. Restrictions of 237,000 military jobs for women was rescinded in 2011 due to the need of women's participation and expanding duties in the wars following September 11, 2001 terrorist attacks (King 2016). Currently, all ground combat occupations and types of military units are open to women, including eligibility for Special Operations Forces in all US military branches (Department of Defense military services: Army, Navy, Marine Corps, Air Force; Department of Homeland Security: Coast Guard). As of 2018, women comprise $16.3 \%$ active duty military personnel, $19.8 \%$ of guard and reserve services, and $17.4 \%$ of Coast Guard reserves (DOD, 2018).

Historically women have provided casualty care (Carlson, Stromwall, \& Liets, 2013) with the same risks as male soldiers, have died and been wounded in action, and taken as prisoners of war in every major U.S. conflict (King, 2016; Murdoch, 2013). As of 2018, it has been documented that 170 service women died and 1,102 were wounded in action. In this history of the US military, two enlisted servicewomen received the 
Silver Star for heroism during the ongoing conflicts in Iraq, Afghanistan, and Syria (DOD, 2018).

\section{Gender-Based Harassment, Discrimination, and Assault in the US Military}

In the broader U.S. society, there is growing public awareness of sexual violence toward women and it is considered a significant public health concern (Krantz \& Moreno, 2005). In the general population, studies have shown that men and women who experience sexual violence suffer severe and chronic negative physical and emotional effects (Krantz, 2005). As such, increased morbidity and mortality (World Health Organization, 2018) is higher among women who report traumatization with abuse history compared to those without. Although a few studies have found a relationship between sexual abuse and increased risk for poor health outcomes and early mortality, less is known about the association of social conditions and contexts in which sexual violence occurs and the relationship to health (World Health Organization, 2018).

Military sexual trauma (MST) is a term adopted by the VHA; MST refers to both sexual harassment and sexual assault that occur in the US military. Both men and women can experience MST and the perpetrator can be of the same or of the opposite gender. A general definition of sexual harassment is unwelcome verbal or physical conduct of a sexual nature that occurs in the workplace or an academic or training setting. Sexual harassment includes gender harassment (e.g., putting someone down because of their gender), unwanted sexual attention (e.g., making offensive remarks about another's sexual activities or their body) and sexual coercion (e.g., implied special treatment for someone if they are sexually cooperative) (Department of Veterans Affairs, 2018). 
Sexual assault is any sort of sexual activity between at least two people in which one of the people is involved against his or her will. Physical force may or may not be used. The sexual activity involved can include many different experiences including unwanted touching, grabbing, oral sex, anal sex, sexual penetration with an object, and/or sexual intercourse.

Among active duty populations rates of military sexual harassment have been as high as $74 \%$ among men and $90 \%$ among women (Murdoch \& Nichol, 1995; Murdoch, Pryor, Polusny, \& Gackstetter, 2007; Rosen \& Martin, 1998; Street, Gradus, Giasson, Vogt, \& Resick, 2013; Street, Gradus, Stafford, \& Kelly, 2007; Street, Stafford, Mahan, \& Hendricks, 2008). Rates for military sexual assault among active duty populations have been reported as $4 \%$ among men and $71 \%$ among women (Cunradi, Ames, \& Moore, 2005; Murdoch \& Nichol, 1995; Suris \& Lind, 2008; Turchik \& Wilson, 2010). However, the mandated VHA MST screening results vary greatly in comparison, approximately $1 \%$ of men and $25 \%$ of women veteran's screen positive during VHA visits for military sexual trauma (MST+) (Department of Veterans Affairs, 2015).

Sexual harassment and assault in the military does not occur only during training or peacetime. Times of war are associated with increases in rates of sexual harassment and assault (Katz, 2012; Street and Stafford, Iraq War Clinician Guide, 2009). Research with Persian Gulf War military personnel found that rates of sexual assault (7\%), physical sexual harassment (33\%) and verbal sexual harassment (66\%) were higher than those typically found in peacetime military samples (Kimerling, Street, Pavao, Smith, Cronkite, Holmes, \& Frayne, 2010). . 
While there is almost no empirical data comparing experiences of military sexual violence with experiences of sexual harassment and assault that occur outside of military service, there is some anecdotal evidence that these experiences are associated different psychological outcomes (Suris \& Lind, 2008). Sexual violence that is associated with military service most often occurs in a setting where servicemembers live and work. In most cases, this means that servicemember who experience sexual abuse in the military continue to live and work closely with perpetrators who abuse(d) them. Sexual violence that occurs in this setting often means that victims are relying on their perpetrators (or associates of the perpetrator) to provide for basic needs including medical and psychological care (Street \& Stafford, Iraq War Clinician Guide, 2009). Similarly, because military sexual harassment and assault occurs within the workplace, this form of abuse disrupts career aspirations. Perpetrators are frequently peers or supervisors responsible for making decisions about work-related evaluations and promotions (Street, Gradus, Giasson, Vogt, \& Resick, 2013). In addition, survivors are often forced to choose between continuing military careers that require frequent contact with perpetrators or sacrificing their career to protect themselves from further sexual harassment and/or assault.

Most military groups are characterized by high unit cohesion, particularly during combat (MacCaoun, 1996). Unit cohesion is a military concept, defined as "the bonding together of soldiers in such a way as to sustain their will and commitment to each other, the unit, and mission despite combat or mission stress" drives group performance (MacCaoun, 1996 p.61). While optimal levels of unit cohesion are considered to reflect 
positive aspect of military service, the dynamics of cohesion play a role in the negative psychological effects associated with sexual harassment and assault that occurs in the US military. Because organizational cohesion is so highly valued within the military environment, divulging any negative information about a fellow service member is considered taboo. Many reporting parties suffer abuse and retaliation for reporting sexual abuse, which are predictors for early separation from military service (Schweitzer, 2013). Consequently, it is no surprise that the last publicly available DoD study in 2007 found that only $8 \%$ of sexual assailants in the military were referred to courts martial, or military courts, compared with $40 \%$ of similar offenders prosecuted in the civilian court system (Kimerling, Street, Pavao, Smith, Cronkite, Holmes, \& Frayne, 2010).

\section{Theoretical Framework: Total Institutions and Individual Agency}

Following the work of Goffman (1961), I consider the complex interplay between structure and agency inside the U.S. military, a total institution. Goffman defined the total institution as "a place of residence and work where a large number of situated individuals, cut off from the wider society for an appreciable length of time, together lead an enclosed, formally administered round of life" (1961, xiii). Goffman described practices and processes of the total institution that enforced loss of self-determination and autonomy upon entering, such that individuals might "be shaped and coded into an object that can be fed into the administrative machinery or the establishment" (1961, p. 16). This quality of the military as a total institution creates an environment where individuals are deeply influenced by the cultural climate created and maintained by structural forces. This understanding allows us to focus less on individual actors and more on the 
operations of the total institution itself, suggesting then, "we will give less praise and blame to particular superintendents, commandants, wardens, and abbots, and tend more to understand the social problems and issues in total institutions by appealing to the underlying structural design common to them all” (Goffman 1961, p. 123-4).

Zucher's (1965) study of life at sea on a naval vessel was the first application of Goffman's typology of the total institution to the U.S. military (cited in Naphan and Elliot 2015). In their assessment of role exit among veterans transitioning from service to higher education, Naphan and Elliot also note that the military defies some aspects of Goffman's concept: "Today, individuals voluntarily enlist in the U.S. military, are compensated for their work, are given responsibilities, and are often recognized for their service, such that the military does not make 'total' claims on its members" (2015, p. 37). As noted by McEwen (1980), total institutions are imprecisely "closed" systems, which highlights the importance of the broader cultural climate of the society from which individuals who comprise the institution are drawn. McEwen suggests we consider the "impact of such organizations on their members- on their senses of self and on their values, attitudes, relationships and behavior" (1980, p. 144). Importantly, in their extensive review of the literature on total and nontotal institutions, McEwen (1980) notes that the effects of working in total institutions on individual members are products of the organizational structure. I draw on this understanding in my approach to policy recommendations, emphasizing the focus on structural rather than individual factors that create an environment where gender-based violence remains prevalent, and may be 
conceptualized as an indicator of the cultural climate within the U.S. military as a total institution.

Acker's (2006) concept of inequality regimes can help to understand how inequality functions within organizations and institutions, just as the US military and VA. According to Acker (2006), "All organizations have inequality regimes, defined as loosely interrelated practices, processes, actions, and meanings that result in and maintain class, gender, and racial inequalities within particular organizations" (p. 443). Acker considers the multiple and fluid nature of inequality within organizations by examining interlocking systems of oppression, e.g. class, gender, race, sexuality, religion, age, and ability, an idea from intersectionality. Acker examines the shape and degree of inequality within an organization according to the "steepness of hierarchy," noting that the "steepest hierarchies are found in traditional bureaucracies" (2006, p. 445), as for example, within the U.S. military. By examining the organizational practices, policies, and ideologies that (re)produce inequality, we can better interpret the individual and institutional dimensions of complex social interaction that occur inside organizations.

Acker (2006) notes that inequality regimes are resistant to change, in part because they are "linked to inequality in the surrounding society, its politics, history, and culture" (p. 443). It is integral, then, that we consider the gendered and sexualized norms of the military as a reflection of the broader society, potentially amplified in the context of the total institution. Acker further notes: "Change projects focused on gendered behaviors that are dysfunctional for the organization provide examples of the almost unshakable fusion of gendered identities and workplace organizing practices” (2006, p. 457). 
Although resistant to change, Acker (2006) does suggest that the staying power of inequalities regimes may be mitigated through strategies that make inequalities more visible, thereby increasing their perceived illegitimacy.

Acker's conceptualization of inequality regimes has provided evidence of its utility on few previous studies, (e.g. Kelly, Wilkinson, Pisciotta, \& Williamson 2015; Whitehead 2013; Healy, Bradley, Forson 2011; Bryant and Jawrpski 2011), no studies have documented the covert (e.g. gender disparities that appear natural) and overt (e.g. military rape) inequality-producing practices and locations of organizational processes across these two organizations: US military and VA. As such, the task of this project is a participation in oppositional knowledge production and emphasize the authority from the voices of privileged 'outsiders within inequality regimes' (Collins 1986; Acker 2006). 


\section{CHAPTER 3: "DON'T ROCK THE BOAT": EXPERIENCES AND PERCEPTIONS OF GENDER-BASED VIOLENCE IN THE U.S. MILITARY}

Authors: Sarah Louise Aktepy and JaDee Yvonne Carathers

Abstract: Research on military sexual trauma (MST) has largely focused on individual determinants and mental health outcomes. These research approaches contribute to an understanding of the prevalence and health consequences of sexual harassment and assault that occurs in the U.S. military. However, they provide little utility for understanding how institutions relate to these outcomes, with few studies that have examined individuals' evaluations of the roles of social institutions and how they relate to the lives of those individuals from women veterans themselves. Therefore, we analyzed interview data from seven Operation Enduring Freedom/Operation Iraqi Freedom (OEF/OIF) women veterans enrolled in VA health care and seven VA health care providers charged with their care who described accounts and interpretations of sexual harassment and assault that occurred in the U.S. military. The prevalence of and dialogue around this type of military experience in all the interviews, both explicitly and implicitly, justified examining these narratives. Institutional betrayal emerged as the way in which participants described and made meaning during the interview process. As an alternative to focusing on the prevalence and health outcomes of military sexual harassment and sexual assault, we propose objective knowledge of these experiences does not exist without considering social conditions and how those involved interpret these conditions. Findings suggest that the way we understand sexual harassment and 
assault in the U.S. military needs to be redirected, with implications for public health and policy reform.

\section{INTRODUCTION}

Studying gender-based violence that occurs within the U.S. military as a "total institution" (Goffman, 1961) allows for an examination of the complex negotiation of institutional structure and individual agency. In this study, we consider the experience of gender-based violence (i.e., discrimination, harassment, and sexual violence, including rape) within the context of the U.S. military by examining participant narratives from seven Operation Enduring Freedom/Operation Iraqi Freedom (OEF/OIF) women veterans enrolled in Veteran's Administration (VA) health care, and seven VA health care providers charged with their care. We investigate how participants construct and make meaning of gender-based violence in the U.S. military.

Previous studies examining gender-based violence in the U.S. military have largely focused on prevalence, associated health outcomes, and individual predictors of perpetration and victimization (Mattocks, Haskell, Krebs, Justice, \& Yano, 2012). This study seeks to enrich our understanding of gender-based violence in the military from the perspective of those with situated knowledge. Findings support previous research on the social problem of gender-based violence in the military as one that is not simply a form of interpersonal violence, but one that can be better understood as a type of institutional betrayal trauma (Reinhardt et al., 2016). Through narrative analysis, this study situates gender-based violence in the U.S. military as a type of institutional betrayal trauma (Reinhardt et al., 2016).) unique to the military as a total institution (Goffman, 1961), and 
reinforced through inequality regimes that re-create gendered and racialized patterns of inequality (Acker, 2006).

\section{LITERATURE REVIEW}

\section{The Military as an Institution}

Following the work of Goffman (1961), we consider the complex interplay between structure and agency inside the U.S. military, a total institution. Goffman defined the total institution as "a place of residence and work where a large number of situated individuals, cut off from the wider society for an appreciable length of time, together lead an enclosed, formally administered round of life" (1961, xiii). Goffman described practices and processes of the total institution that enforced loss of selfdetermination and autonomy upon entering, such that individuals might "be shaped and coded into an object that can be fed into the administrative machinery or the establishment" (1961, p. 16). This quality of the military as a total institution creates an environment where individuals are deeply influenced by the cultural climate created and maintained by structural forces. This understanding allows us to focus less on individual actors and more on the operations of the total institution itself, suggesting then, "we will give less praise and blame to particular superintendents, commandants, wardens, and abbots, and tend more to understand the social problems and issues in total institutions by appealing to the underlying structural design common to them all” (Goffman, 1961, p. 123-4).

Zucher's (1965) study of life at sea on a naval vessel was the first application of Goffman's typology of the total institution to the U.S. military (cited in Naphan \& Elliot, 
2015). In their assessment of role exit among veterans transitioning from service to higher education, Naphan and Elliot also note that the military defies some aspects of Goffman's concept: “Today, individuals voluntarily enlist in the U.S. military, are compensated for their work, are given responsibilities, and are often recognized for their service, such that the military does not make 'total' claims on its members" (2015, p. 37). As noted by McEwen (1980), total institutions are imprecisely "closed" systems, which highlights the importance of the broader cultural climate of the society from which individuals who comprise the institution are drawn. McEwen suggests we consider the "impact of such organizations on their members - on their senses of self and on their values, attitudes, relationships and behavior" (1980, p. 144). Importantly, in their extensive review of the literature on total and nontotal institutions, McEwen (1980) notes that the effects of working in total institutions on individual members are products of the organizational structure. We draw on this understanding in our approach to policy recommendations, emphasizing the focus on structural rather than individual factors that create an environment where gender-based violence remains prevalent, and may be conceptualized as an indicator of the cultural climate within the U.S. military as a total institution.

Acker's (2006) concept of inequality regimes can help to understand how inequality functions within organizations and institutions. According to Acker (2006), "All organizations have inequality regimes, defined as loosely interrelated practices, processes, actions, and meanings that result in and maintain class, gender, and racial inequalities within particular organizations" (p. 443). Acker considers the multiple and 
fluid nature of inequality within organizations by examining interlocking systems of oppression, e.g. class, gender, race, sexuality, religion, age, and ability. Acker examines the shape and degree of inequality within an organization according to the "steepness of hierarchy," noting that the "steepest hierarchies are found in traditional bureaucracies" (2006, p. 445), as for example, within the U.S. military. By examining the organizational practices, policies, and ideologies that (re)produce inequality, we can better interpret the individual and institutional dimensions of complex social interaction that occur inside organizations.

Acker (2006) notes that inequality regimes are resistant to change, in part because they are "linked to inequality in the surrounding society, its politics, history, and culture" (p. 443). It is integral, then, that we consider the gendered and sexualized norms of the military as a reflection of the broader society, potentially amplified in the context of the total institution. Acker further notes: "Change projects focused on gendered behaviors that are dysfunctional for the organization provide examples of the almost unshakable fusion of gendered identities and workplace organizing practices" (2006, p. 457). Although resistant to change, Acker (2006) does suggest that the staying power of inequalities regimes may be mitigated through strategies that make inequalities more visible, thereby increasing their perceived illegitimacy.

To examine gender-based violence in the U.S. military among women veterans is to attend to the gendered dimensions of inequality shaped by the structural facets of the military institution. By examining the practices, policies, and ideologies that reproduce complex inequalities, we can interpret the implications of gender-based violence in the 
U.S. military as a gendered outcome of inequality regimes within the military total institution.

\section{Military Sexual Trauma, Gender, and Health}

The U.S. military utilizes a specific understanding of gender-based violence through the terminology: military sexual trauma (MST). Although several definitions of MST are used across organizations, the Department of Veterans Affairs (DVA) describes MST as any unwelcome verbal or physical conduct of a sexual nature that occurs across military settings to include gendered harassment, unwanted sexual attention, and sexual coercion (DVA, 2016). Sexual assault is defined as any sort of sexual activity between at least two people in which one of the people is involved against their will, where physical force may or may not be used (DVA, 2016). MST also includes many different experiences including unwanted touching, grabbing, oral sex, anal sex, sexual penetration with an object, and/or sexual intercourse (DVA, 2016). In this study, we attempt to deconstruct the MST designation as it potentially impacts servicemembers and veterans as they make meaning out of their experiences with gender-based violence. Because the MST designation is utilized in delivery of VA benefits, this label should be carefully evaluated for the potential reification of gender-based violence is an identity marker. As such, we utilize gender-based violence as the preferred terminology within this study, except where MST is used explicitly by others.

Studies document high prevalence rates of gender-based violence in the U.S. military among women (Goldzweig, Balekian, Rolon, Yano, \& Shekelle, 2006; Kimerling, Gima, Smith, Street, \& Frayne, 2007; Kimerling et al., 2010). According to 
the DVA (2016), about one in every four women and one in 100 men seen for VA health care have a positive screen for MST documented in the VA health record. Studies suggest that 31 percent of OEF/OIF women veterans reported MST, while self-reported rates of sexual harassment among active duty men were 27 to 38 percent, with one percent of men reporting sexual assault (Maguen et al., 2012; Mondragon et al., 2015; Street, Stafford, Mahan, \& Hendricks, 2008). In general, MST reporting trends indicate that the occurrence of gender-based violence for both men and women has increased, though this increase is attributed to improved MST reporting procedures by the VA and the U.S. Department of Defense (Hoyt, Rielage, \& Williams, 2011; U.S. Department of Defense, 2011). Although gender-based violence in the U.S. military occurs during periods of training, wartime, and peacetime, it has been suggested that the stress of war may be a factor in the increase of sexual assault (Wolfe et al., 1998). Gender also meaningfully interacts with sexuality in experiences of gender-based violence; for example, Lehavot and Simpson (2012) examined victimization among 379 lesbian, gay, and bisexual veterans finding 48 percent of women in the sample indicated at least one experience of victimization related to sexual orientation.

Research on gender-based violence in the U.S. military and mental health outcomes suggest severe sequelae in both women and men, including posttraumatic stress disorder (Hoyt et al., 2011; Kimerling et al., 2007; Magley, Walkdo, Drasgow, \& Fitzgerald, 1999). Studies suggest that PTSD as a result of rape is long-term and has severe negative physical and social consequences on one's health (Yaeger, Himmelfarb, Cammack, \& Mintz, 2006). Women who experience gender-based violence in the U.S. 
military are at an equal or higher risk for developing PTSD as are male combat veterans (Kimerling et al., 2007). Yaeger et al. (2006) found that 60 percent of women who experienced gender-based violence had PTSD, and rape led to PTSD in as many as 90 percent of women at four weeks post-assault and remained as high as 47 percent at three months post-assault. Similarly, another VA study found that women sexual assault survivors are at an increased risk for developing major depression, self-blame, anxiety, phobias, substance abuse, suicidality, and substantially increased health care use (Wolfe et al., 2007). Importantly, studies suggest that servicemembers who experience genderbased violence have worse health outcomes in comparison to civilian sexual assault survivors (Mulhall, 2009; Wolfe et al., 1998).

Studies note that servicemembers who experience gender-based violence in the U.S. military often work and live in the same environment as their assailants (Lahno, 2001). In these cases, survivors are required to collaborate with or rely on their attacker to delegate or complete work tasks and depend on their perpetrators for basic needs, such as medical, dental care, safety, survivability, and economic security (Katz, 2016; Katz, Bloor, Cojucar, \& Draper, 2007; Mulhall, 2009). Researchers suggest that those who experience gender-based violence may be discouraged from disclosing the event for fear of retaliation and career consequences (Hoyt et al., 2011; Kimerling et al., 2007). Unit cohesion may create environments where those who experience gender-based violence are strongly encouraged to keep silent, reports of gender-based violence to the command are dismissed, and victim-blaming by others within the chain-of-command may occur for those who do report (Allard et al., 2011; Katz, 2016; Katz et al., 2007; Mulhall, 2009). 
Whether through restricted or unrestricted U.S. military processes, servicemembers who report gender-based violence may end up having frequent contact with their attacker and may be at risk for further abuse, or surrender their careers and economic security for the sake of mission readiness, unit cohesion, and even survivability of their fellow servicemembers (Allard et al., 2011; Katz, 2016; Katz et al., 2007; Mulhall, 2009). In cases of sexual assault that are substantiated, Cernak (2015) suggests most do not result in court-martial charges or go to trial, rather they result in lesser charges such as dismissal, reduction in rank, or fines. Researchers suggest that these factors contribute to the underreporting of gender-based violence in the U.S. military (David, Simpson, \& Cotten, 2006).

\section{Gender-Based Violence as Institutional Betrayal Trauma}

Institutional betrayal is defined as wrongdoings perpetrated by an institution upon individuals dependent on that institution, including failure to prevent or respond supportively to wrongdoings by individuals (e.g., sexual assault) committed within the context of the institution (Reinhardt, Smith, \& Freyd, 2016; Smith \& Freyd, 2013, 2014). Institutional betrayal is a concept that has broad applications to many forms of social harm and injustice (Smith \& Freyd, 2014), including the military (Reinhardt et al. 2016). The occurrence of gender-based violence and the military's failure to prevent, address, or resolve it is a violation of trust and safety and can be better understood as a betrayal and, ultimately, as an institutional betrayal (Reinhardt et al., 2016). Freyd (1994) defined betrayal trauma as a trauma that occurs when the people or institutions on which a person depends for survival significantly violate that person's trust or well-being. In contrast to 
the traditional assumptions of trauma-research that suggest fear is the central aspect of responses to trauma, betrayal is a factor that can explain effects of trauma not accounted for by life threat alone (Kelley, Weather, Mason, \& Pruneau, 2012). The military environment requires a trust and reliance on the performance of others, subject to the decisions of mere acquaintances or even complete strangers (Lahno, 2001).

Servicemembers are required to have what Henslin (2001) refers to as trustability. Trust is a fundamental aspect of everyday life in society; however, for servicemembers, it is a vital necessity (Henslin, 2001). In the U.S. military, trustability is required for unit cohesion, efficiency during military operations and survivability within the military environment, and ultimately job and economic security. Freyd's (2013) concept of institutional betrayal builds on betrayal trauma theory, which predicts that the degree to which a negative event represents a betrayal by a trusted and needed other will influence the way in which that event is processed and remembered.

It has been suggested that traumas higher in betrayal, in contrast to traumas lower in betrayal, are associated with many negative psychological (Katz, 2016; Martin, Cromer, DePrince, \& Freyd, 2013), and physical health problems (Katz, 2016; Klest, Freyd, Hampson, \& Dubanoski, 2013). The research in this area has shown that interpersonal trauma (e.g., sexual abuse) that involved betrayal or depended-upon relationships are the most harmful, especially those involving relationships necessary for survival (Goldsmith, Freyd, \& DePrince, 2012). Kelst, Freyd, and Hampton (2013) found that higher betrayal traumas predicted worse overall health status and health trajectories over a 10-year period of time. Therefore, examining accounts of gender-based violence in 
the U.S. military from the veterans themselves and VA providers charged with their care may provide insight into the factors that make gender-based violence uniquely harmful. By drawing on Smith and Freyd's $(2007,2013,2014)$ concept of institutional betrayal, gender-based violence in the U.S. military can be better understood as a social problem, rather than solely as interpersonal violence. Following Reinhardt et al. (2016), we apply this concept to the U.S. military institution, while drawing on sociological theory to articulate the effect of "inequality regimes" which produce policies, practices, and ideologies (Acker 2006) that, we suggest, embed gender-based violence into the military as a "total institution" (Goffman 1961). Using narrative analysis, we examine participants' experiences and perceptions of gender-based violence in the U.S. military through the theoretical framework of inequality regimes in the military as a total institution, with implications for public health and policy reform.

\section{METHOD}

This qualitative study draws on in-depth interviews with seven OEF/OIF women veterans and seven VA service providers. Sampling for this study occurred in collaboration with the Women Veterans Cohort Study (WVCS), a prospective survey involving OEF/OIF men and women veterans at two large VA facilities in the United States. Recruitment flyers describing the study were given to women veterans enrolled in the WVCS. In addition, flyers were posted at the same VA facility and electronically distributed through a veteran listserv at a nearby university. Veterans who were interested in this study contacted the study investigator (first author) and screened for eligibility; criteria for women veterans included OEF/OIF participation and current enrollment in VA health 
care. The VA health care providers enrolled in this study were identified by referral from the women veteran participants enrolled in the same VA facility.

All study participants volunteered their time and were paid 25 dollars. Interviews were conducted by the first author (who is also a woman veteran) between January and November 2009 and lasted from 35 minutes to 114 minutes. During the semi-structured interviews, women veteran participants were not specifically asked if they experienced gender-based violence in the U.S. military. Rather, they were asked to describe their experiences as women serving in the U.S. military. Themes and information from initial interviews were used to guide the interviews that followed, allowing emergent themes to direct interview questions. As a result, the interview guide was revised during the data collection process. All interviews were audio-recorded with consent from participants and professionally transcribed by a VA-authorized transcription agency. This study was approved by Indiana University's Institutional Review Board and the Roudebush VA Medical Center research board.

To protect the identity of participants, locations disclosed during the interviews were omitted. In some instances, women veterans were stationed where they were the only woman on that military base, assignment, unit, or command in that country or geographical region, which could make them easily identifiable. Also, some of these women intended to rejoin the military or were in a reserve or inactive ready reserve status in which they could be or had been activated depending on U.S. military necessity.

Transcripts were reviewed to gain a sense of both veteran and provider experiences in the interview data. Study investigators met to discuss analysis methods, 
emergent codes and themes, and discrepancies throughout the analysis process. Informed by the previous literature, line-by-line coding was used to engage the data in detail, allowing themes to emerge inductively from the data. Emergent themes presented in the analysis focused on OEF/OIF women veterans' accounts and interpretations of their experiences of gender-based violence in the U.S. military, and VA provider accounts of working with women veteran patients. All participants talked about gender-based violence in their interviews, indicating saturation within the sample.

\section{Sample Characteristics}

All the respondents identified their race as white, and their ages ranged from 28 to 52 years old. Five of the seven women had at least a four-year college degree. Of the veterans, five were enlisted personnel and two were officers. Four of the seven women had children. One had been divorced, and five were married at the time of the study. Represented military branches included Army, Army National Guard, Air Force, Marine Corps, and Navy. Two of the veteran participants were honorably discharged from the military and then later rejoined, having breaks in military service for at least two years. Two served in more than one military branch. One veteran in this study retired from the military, serving more than 20 years of active duty service. Five of the seven women were combat veterans. One of the women veterans had participated in combat flight missions, and two performed numerous convoy operations in Iraq and Afghanistan. Four of the women veterans had deployed at least twice, and one of these veterans had completed two tours in Iraq. All women in this study were VA service-connected disabled veterans and enrolled in VA health care. 
All participants reported gender-based violence in the U.S. military (e.g. discrimination, harassment and sexual violence). Three of the seven reported being medically discharged or receiving a mental health diagnosis related to their experiences of gender-based violence, and surrendering their military careers; two of these women used the term rape to describe their experiences of gender-based violence while serving active duty.

The VA providers ranged from physician, nurses, and licensed clinical social workers. VA clinicians all identified as women, including one Black and six white participants. Due to the small number of women clinicians working as VA health providers in a system designed to serve men as servicemembers, further details are excluded to protect participants' confidentiality. All clinician participants discussed treating patients who experienced gender-based violence in the U.S. military.

\section{Potential Limitations}

This qualitative study draws on a small sample of veterans and VA health care providers at the same VA facility in the Midwest. The purpose of this study is to understand the experience of gender-based violence in the U.S. military from the perspective of those with situated knowledge of the phenomena, i.e. veterans and the clinicians who serve them. As such, the sample served sufficient for the proposed research question. Utilizing narrative analysis, we can better conceptualize the process of making and remaking meaning through interpersonal and institutional interactions that shape participants' experiences of gender-based violence in the U.S. military. The perspectives of VA clinician participants on experiences of treating and managing 
gender-based violence among women veterans lend greater transferability to the findings. In this way, we suggest that the potential limitations of the sample do not supersede the utility of the data.

Future research should build on this work by including a larger and more diverse sample, including men, racial or ethnic minorities, and veterans who identify as LGBT. Participants were not asked about their sexual identity, as this study was conducted prior to the repeal of "Don't Ask, Don't Tell" that took effect in September 2011 (DOD, 2016). It is unclear how self-reported military experiences may change and transition over time and develop with VA service-connected disability status and VA health care enrollment. We encourage researchers to examine self-reported data collected from veterans with and without VA service-connected disability status, veterans who opt out of the VA health care system, and other service-era and wartime-era veterans. Because of high incidence of gender-based violence, VA and DOD policies related to the inclusion of LGBT individuals, and VA disability compensation for gender-based violence and associated health outcomes, should be considered and may provide a better understanding of the social problem of gender-based violence in the U.S. military across more diverse veteran groups.

\section{FINDINGS}

OEF/OIF Women Veterans' Experiences of Gender-Based Violence

Every OEF/OIF veteran in the study described firsthand experiences of genderbased violence in the U.S. military, including accounts of rape, sexual assault, sexual harassment, and gendered harassment. The type and duration of gender-based violence 
described varied from frequent mild sexual harassment to a one-time incident of rape. Gender-based violence was described by participants as very common and even normative in the U.S. military. Majority of participants described gender-based violence as being apparent in wartime and peacetime, occurring whether one was deployed or in the United States. For example, one woman noted when describing sexual harassment, she experienced: "It didn't matter just at war; it was my whole career I had to put up with comments." All accounts were reported to be servicemember-on-servicemember sexual trauma and occurred during military operations or on military installations. The majority of perpetrators were known by women veterans, were officers and enlisted personnel, and worked in the same unit or command.

One of the participants used the term negative experience, verbiage echoed from the VA instrument to indicate MST. For example, one participant shared, "My one-year experience in [omitted] was a very negative one. [Silence] I had about a five-year break from the military and lots of counseling to get over the experience that I had there." Although this statement does not overtly describe the occurrence of gender-based violence, the pauses and silences suggested abuse beyond what was verbalized. In the context of the interviews, silences were profound; unmistakably, they could only imply what one woman referred to as the "unsaid thing." After these pauses or silences, women would continue with statements, such as, "Being on an isolated base was very negative because men behave badly." Rather than providing descriptions of physical harm to body or mind, participants provided descriptive accounts leading up to and after the interpersonal violence occurred and adopted statements, such as "and then you can guess 
what happened" or "and then, you know." All participants identified characteristics associated with the context in which gender-based violence occurred that made them unique compared to other types of military-related trauma.

VA service providers talked about the experiences of gender-based violence discussed among their VA patients. These experiences ranged from rape, sexual assault, sexual harassment, and gender harassment. For example, one VA provider said, "Many of them have been either sexually abused in the military or they've been approached or harmed some way physically by being pushed by the men, usually put down by the men—verbally put down by the men." VA providers also described accounts of patient experiences they did not associate with combat, rather gender discrimination and harassment in which trust in the military institution was betrayed. In one example, a provider described an intuitional betrayal trauma that occurred:

... even though they weren't right there, they were exposed to, maybe they were in Afghanistan or Iraq but never in a combat situation, but there are other things like one woman that we saw was traumatized by her fellows servicemembers. She was having an asthma attack, and they wouldn't get treatment for her. She was having some kind of personal conflict with her superior officer, and that traumatized her and caused her PTSD, so I think it is more, there's more than just being directly in combat.

In this account, the provider described her patient's experience that involved harassment but also betrayal by the institution, including a violation of trust, safety, and survivability by military leadership and institution. Most providers highlighted that combat trauma was not the sole predictor of negative health outcomes for VA patients.

The following sections highlight some of the experiences of gender-based violence reported by participants, including harassment, discrimination, and assault. 
Harassment and discrimination. Participants described gendered harassment occurring at various times and frequency throughout military service, including on deployment or while in the United States. Harassment was described as "a daily thing" and unwanted sexual attention as a frequent occurrence across all interviews. For example, one of the women noted that harassment "was just comments [servicemembers] would make." One woman described harassment as something that was commonly implied and rarely unconcealed: "Most of the people were really careful how they worded things because it's such a big issue in the military...it's just innuendo kind of things like, "Well, can I do anything for you?" "Well sure I can.”... It's not overt, it's not overly obvious. But it’s just implied."

In addition, one veteran described an account of gendered harassment that involved a perpetrator who was her supervisor and in a leadership position within her chain of command: "I was asleep, and someone was banging on my door, and I opened it up and it was [omitted] an officer wasted [intoxicated] in the enlisted barracks, and he was like, 'Let me come in' ... I just slammed the door in his face. ... Yeah, he was married with kids." This account demonstrates a violation of trust by the institution due to the perpetrators' status within the institution, and reveals the complex negotiation of gendered and sexual norms embedded in the institutional dynamics of the military as a total institution.

Rape and sexual assault. Many women described threats or accounts of sexual assault that included unwanted touching or grabbing. For example, one participant said, "One guy in the warehouse tried to grab me." In most instances, participants would pause 
at times when they reflected on these experiences, and for many of them, it was as if this was the first time they had spoken of these experiences. One participant said, "I never had anybody force themselves on me [silence]. Well, I had a couple people try, but as soon as I said no, they stopped."

Two of the seven women veterans adopted the term rape to describe their experience of gender-based violence during the interviews. In one of the two accounts of rape, the perpetrator was known to be a fellow servicemember in the same command. During the interview, the participant disclosed in detail how the perpetrator used deception (a key component of betrayal) to gain entry into her barracks room: "There were tornadoes all the time in the spring, and so they would knock on the door with a cue ball and that's what it sounded like ... so I got up and I opened the door." The participant described how a cue ball was used as part of the protocol by the watch-stander to knock on every barracks room door during tornado drills due to the distinct sound. This was adopted as an alarm for servicemembers to ensure they would wake and get into formation with their command. She recalled, "We didn't have anything like chain locks, and he pushed his way in the door and covered my mouth. I couldn't scream or anything." This account highlights the interplay of betrayal and the military institutional structure, such as the use of unit practices designed to promote safety in instances of inclement weather. In this account, the cue ball was used as a deceptive mechanism in which a violation of trust occurred at the institutional level.

In the other account of rape, the gender-based violence occurred in a combat zone, and the perpetrators were described as fellow servicemembers, but their identities 
were unknown. During the interview, this participant did not immediately state that her experience of gender-based violence was rape until the tape recorder was turned off. Her account was initially described in the interview in the following way:

When I deployed, and when I was back at base camp, I had an incident where I was basically fighting to keep from being pulled out of a bathroom stall. I came home shortly after that. I hate that my whole military career . . . has been defined by this one incident and is the most substantial memory of my entire career . . . I reminded [other women] to walk with their battle buddies, to be aware of their surroundings, to be cautious when I perceived them as being too friendly with the [men] on our camp . . . that morning, I fought for my life to keep that bathroom stall door closed ... I look back on it now, and they must have known my routine.

The incident occurred in a green zone in theater where coalition forces have high security. In these locations, servicemembers eat food from the mess hall, engage in physical training, attend to personal hygiene, and obtain medical attention while waiting for the next mission. The confinement within a total institution means these encounters are sometimes unavoidable.

\section{Perceptions of Institutional Betrayal}

Participants described the male-dominant military institution as a "very hard place to be as a female." The experiences of gender-based violence described above were understood not only as betrayals by individual servicemembers, but by the U.S. military as an institution. Similarly to Alder et al.'s (2011) work about the US military, this study highlights characteristics of gendered institutions, including covert and overt institutional practices that exclude women servicemembers from some military roles, duties, and military occupations, faulty processes for reporting gender-based violence, and other symbolic forms violence embedded in military practices that led to isolation of women servicemembers. We apply Acker's (2006) framework to understand these as practice, 
policies, and ideologies of inequality regimes within the military institution; here we examine social isolation, reporting policies, and VA response conceptualized as institutional betrayal.

Isolation, exclusion, and marginalization. Servicemembers experience various forms of social and symbolic isolation, including exclusion and marginalization. Many of the participants described being isolated from other women servicemembers, such as being the only woman or one of very few at their duty station or geographical location. One participant described feeling isolated because of, "the way [men] viewed women," which she suggested exacerbated her already existing sense of isolation. Another woman described her environment while stationed for a year: "I didn't have anybody to lean on, you know, girl-stuff lean on. We were at an isolated base where we could not leave base . .. I don't know the exact ratio of men to women, but I think it was something like 50 to one." Another said, "I was the only woman on the base except for the occasional woman student that would come through about every third class." She said, "Everything was catered to the men, making it a very hard place to be."

The literal and symbolic isolation of women embedded in this masculine institution often positioned them as outsiders, seen in examples of gendered harassment, discrimination, and general sexism. According to one participant, "The way they [men servicemembers] viewed women [as sex toys]" was very negative. She went on to say:

The morale van was used to go down into wherever they were picking up dancers and bringing them to the club that was on our camp. There were women dancers that were very minimally dressed, and they were the local gals brought there for the male students and instructors. 
In this account, this participant understood these dancers to be sex workers. She described the bringing of sex workers onto the military base as a common, informal, and normalized practice by the institution during her service at the base where she was assigned, a duty location that did not permit servicemembers to leave the base.

Participants described practices by superiors within the unit or command that reinforced women as "others" and outsiders. For example, one participant described her perception of changes that were made by the unit commander, prior to being mobilized, that contributed to her further isolation:

We had [service members] attached to us from other units to bring our unit up to full strength, so we had 12 females, and before we ever left our PREMOB (Premobilization) site, he cut nine females. He didn't want any women with them at all, and it's not like we were going to the field.

In this account, nine women were excluded from being mobilized to participate in a training activity. The U.S. military's policies have engaged in job sorting practices that have excluded women from numerous military jobs in addition to combat roles, such as infantry. This is one way that inequality regimes have been difficult to erode within this total institution. Military officials have justified these policies and practices by arguing that sexual tension between men and women erodes unit cohesion, and suggesting that women's lack of physical strength is a safety issue. These arguments ignore the fact that women have been serving in combat since and beginning with the Revolutionary War (Murdoch et al., 2006). In addition, these policies and practices fail to acknowledge differences in physical strength and variations in sexual practices within groups of men and women. 
Six of the participants described instances where their marginalization within the military was demonstrated through language: "I was told that I didn't belong in the military." One woman recalled an occasion where she was in a morning meeting with her commanding officer, executive officer, and direct supervisor when the following situation occurred: "One of the officers said, 'What are you going to do when you get out of the military?" She said, "What do you mean?" and he replied, "There's no way you're going to make it." All of the women described instances where supervisors would make statements along the lines of, as one reported, “I like you as a person, but I don't like you as a military person." Another woman stated, "I had to eat a lot of crow when I was mobilized and keep my mouth shut when I didn't want to because it wouldn't have accomplished anything." Another woman seemed to sum up a common theme when she said that not being a member of the "Good Ol' Boys Club was always an issue."

In the context of multiple forms of social and symbolic isolation, gender-based violence can be seen as an institutional betrayal, i.e. inequality regimes reinforce the impact of gender-based violence in the context of the military as a total institution. The participants' perceptions of institutional betrayal are informed by their experiences and direct knowledge of the intricate practices, policies, and ideologies (e.g. isolation) that reinforce their gendered oppression.

Reporting military sexual trauma experiences. Participants revealed a number of responses from the military institution to their reports of gender-based violence that demonstrate the participants' perceptions of reporting response as institutional betrayal. The women in the study who identified as being raped did report it to the military 
institution, including their command and/or victim advocates of the DOD's Sexual Assault Prevention and Response Office (SAPRO). Three of the four accounts of sexual assault (described as attempted rape) were reported to a superior among their leadership in the chain of command, and none of the accounts of gendered harassment or discrimination were reported to anyone. When asked if she reported her sexual assault experience, one participant replied, "Of course. I was told that I had a problem with authority. I was reprimanded.” Another participant who stated she had been sexually assaulted never reported it and stated, "I just assumed that's the way life was and that I had to deal with it." Another woman who described experiencing ongoing sexual harassment said she did not report it because it would "rock the boat." All but one participant who reported MST to institutional leadership were required to work and live along the men who harassed and/or raped them, indicating the pervasive power of inequality regimes within the military total institution. The frequency and duration of the contact with assailants after reporting differed by factors such as, rank, esteem, period of service, and location.

One exception was an instance of rape where the woman servicemember could not identify the perpetrators. One women veteran who identified as being raped on the military base said, after she reported it to military leadership, she was then tasked with duties by her chain of command during the rape investigation that required her to have frequent contact with the servicemember who raped her although she had been relocated and he had been reassigned to a similar unit on the same military installation. As a consequence of the gendered dynamics within total institutions, such practices are likely 
to influence the underreporting of gender-based violence. All women, including those who reported incidents of rape, described dissatisfaction with how their chain of command, military leadership and institution addressed their reporting of MST regardless of formal or informal reporting processes.

One of the participants stated that if the guard on duty had not seen her rapist enter her barracks room, the command would have perceived her as a "troublemaker" for reporting it and would not have believed the attack occurred:

Everyone in my unit knew what had happened, so the only reason I think why I wasn't ostracized is because someone in my unit witnessed him coming in my room and got the guard on duty. If it had just been me accusing him, then I don't think anybody would have talked with me for the rest of the time I was there. It's sad that it has to almost be eye-witnessed for it to be credible.

It is important to note that instances of betrayal included the belief that their chain of command and the institution would protect them from servicemember-on-servicemember sexual violence and advocate for them if they reported it. Violations of trust and diminished trustability in the chain of command and military leadership are demonstrated in the following statement: "The command is supposed to fix things, but the command is sometimes the perpetrators of the problem. How can they fix the problem that they are causing?” All study participants developed individual management strategies to maintain their military employment obligation since the institution did not provide protection or resolution for them, further validating their perceptions of institutional betrayal.

Service providers described their perspectives on the significant underreporting of servicemember-on-servicemember sexual violence within the U.S. military. For example, one of the providers stated, “[gender-based violence] is not addressed well. That's not 
addressed by the military that I can tell." Another provider said, "Women and men who suffered sexual trauma did not know that that was alright to speak about. You know, there was such a secrecy and shame about it that they kept it secret." A third VA provider stated, "The women aren't confident enough to bring it up to the military, and confidence has to do with not being afraid. I think they're fearful." VA providers expressed the need for greater acknowledgement and efforts to address sexual violence in the military. They considered MST prevention and interventions to be ineffective, as evidence by the descriptions of fear associated with reporting sexual violence within the institution among their VA patients.

Mistrust of the VA health care institution. VA provider participants help make explicit the ongoing institutional betrayal as it impacts veterans" access to health care and disability services. Many of the providers noted that they observed that gender-based violence was most commonly disclosed to VA providers by Operation Desert Storm/Operation Desert Shield veterans and OEF/OIF-era veterans, veterans who had served in the most recent wars (at the time of the study interviews). One informant suggested that veterans from previous eras are unwilling to address gender-based violence in the U.S. military with VA providers: "But once you start getting into the Gulf War, they start talking more about MST and the unpleasantness that they had to endure in those areas." However, a majority of VA providers reported that they observed gaps in service use among their VA patients who experienced gender-based violence. The providers described patients who were denied VA services for extended periods of time or who sought VA health care only years after their military service obligation had been 
fulfilled. One provider described a pattern of mental and physical withdrawal from VA services among patients undergoing care related to gender-based violence. She stated, "She would just go back to that, I guess defense mode, and shut down." Shutting down can be understood as a withdrawal from VA health care due to lack of trust in the VA system. Another provider explained that, in general, military veterans seeking VA health care had a lack of trust in the VA health care institution: "So, I think it's more mental at first, and I think they're very reluctant to talk about it [gender-based violence] until they, I think, they might see us as maybe not being here to help them. I think they might have a trust issue. Like we let them down." This account demonstrates transference (Zerebuval, 2013) across DOD and VA health care institutions. In this case, factors can be perceived as a conspirator in the systemic denial of military sexual traumas or as a potential source of retaliation for reporting, as significant power differences between patients and providers exist within the health care institution (Zerubavel, 2013). In this way, VA providers also confirmed that gender-based violence is experienced as institutional betrayal through the practices, policies, and ideologies of the military total institution. These perceptions of institutional betrayal allow a better understanding of the experience of gender-based violence in the U.S. military.

\section{DISCUSSION}

This study examines experiences and perceptions of gender-based violence in the U.S. military reported by participants who are OEF/OIF women veterans and the VA health care providers who serve them. Experiences of gender-based violence include discrimination, harassment, and sexual violence, including rape. All participants 
discussed experiences of gender-based violence in the U.S. military although they were not selected based on having had these experiences. Participants' perceptions of genderbased violence in the U.S. military indicate the persistence of inequality regimes that embed interlocking mechanisms of oppression as practices, policies, and ideologies within social institutions. Participants perceived gender-based violence as institutional betrayal through the lens of isolation, exclusion, and marginalization, demonstrated through mistrust of the reporting process and the VA health care system. Findings indicate the need to critically evaluate the MST-designation as a mechanism that potentially structures access to VA service-connected benefits.

$\mathrm{OEF} / \mathrm{OIF}$ women veterans made claims during the interview process that allowed gender-based violence in the U.S. military to be publicized, explicated, and radically changed from a purely private trouble into a public issue (Emerson \& Messinger, 1997). After participants underwent the transition from the military institution to their serviceconnected disabled veteran status, they were able to describe gender-based violence in the U.S. military without repercussions to their military career. During interviews, all informants described varying types of gender-based violence, including accounts of rape, sexual assault, sexual and gendered harassment, and discussed institutional factors that shape negative military experiences, in this case, gender-based violence. Although sexual violence within the military has been formally designated as military sexual trauma (MST) by the VA, this terminology was not used by women veteran participants at the time of this study. Rather than only describing interpersonal violence, women veterans and VA providers alike described factors of the military total institution that contribute to 
sexual violence in the U.S. military. These policies, practices, and ideologies include isolation, exclusion, the marginalization of military women, and faulty reporting processes (which inform claims for VA benefits), all of which participants suggested normalized and perpetuated gender-based violence during military service. So, rather than individualized, the women described these experiences as both interpersonal and structural, the product of a total institution and institutional betrayal ... something like that...

\section{Implications for Theory}

This study finds support for gender-based violence in the U.S. military as an institutional betrayal trauma, and furthermore identifies inequality regimes in the military as policies, practices, and ideologies that maintain, sustain, and perpetuate the ongoing cycle of gender-based violence within the U.S. military as a total institution. Women veterans who described accounts of reporting gender-based violence were treated as threats to mission readiness and experienced various forms of retaliation from the institution, also known as “command rape” (Service Women's Action Network [SWAN], 2016). Women veteran participants who reported gender-based violence to the institution found that perpetrators were not effectively pursued or prosecuted through the military justice system, even in cases of sexual assault and rape. Instead, the institution returned these women to work with their assailants, thus, three of these OEF/OIF women veterans surrendered their military careers prior to their obligated military discharge date, while perpetrators maintained their status servicemembers with the U.S. military. Results are consistent with the literature that reporting interpersonal violence involves failed attempts 
to receive help from the military justice system (Platt, Barton, \& Freyd, 2009; Smith \& Freyd, 2013).

One complex aspect of gender-based violence in the U.S. military is that servicemembers, superiors, and subordinates alike embody, represent, and construct the hierarchical command of the U.S. military institution. Therefore, the interpersonal aspect of sexual violence within the institution can also be understood as institutional betrayal trauma. We can interpret these interpersonal interactions as informed by the gendered and sexualized norms embedded in the total institution. In this way, gender-based violence emerges from the institutional dynamics of the military institution. Findings suggest that gender-based violence is a type of military-related trauma in which the sense of betrayal among victims is magnified by the awareness that perpetrators of sexual violence are trusted and relied-upon individuals within the institution; therefore, the military institution is understood by the participants to be the causative institution of gender-based violence. Therefore, we must change our understanding and existing policy, research, and treatment approaches for gender-based violence that occurs in US military contexts.

\section{Implications for Policy}

The findings raise ethical concerns related to gender-based violence prevention and intervention strategies for DOD and VA alike with implications for military officials, policymakers, researchers, and health care professionals. Given the results, we find that the DOD is an improper setting for gender-based violence reporting processes, investigations, and prosecution of perpetrators considering the hierarchical structure of the military as total institution and the military's track record concerning cases of sexual 
abuse in the U.S. military (Cernak, 2015), and the difficulty of eroding the power of inequality regimes (Acker, 2009). Future studies should focus on the social context in which gender-based violence occurs and the institutional factors that contribute to higher levels of betrayal and health related challenges among women veterans. Recognition of gender-based violence in the U.S. military as an institutional betrayal trauma may improve efforts to better address the social problem of MST and quality of life outcomes for servicemembers and veterans (Cernak, 2015; SWAN, 2016). We further suggest that the effect of the military as a total institution situates the MST-label (as reflected in VA health records) as one that is reified through the interplay of individual and institutional processes, such as reporting, prosecuting, and receiving service-connected benefits. As such, we recommend examining the potential impact of internalization of this institutionalized label, with the goal of promoting greater agency and self-determination for servicemembers and veterans who experience gender-based violence.

\section{REFERENCES}

Acker, J. (2006). Inequality regimes: Gender, class, and race in organizations. Gender \& society, 20(4), 441-464.

Braun, V., \& Clarke, V. (2006). Using thematic analysis in psychology. Qualitative Research in Psychology, 3, 77-101. doi:10.1191/1478088706qp063oa

Cernak, S. (2015). Sexual assault and rape in the military: The invisible victims of international gender crimes at the front lines. Michigan Journal of Gender Law, 22(1). Retrieved from https://repository.law.umich.edu/mjgl/vol22/iss $1 / 5$ 
David, W. S., Simpson, T. L., \& Cotton, A. J. (2006). Taking charge: A curriculum of self-defense and personal safety training of female veterans with PTSD because of military sexual trauma. Journal of Interpersonal Violence, 21, 555-565. doi: $10.1177 / 0886260505285723$

Department of Veterans Affairs (DVA). (2016). Military sexual trauma. Retrieved from http://www.mentalhealth.va.gov/msthome.asp

DOD Annual Report on Sexual Assault. (2011). Sexual assault in the military (U.S. Commission on Civil Rights).

Emerson, R. M., \& Messinger, S. L. (1977). The micro-politics of trouble. Social Problems, 25, 2. doi:10.2307/800289

Freyd, J. J. (1994). Betrayal trauma: Traumatic amnesia as an adaptive response to childhood abuse. Ethics and Behavior, 4, 307-329. doi:10.1207/s15327019eb0404_1

Freyd, J. J., \& Barrell, P. (2013). Blind to betrayal: Why we fool ourselves we aren't being fooled. City, NJ: Wiley.

Freyd, J. J., DePrince, A. P., \& Gleaves, D. H. (2007). The state of betrayal trauma theory: Reply to McNally-conceptual issues and future directions. Memory, 15, 295-311.

Freyd, J. J., \& Birrell, P. J. (2013). Blind to betrayal. City, ST: John Wiley \& Sons.

Goffman, Erving. (1961). Asylums: Essays on the social situation of mental patients and other inmates. New York: Anchor Books. 
Goldsmith, R. E., Freyd, J. J., \& DePrince, A. P. (2012). Betrayal trauma: Associations with psychological and physical symptoms in young adults. Journal of Interpersonal Violence, 27, 547-567. doi:10.1177/0886260511421672

Goldzweig, C. L., Balekian, T. M., Rolon, C., Yano, E. M., \& Shekelle, P. (2006). The state of women veterans' health research. Journal of General Internal Medicine, 21, 82-92. doi:10.1111/j.1525-1497.2006.00380.x

Hall, M. E., Sedlacek, A. R., Berenbach, J. R., \& Dieckmann, N. F. (2007). Military sexual trauma services for women veterans in the Veterans' Health Administration: The patient-care practice environment and perceived organizational support. Journal of Psychological Services, 4, 229-238.

Henslin, J. (2001). Essentials of sociology. Contemporary Sociology, 13(3).

Holstein, J. A., \& Gubrium, J. F. (2012). Varieties of narrative analysis. Los Angeles, CA: Sage.

Hoyt, T., Rielage, J. K., \& Williams, L. F. (2011). Military sexual trauma in men: A review of reported rates. Journal of Trauma and Dissociation, 12, 244-260. doi: $10.1177 / 1534765611430724$

Katz, L. S. (Ed.). (2016). Understanding and treating military sexual trauma. New York, NY: Springer.

Katz, L. S., Bloor, L. E., Cojucar, G., \& Draper, T. (2007). Women who served in Iraq seeking mental health services: Relationships between military sexual trauma, symptoms, and readjustment. Psychological Services, 4, 239-249. doi:10.1037/1541-1559.4.4.239 
Kimerling, R., Gima, K., Smith, M. W., Street A., \& Frayne, S. (2007). The Veterans Health Administration and military sexual trauma. American Journal of Public Health, 97, 2160-2166. doi:10.2105/AJPH.2006.092999

Kimerling, R., Street, A. E., Pavao, J., Smith, M. W., Cronkite, R. C., Holmes, T. H., \& Frayne, S. M. (2010). Military-related sexual trauma among Veterans Health Administration patients returning from Afghanistan and Iraq. American Journal of Public Health, 100, 1409-1412. doi:10.2105/AJPH.2009.171793

Lahno, B. (2001). On the emotional character of trust. Ethical Theory and Moral Practice, 4, 171-189. Retrieved from https://www.jstor.org/stable/27504185 Maguen, S., Cohen, B., Li, R., Bosch, J., Kimerling, R., \& Seal, K. (2012). Gender differences in military sexual trauma and mental health diagnoses among Iraq and Afghanistan veterans with posttraumatic stress disorder. Women's Health Issues, 22, 61-66. doi:10.1016/j.whi.2011.07.010

Mattocks, K. M., Haskell, S. G., Krebs, E. E., Justice, A. C., \& Yano, E. N. (2012). Women at war: Understanding how women veterans cope with combat and military sexual trauma. Social Science and Medicine, 74, 537-545. doi:10.1016/j.socscimed.2011.10.039

McEwen, C. A. (1980). Continuities in the study of total and nontotal institutions. Annual Review of Sociology, 6(1), 143-185.

Mondragon, S. A., Wang, D., Pritchett, L., Graham, D. P., Plasencia, X. X. \& Teng, E. J. (2015). The influence of military sexual trauma on returning OEF/OIF male veterans. Psychological Services, 12, 402-411. doi:10.1037/ser0000050 
Mulhall, E. (2009). Women warriors: Supporting she 'who has borne the battle.' Iraq and Afghanistan Veterans of America.

Naphan, D., \& Elliot, M. (2015). "Role exit from the military: Student veterans' perceptions of transitioning from the US military to higher education." Qualitative Report, 20(2).

Reinhardt, K. M., Smith, C. P., \& Freyd, J. J. (2016). Came to serve, left betrayed: MST and the trauma of betrayal. In L. S. Katz (Ed.), Understanding and treating military sexual trauma (pp. XX-XX). New York, NY: Springer.

Smith, C. P., \& Freyd, J. J. (2013). Dangerous safe havens: Institutional betrayal exacerbates sexual trauma. Journal of Traumatic Stress, 26, 119-124.

Smith, C. P., \& Freyd, J. J. (2014). Institutional betrayal. American Psychologist, 69, 575-587. doi:10.1037/a0037564

Street, A. E., \& Stafford, J. (2004). Military sexual trauma. Issues in caring for veterans. In P. P. Schnurr \& S. J. Cozza (Eds.), Iraq War clinician guide (2nd ed.). Washington, DC: Department of Veterans Affairs, National Center for Posttraumatic Stress Disorder.

Street, A. E., Stafford, J., Mahan, C. M., \& Hendricks, A. (2008). Sexual harassment and assault experienced by reservists during military service: Prevalence and health correlates. Journal of Rehabilitation Research and Development, 45, 409-420. Retrieved from https://www.ncbi.nlm.nih.gov/pubmed/18629749

Wolfe, J., Sharkansky E. J., Read, J. P., Dawson, R., Martin, J. A., \& Ouimette P. C. (1998). Sexual harassment and assault as predictors of PTSD symptomatology 
among U.S. female Persian Gulf War and military personnel. Journal of Interpersonal Violence, 13, 40-57. doi:10.1177/088626098013001003

Yaeger, D., Himmelfarb, N., Cammack, A., \& Mintz, J. (2006). DSM-IV diagnosed posttraumatic stress disorder in women veterans with and without military sexual trauma. Journal of General and Internal Medicine, 21, 65-69. doi:10.1111/j.15251497.2006.00377.x

Zerubavel, E. (2006). The elephant in the room: Silence and denial in everyday life. New York, NY: Oxford University Press. 


\title{
CHAPTER 4: FIRST DO NO HARM: ASSESSING VETERANS AFFAIRS SCREENING FOR MILITARY SEXUAL ABUSE AMONG OUR NATION'S VETERANS
}

\author{
Authors: Sarah Aktepy, Anne Sadler, Gala True, Sarah Ono, Kelly Burkitt, and Susan \\ Zickmund
}

Abstract: This mixed method study examined veteran remembrance of VA screening for MST from four geographically diverse VA Medical Centers. The sample includes survey and interview data from 76 male and female veterans with MST status documented in the electronic medical and responses to the Sexual Experiences Questionnaire - Department of Defense version (SEQ-DoD). The analysis highlights data discrepancies using the MST screening protocol, and low remembrance and distress among veterans screened for military sexual abuse history by clinicians in the VA health care setting. Our findings suggest dire need for institutional responsibility and a shift in conduct for addressing military sexual abuse and health sequelae among our nation's veterans within US military and VA contexts.

Keywords: veterans, healthcare, screening and assessment, military sexual assault, military sexual harassment 


\section{INTRODUCTION}

Sexual violence is a global public health care concern (Dahlberg \& Mercy, 2009; Krug, Mercy, Dahlberg, \& Zwi, 2002). Several scholars have focused on the risk of sexual violence and subsequent difficulties greater for military service members as compared to non-military service members (Mengeling et al, 2017; Zinzow, Grubaugh, Monnier, Suffoletta-Maierle, \& Frueh, 2007). Estimates of sexual harassment during military service for veterans are reported as high as $74 \%$ in men and $90 \%$ in women (Department of Defense, 2014; Kimerling, Gima, Smith, Street, \& Frayne, 2007; Murdoch \& Nichol, 1995; Murdoch, Pryor, Polusny, \& Gackstetter, 2007; National Defense Research Institute [NDRI] 2014; Rosen \& Martin, 1998; Street, Gradus, Giasson, Vogt, \& Resick, 2013; Street, Gradus, Stafford, \& Kelly, 2007; Street, Stafford, Mahan, \& Hendricks, 2008 ), with sexual assault during military service ranging from $1 \%$ to $12 \%$ in men and $10 \%$ to $71 \%$ in women (Cunradi, Ames, \& Moore, 2005; Department of Defense, 2014; Kimerling et al., 2007; Murdoch \& Nichol, 1995; National Defense Research Institute [NDRI] 2014; Suris \& Lind, 2008; Turchik \& Wilson, 2010). Although rates of military sexual harassment and assault are higher among women, the actual number of men who experience sexual harassment and assault in the military is similar to the number of women (Turner \& Frayne, 2004) because majority of service members are men (83\%) (Department of Defense, 2015).

Public Laws 103-452 and 106-117 require screening veterans for MST histories and offer mental health counseling by the VA medical system. To provide context for this study, we briefly describe how the Department of Veterans Affairs (VA) has 
implemented assessment of the veteran population for histories of sexual assault and harassment that occurred during military service--histories defined as military sexual trauma (MST) by the VA. The MST screen consists of two questions regarding experiences with sexual harassment (e.g., verbal remarks, touching, or pressure for sexual favors) and sexual assault (e.g., force or threat of force to have sex with you against your will) that occurred during military service (Kimerling et al., 2007; McIntyre et al., 1999). The VA's process for universal screening for MST is integrated within standard clinical practice and is implemented by individual providers, a factor associated with better screening compliance (Kimerling et al., 2007). The response options are "No," "Yes," and "Declined to answer" (Kimerling et al., 2007; 2008; U.S. Department of Veterans Affairs, 2016). A yes response to either question is recorded as a positive screen (MST+) and documented in the electronic medical record (EMR; Kimerling et al., 2007). The MST screen is administered once for veterans who provided a yes or no response. Veterans who decline to answer are rescreened the following year, and patients who initially screened negative (i.e., answer "No" to both questions) will have their screen status updated if later disclosed to a healthcare provider. All veterans who report MST are eligible for MST-related healthcare services, free of charge (American College, 2011; U.S. Department of Veterans Affairs, 2010; U.S. Government Publishing Office, 2000). Universal screen rates for the VA are nearly $100 \%$ (U.S. Department of Veterans Affairs, 2010, 2015). However, overwhelming evidence suggests that VA's current screening method produces inaccurate results; less than $1 \%$ of screened male veterans and $20 \%$ of screened female veterans have a documented MST status in the EMR. 
Compared to survey data from other sources, these rates are significantly low; for example, the sexual harassment rates for male active-duty soldiers has been reported as high as $74 \%$ and similar discrepancies exist among female soldiers (U.S. Department of Veterans Affairs, 2015). Discrepancies between the MST rates reported using the VA two-question screen and findings from other studies indicate that the VA is falling dangerously short of the Congressional mandate to accurately report military sexual abuse statistics, and provide veterans seeking related therapeutic treatment accordingly. The VA two-question screen creates a potentially large cohort of veterans who have not been identified or offered appropriate services.

\section{Theoretical Framework}

Given the implications of military sexual abuse and health sequelae as evidenced by the public laws enacted to mandate it, the current screening method must be assessed. Our study was designed to sample a demographically and experientially diverse group of veterans that will allow us to gather information about the utility of VA MST screening approaches in the clinical care setting. Following the work of Goffman (1961), we consider the complex interplay between structure and agency across two militaryrelated institutions: the VA and U.S. military, a total institution. Goffman defined the total institution as "a place of residence and work where a large number of situated individuals, cut off from the wider society for an appreciable length of time, together lead an enclosed, formally administered round of life" (1961, xiii). Goffman described practices and processes of the total institution that enforced loss of self-determination and autonomy upon entering, such that individuals might "be shaped and coded into an object 
that can be fed into the administrative machinery or the establishment" (1961, p. 16). This quality of the military as a total institution creates an environment where individuals are deeply influenced by the cultural climate created and maintained by structural forces. This understanding allows us to focus less on individual actors and more on the operations of the total institution itself, suggesting then, "we will give less praise and blame to particular superintendents, commandants, wardens, and abbots, and tend more to understand the social problems and issues in total institutions by appealing to the underlying structural design common to them all” (Goffman 1961, p. 123-4).

In the assessment of role exit among veterans transitioning from service to higher education, Naphan and Elliot (2015) note that the military defies some aspects of Goffman's concept: “Today, individuals voluntarily enlist in the U.S. military, are compensated for their work, are given responsibilities, and are often recognized for their service, under the law are entitled to certain VA benefits and entitlements such that the military does not make 'total' claims on its members" (2015, p. 37). As noted by McEwen (1980), total institutions are imprecisely "closed" systems, which highlights the importance of the broader cultural climate of the society from which individuals who comprise the institution are drawn. McEwen suggests we consider the "impact of such organizations on their members - on their senses of self and on their values, attitudes, relationships and behavior" (1980, p. 144). Importantly, in their extensive review of the literature on total and non-total institutions, McEwen (1980) notes that the effects of working in total institutions on individual members are products of the organizational structure. We draw on this understanding in our approach for this study, emphasizing the 
focus on structural rather than individual factors that create an environment where military sexual abuse remains prevalent, with "transferability" of cultural climate from the U.S. military, a total institution, to the VA clinical care setting. As noted above, high screening rates do not necessarily reflect accurate reporting rates of military sexual abuse. Drawing on Goffman's conceptualization of total institutions, we adopt a multimethod research design to examine how discrepancies persist between MST screening rates and military sexual harassment and sexual assault reporting rates in the VA clinical care setting.

\section{BACKGROUND}

The VA is mandated by Congress to assess the nation's veteran population for histories of sexual harassment and sexual assault that occurred during military service - histories referred to as MST. Consequently, the VA has implemented a required two-question MST screening test to be administered by primary care providers (PCPs) or clinicians. However, the two-question MST administered in a primary care setting was not pilottested and the accuracy of the approach is largely unknown.

\section{Definitions of Military Sexual Harassment and Sexual Assault}

Appreciation of the aims and goals of this study requires a clear understanding of the definitions of sexual assault and sexual harassment as provided by Congress and the VA and of the wording of the two MST screening questions upon which the VA currently relies to identify and refer veterans who may have experienced MST. Hence we provide the two definitions and the two MST screening questions below. 
Congressional definitions. Sexual harassment: repeated unsolicited verbal or physical contact of a sexual nature, which is threatening in nature. Sexual assault: physical assault of a sexual nature; battery of a sexual nature.

Veterans Administration definitions. Sexual harassment: unwelcome verbal or physical conduct of a sexual nature that occurs in the workplace or an academic or training setting. Sexual harassment includes gender harassment (e.g., put you down because of your gender), unwanted sexual attention (e.g., made offensive remarks about your sexual activities or your body) and sexual coercion (e.g., implied special treatment if you were sexually cooperative). Sexual harassment may include: a put-down because of your gender; flirting when you've made clear it's not welcome; sexual comments or gestures about your body or lifestyle; and pressure for sexual favors

Sexual assault: any sort of sexual activity between at least two people in which one of the people is involved against his or her will. Physical force may or may not be used. The sexual activity involved can include many different experiences including unwanted touching, grabbing, oral sex, anal sex, sexual penetration with an object, and/or sexual intercourse.

2-item MST screening questions. (1) When you were in the military, did you ever receive uninvited and unwanted sexual attention (e.g., touching, cornering, pressure for sexual favors, verbal remarks)? (2) When you were in the military, did anyone ever use force or the threat of force to have sex with you against your will?

Mandated MST screening of veterans. The screening mandate is currently met by administration of the two-question screening test in primary care sites, usually by a 
(medical, not psychiatric) primary care physician during a clinical visit not intended for trauma evaluation and (nearly) always as a result of a computer prompt that occurs amidst other prompted questions about smoking, drinking, colorectal cancer, diabetic and hypertensive medication management, and so on (Street, Kelly, \& Kimerling 2006). There is no mandated training of screeners, nor mandated education of what to do when patients screen positive (other than to check a computer-prompt box that alerts the VA facility's MST Coordinator that an MST screen-positive patient requests follow-up after having screened MST positive).

\section{Rates of MST in Active Duty Soldiers}

The largest of two studies on military sexual harassment and sexual assault were completed by the Department of Defense (DOD), in 1988 and 1995 respectively and representing tens of thousands of military personnel (Fitzgerald, \& Gelfand 1995; Martindale 1991; Fitzgerald, Drascow, Magley 1999). The 1988 study of 20,400 personnel reported that $17 \%$ of the men surveyed experienced sexual harassment in the prior year (Martindale 1991). Seven years later, the 1995 follow-up DOD study compared results using two different assessment methods: one approach used the same questionnaire used in 1988 (completed by $46 \%$ of 27,759 potential respondents); and another approach used a revised version of the 1988 questionnaire that was more behaviorally-based (completed by $58 \%$ of 46,467 potential respondents) (Bastian, Lancaster, Reyst 1996). The repeat-use of the 1988 questionnaire indicated that $14 \%$ of the men had experienced sexual harassment in the prior year, suggesting a somewhat lower rate in 1995 than in 1988. However, when the comprehensive Sexual Experiences 
Questionnaire (SEQ) was used, nearly 3 times the number of men - 38\% - reported having experienced one of the behaviors listed in the survey in the prior year (Bastian, Lancaster, Reyst, 1996). Fitzgerald, Drasgow, and Magley subsequently reported on these behaviors separated into narrower categories: $35 \%$ reported acts of "sexual hostility"; 15\%, "sexist hostility"; and 8\%, "unwanted sexual attention" (Fitzgerald, Drascow, Magley, 1999).

Also in 1995, Rosen and Martin administered the SEQ to 1,060 men soldiers from Army combat support and combat service support units (Rosen \& Martin, 2002). Results indicated $74 \%$ of the men reported having experienced at least one of the SEQ-assessed behaviors in the previous year; $71 \%$ of the men had experienced gender harassment; $40 \%$ unwanted sexual attention; and 10\% sexual coercion. When self-definition "Acknowledged Harassment" was explored, few men were willing to self-define themselves as victims of sexual harassment. Even among men who reported attempted rape, only $29 \%$ of men defined this as sexual harassment. Men were more than two times less likely than women to define attempted rape as "harassment." Rosen and Martin conjectured that" the avoidance of stigma and [the desire to be perceived of as] retaining control may affect the recognition of ... sexual harassment, particularly among men in a hyper masculine organization in which sexual victimization may be perceived as a threat to gender identity." (Rosen \& Martin, 2002).

Several studies have been published about male veterans' experiences with sexual assault and/or harassment (whereby they were asked to look back and describe what occurred to them during active duty military) (Fontana, Litz, \& Rosenheck, 2000; 
Murdoch et. al., 2006; Murdoch et al., 2004; Poulsny \& Murdoch, 2005; Kang, 2005).

Fontana, Litz, and Rosenheck, surveyed 1,307 men within one year of returning to the U.S from Somalia. "Sexual harassment" and "sexual abuse" was not defined for study participants, and experience was assessed in one item using a 5-point response option that ranged from "never" to "nearly all the time." Mean sexual harassment/abuse (on a scale from 0 to 4) was 1.20 (s.d., 0.64) (Fontana \& Litz, 2000).

Murdoch at al. (2006) studied a representative sample of 1,654 male veterans seeking VA disability benefits for PTSD. Investigators used the 21-item Sexual Harassment Inventory (SHI) that has three domains: 1) hostile, sexualized work environment; 2) quid pro quo demands for sexual favors in exchange for better treatment; and 3) criminal sexual misconduct (e.g., "flashing" or forced sex). Subscales were reported to have factorial validity, and alpha values were 0.92 to 0.93 (Murdoch et. al., 2006). Study participants also were asked if someone had attempted or had successfully forced them to have sex against their will. Twenty-nine percent of the men reported sexual harassment (Murdoch et. al., 2006) Four percent reported in-service sexual assault (Murdoch et. al., 2004). More non-combat (13\%) than combat (4\%) veterans reported inservice sexual assault. Two percent of World War II veterans reported sexual assault compared to $13 \%$ of Gulf War veterans."(Polusny \& Murdoch, 2005). Sexual assault had a significant, independent association with current PTSD symptoms (Murdoch et. al., 2006). Murdoch posits that ". . masculine gender socialization (e.g., social stigma against vulnerability, weakness, and homosexuality) may lead to an overwhelming sense of powerlessness and shame among male combat veterans who are also sexual assault 
victims ... [and] could silence men's disclosure ... limit[ing] their emotional and cognitive processing of traumatic events.”(Murdoch, 2004).

Kang et al. published findings from a nested case-control analysis of 1,381 Gulf War veterans with current PTSD compared with 10,060 Gulf veteran controls without PTSD evaluating self-reported/-defined effects of combat experiences of sexual harassment/assault. Exposure to MST was assessed by asking, "While in the Persian Gulf, do you believe you were exposed to or did you experience any of the following?" Included in the 23 response options were: "Experienced sexual harassment"; and "Suffered forced sexual relations or a sexual assault." Low rates of sexual harassment and assault ( $0.6 \%$ and $0.2 \%$, respectively) were reported, for reasons that are likely similar to why low MST rates may have been found in VA screening: no definitions were provided; and wording that nuanced experiences only in an extreme way (e.g., "suffered," "assault") and language that was indirect and unclear (e.g., "relations") were employed. MST Leads to Poor Outcomes

Goldzweig et al. (2006) summarizes nine studies that have documented poor physical health, mental health, and substance abuse outcomes for female veterans with MST. Similar research is only now emerging about the link between MST and outcomes in male veterans. Fitzgerald et al. (1999) reports that having experienced MST is associated with lower psychological well-being and health satisfaction in males. Fontana, Litz, and Rosenheck, (2000) and Kang et al. (2005) indicate that both sexual harassment and sexual assault are associated with PTSD in active duty men and male veterans (equivalent to that in woman). Magley et al. (1999). report that sexual harassment exerts 
a negative effect on psychological, health, and job-related outcomes for male and female personnel in similar ways. We anticipate that the future literature on the outcomes of male-experienced MST will mirror what was found in a previously lagging literature on outcomes of childhood sexual abuse (CSA) in boys when it was compared to the larger, earlier literature for that in girls: the outcomes of sexual abuse for males and females were (and will be for MST) similar in scope, depth, and frequency, albeit with some unique areas of impact for each sex. For example, CSA-associated outcomes in males include "PTSD, major depression, anxiety disorders, borderline personality disorder, antisocial personality disorder, paranoia, dissociation, somatization, bulimia, anger, aggressive behavior. . legal trouble $[, \ldots$ and $]$ sexually-related problems," as well as substance abuse problems (Holmes \& Slap, 1998). "Sexually-related problems" include higher numbers of lifetime sexual partners, less frequent condom use, more frequent risky sexual behaviors, higher rates of sexually transmitted infections (including HIV), and responsibility for more unwanted pregnancies (Bartholow et.al., 1994). Improved screening will allow study of military sexual abuse and related health sequelae for male and female veterans via database studies.

When we summarized the results of additional studies documenting military sexual harassment and sexual assault in active duty personnel, we found: 1) rates of reported sexual harassment and assault are higher when a comprehensive, behavioral measure is employed; 2) when self-definition is required, men either do not appear to know how to define sexual harassment/assault, or they are very reluctant to self-label a victims or describe military sexual abuse as trauma; and 3) early findings for the SEQ 
indicated it had strong internal consistency, reliability, and emerging construct validity(Kimerling \& Street, 2006; Kang, 2005; Resnick \& Blum, 1994). In our analysis, we draw on a database of documented MST status among VA users, responses of the Sexual Experiences Questionnaire-SEQ, and 76 interviews with veterans enrolled in VA health care. To our knowledge, our study is the first to draw on Goffman's conceptualization of total institutions and insight from previous studies which demonstrate ethical concern for the federally mandated screening approach by VA used to identify our nation's veterans for histories of military sexual abuse in the VA clinic setting.

\section{METHOD}

This project employed a multi-method research design to examine possible explanations for persistent discrepancies of MST screening rates assessed at the VA point of care. Analytic data for the study was collected from 2011-2012 from four geographically diverse VA Medical Centers: Iowa City, Miami, Pittsburgh, and Philadelphia. First, VisTa Data Warehouse were collected from a random sample of 143 men and women veterans who had a documented MST+/- status in the VA electronic medical record (EMR) from the previous two years across all data types for this study. Second, the same veterans provided responses to the Sexual Experiences Questionnaire (SEQ) Department of Defense version (SEQ-DoD) were analyzed to further stratify the sample into three categories: (a) MST+/SEQ+, (b) MST-/SEQ-, and (c) MST-/SEQ+. Third, based on a stratified sample from these veterans' responses to the SEQ-DoD and VHA two-item screen data in the EMR, 76 semi-structured interviews were conducted with 
these veterans to elucidate veterans remembrance of being asked the MST two-item screening questions in a VHA clinical care setting.

\section{VisTa Data Warehouse of MST +/- Status of Veterans}

We used the VisTa Data Warehouse to identify potentially eligible male and female veterans enrolled in VA care who were asked the two-item MST screening questions by a VA primary care provider within the past two years. Military sexual harassment ("While you were in the military, did you experience any unwanted sexual attention, such as verbal remarks, touching, or pressure for sexual favors?") and military sexual assault ("Did anyone ever use force or threat of force to have sex with you against your will?"). Response options are "No," "Yes," and "Declined to answer." A "yes" response to either question is recorded as a positive screen (MST+). The MST screen is

administered once for veterans who provide a yes or no response; however, patients who initially screen negative (i.e., answer "No" to both questions) may have their status updated if they later disclose MST to a healthcare provider. Veterans who decline to answer are rescreened the following year. Veterans who had a VA psychiatric hospitalizations or diagnoses, including dementia, psychosis, and schizophrenia, that might indicate inability to provide informed consent were excluded from the study, and one site's Institutional Review Board (IRB), which required Veterans diagnosed with PTSD be excluded from that site's sampling pool.

A greater number of Veterans who screened VHA MST+ were also oversampled to improve reliability estimates for this smaller subgroup, especially among VHA MST+ men who represent 1\% of the population (U.S. Department of Veterans Affairs, 2015). 
Site-specific recruitment protocols were used to address site IRB requirements and constraints. Two sites mailed study packets that included a letter describing the study and a postage-paid 'opt-in' letter indicating their interest in being contacted about study participation. The other two sites worked with VHA healthcare providers within clinics to identify potential participants.

\section{The Sexual Experiences Questionnaire-DOD}

Eligible veterans were consented to participate and administered the SEQ-DOD version - a published measure that documents experiences with sexual harassment/assault in the military (Fitzgerald, Gelfand, \& Drasgow, 1995; Fitzgerald, Magley, Drasgow, \& Waldo, 1999). Designed as a self-report inventory to assess the prevalence of sexual harassment, the SEQ-DOD use of the term sexual harassment encompasses sexual harassment and sexual assault behaviors. This was chosen because it aligns with the time period addressed by the VHA MST screen (i.e., military service) and because it has been used routinely in DOD surveys assessing the prevalence of military sexual harassment (Fitzgerald, Drasgow, et. al., 1999; Fitzgerald, Magley et. al., 1999; Lipari, Lancaster, \& Jones, 2005;). Sexual harassment and assault screenings vary based on their purpose and definition of sexual harassment. The SEQ is considered the current best available assessment tool to identify veterans with history of military sexual harassment and military sexual assault and helped us confirm the MST status in veterans, since a primary reason for the quantitative data collected of the study was to assess the accuracy of the current VHA two-item screening tool. 
The SEQ-DOD uses the term sexual harassment to encompass a broad range of experiences comprising four domains: sexist hostility, sexual hostility, unwanted sexual attention, and sexual coercion. Unwanted sexual attention includes items assessing sexual assault (Fitzgerald, Magley et al., 1999). These four domains have been found to be consistent for military and civilian populations (Fitzgerald, Drasgow et al., 1999). Endorsement of the SEQ-DOD domains were used to further stratify the recruitment sample for qualitative interviews into three categories: (a) MST+/SEQ+, (b) MST-/SEQ-, and (c) MST-/SEQ+. There were no cases representing MST+/SEQ-. However, MST/SEQ+ category included participants with a false MST- status recorded in their record given their elevated SEQ score and were labeled "false negative" for the study. Only onethird of participants were recruited for the interview from any SEQ score tertile for both the "true MST positives" and "false MST negatives," (e.g., one-third recruited from the lowest, one-third from the middle, and one-third from the highest score tertiles).

\section{Qualitative Interviews}

A total of 76 Veterans completed the interview. Recruitment categories by experiences are presented in Table 1.

\begin{tabular}{lccc}
\hline \multicolumn{4}{c}{ Table 1. Participant MST/SEQ Categories by Gender } \\
\hline & MST+/SEQ+ & MST-/SEQ- & $\begin{array}{c}\text { MST-/SEQ+ } \\
\text { (false negative) }\end{array}$ \\
\cline { 2 - 4 } Women & 16 & 4 & 18 \\
Men & 14 & 4 & 20 \\
\hline
\end{tabular}

Note: $\mathrm{N}=76$

All interviews were conducted by members of the research team in 2011-2012. The digital audio recorded interviews were downloaded to the computer using the current VA Data Safety Monitoring board-approved software program. Audiofiles were coded using 
thematic analysis, whereby "themes" infer units of meaning present within and across interviews. Thematic saturation of narratives occurred with a relatively stable number of qualitative interviews, traditionally believed to be achievable at 15 cases. Refinement of the codes was an iterative process with team discussions to refine or expand codes, resolve discrepancies, and agree upon a final coding structure that captured the main themes. Conceptual memos were used to develop a theory of the relationships among codes and deeper meanings of the veterans' responses. The analysis and interpretation of the data were discussed among authors and any general/or specific feedback were presented to corresponding team members.

The sample consisted of equal numbers of men and women, by design. The mean age was 52 years; 64\% self-identified as being White, 36\% as being African American, and $11 \%$ as being Hispanic. Twenty-four percent had served during the most recent eras of service (OEF/OIF); 46\% served in a war zone. Sixty-one percent served in the Army; $56 \%$ belonged to a lower enlisted rank (pay grades E1-E4); 67\% had household incomes less than $\$ 50,000$; and $74 \%$ had college or higher education.

The analytic qualitative data of this paper focused on the responses to the interview script question: "Do you remember being asked these [MST screening] questions?" Study participants were given a copy of the MST screening questions and also read to participants verbatim. During the interview, the two-item screening questions were also shown to participants on pieces of paper, along with where and how the questions were asked and by whom. Veterans who did not remember the screening questions being asked of them, were asked about perceptions of the MST screening 
questions. The interviews ranged in length from 28 minutes to 3 hours and 2 minutes, with an average length of 1 hour and 18 minutes.

\section{RESULTS}

The SEQ is considered the current best available assessment tool to identify veterans with history of military sexual abuse histories, therefore we compared its accuracy to the documented MST status in the electronic health records of VA users, since a primary reason for the quantitative data collected of the study was to assess the accuracy of the current VHA two-item screening tool. Using the VisTa Data Warehouse of veteran responses of the two-item MST screening questions, SEQ-DOD data, and veteran interviews, we present our main findings. Following Goffman (1964), we address themes from the data that represent several aspects of total institutions, including: 1) veteran responses to screening, and 2) impact of screening on veterans.

\section{Rate of MST Screening by Gender}

Table 2 shows local rates of MST screening using the current, electronicallybased, two-item prompt indicate that approximately $1 \%$ of assessed male veterans in VA have documented MST histories - see male veteran rates, compared to those for female veterans for VA health clinics that participated in this study (Kimerling, Street, Gima 2006). This prevalence is surprisingly low when compared to rates of MST identified veterans when administering comprehensive instrumentation to active duty military samples. This is evidence of an ineffective screening method, as it fails to produce accurate results as compared to SEQ scores. 
Table 2. Local Rate of MST Screening by Gender.

\begin{tabular}{lcccc}
\hline & \multicolumn{2}{c}{ Women } & \multicolumn{2}{c}{ Men } \\
\cline { 2 - 5 } & \# Screened & \% Positive & \# Screened & \% Positive \\
\hline Iowa & 1,582 & 24.1 & 36,259 & 1.1 \\
Miami & 2,292 & 14.4 & 43,177 & 1.0 \\
Philadelphia & 2,133 & 20.2 & 47,559 & 1.3 \\
Pittsburgh & 1,634 & 23.9 & 41,936 & 1.0 \\
\hline
\end{tabular}

Veteran Remembrance of MST Screening in VA Clinical Care Setting

Overall, $51 \%$ of the participants enrolled in the study did not remember being asked the MST screening questions. Stratified based on MST status/SEQ score (+/-), the following veterans did not recall being asked the screening questions: 75\% MST-/SEQ-; $69 \% \mathrm{MST}-/ \mathrm{SEQ}+$; and $40 \% \mathrm{MST}+/ \mathrm{SEQ}+$. In terms of gender, $40 \%$ of females and $69 \%$ of males did not remember being asked the MST questions. When stratified by MST status/SEQ scores and gender, the following veterans did not remember being asked the screening questions: MST+/SEQ+ 25\% females and 57\% males; MST-/SEQ- 50\% females and 100\% males; MST-/SEQ+ 67\% females and 70\% males.

Stratified by gender, $25 \%$ of females and $57 \%$ of males with a documented SEQ+ and MST+ did not recall being screened. In cases of SEQ+ and MST-, 67\% females and $70 \%$ of males did not remember being screened at the VA point of care. An example response was "I've never been asked anything about sexual abuse in the military ... never. Nobody ever asked me if I was raped. Nobody ever asked me anything about sexual nothin' period." These findings clearly indicate that the universal screening mandate is an ineffective mechanism for identifying veterans with military sexual abuse history. 
Notably, men and women Veterans with a documented MST- screen were most likely to report a non-remembrance of being asked the screening questions: "I've never had these questions asked to me" (female, MST-/SEQ+). Another Veteran stated: "Oh. No, this is the first time I've ever had a discussion about this matter" (male, MST/SEQ+). Veterans with MST- status and high SEQ+ scores—did not recall being asked the screening questions. Remarkably, $100 \%$ of MST-/SEQ- males did not recall being asked the MST screening questions. Overall, men were less likely to remember being screened for history of sexual abuse in the US military.

When compared to studies of active-duty sampling and SEQ scores more broadly, we anticipated men to report a higher rate of military sexual abuse. However, using Goffman's framework, harassment and assault in the military can be understood as cultural components of a total institution that shape gendered and sexual interactions. In this view, the military as a total institution shapes the experience of masculinity such that reporting of sexual abuse often results in scrutiny of masculinity, institutional retaliation, further abuse, and one's ability to serve (King 2000). Conceptually, the gendered dynamics of masculinity within the total institution are distorted by men reporting military sexual abuse. It may also influence how men experience the interplay of structure and agency in their own self-definitions as a 'warrior,' a rhetoric emphasized in masculine ethos of rugged individuality, and embodied and cultural necessity of its members to achieve the goals of the institution and prevent disruption of unit cohesion within the total institution. 
Forgetting. In many instances, veterans who identified as experiencing sexual abuse in the military emphasized they "buried" their thoughts and had forgotten their MST experiences: "I'd pushed it so far back, I just totally forgot about the incident." They stated that they would just "block" out past experiences but acknowledged persistent difficulties of forgetting the incidents. For example, “I didn’t feel like it was being evasive. It was something I had buried ... And starting to come to the surface.” Other veterans stated: “I kind of just block past experiences. I really don't like to talk about it much" and "I mean, I got myself together, because I had to go back to work ... dust off and go back to work. You know? [laughter] Get rid of your feelings and get back to work." This thematic finding indicates that veterans are either remembering and not disclosing MST, are actually not remembering their experiences. Whether veterans remember the MST experience or not, they are still impacted by the institutional norms established by the VA and reinforced by the gendered dynamics of the military as a total institution.

Surprise. Of the veterans who remembered being asked the screening questions, many stated they found being asked the MST screening questions in the VA health care setting as "surprising" and "quite interesting." For example, one veteran said, "I was surprised. I didn't expect these questions to be asked, and so it caught me off guard a bit." Majority of veterans stated they did not expect to be asked questions about military sexual harassment or assault experiences at the point of care in the VA health care setting.

When you've had something like this happen to you, when somebody says the question like this, it's like somebody punching you right in the gut, 
you lose your wind, you lose everything, your thought and everything, when they ask that question.

These questions position the veteran to recall potentially traumatic situations in their service history, regardless of whether they are seeking care related to that experience or not. Therefore, veterans are caught off guard by these questions, and may feel shame around disclosure as a quality of institutional relationality (i.e., their positionality within the military as a total institution in terms of shaping their identity as a veteran).

Distress. Other veterans stated that the MST screen evoked memories and emotions associated with it. The emotions veterans reported included feelings of being “angry," “defensive," or "sad.” Many veterans also discussed experiencing "anxiousness," "sweating," "crying," or "difficulty breathing" when screened by a VA healthcare provider.

Just the whole incident coming back to mind. It felt like somebody was stabbing me in my chest. There were physical pains as well the emotional pains, and it surprised me. I thought I'd dealt with it. So, there was anxiousness, physical pain in a sense that, I couldn't breathe and I was fighting back the tears.

Another participant shared: "After that first time [MST Screen], I just felt sad ... I felt really sad. When I heard those words, it really made me stop and made me realize what I'd been through . . . it was hard. It made the whole rest of the visit [medical appointment] kind of a blur."

Like incest, due to the interdependent nature of the military institution and its members, the effects of military sexual abuse can last a lifetime, with a range of emotional reactions and adverse effects on the person's ability or willingness to discuss history of abuse, seek social support or therapeutic treatment if the person is having 
difficulty (Freyd 2016; Scheitzer 2018, Kimerling 2000; King 2000). Therefore, a vast majority of sexual abuse survivors choose not report abuse (Freyd 2016; King 2000).

Defensive. Again, screening may often take place when MST treatment is not the agenda for the health care visit, making the experience one potentially fraught with emotion. For veterans who adopted traumatic amnesia as a protective mechanism, creating an adaptive defensive wall of protection from pain during their service may be flooded with emotion at the time of MST screening due to sudden memory recall of the abuse. For example, Jane stated: "I just remember at first being defensive . . . like, 'Back off!'... I've already buried those memories!” A female veteran, Samantha described her response to the screen:

When she used that term [MST] it kinda made me angry . . . defensive, because I didn't feel I met that term. I really didn't feel that I met that designation. Because I have in my head what I consider to be MST. So, it made me uncomfortable 'cause she kept using that phrase in reference to me and I really wasn't at that point, ready to admit that that's what it was.

Samantha's response helps us understand the potential impact of the MST screening as a personal identifier, a label as victim or traumatized that may inform the care received within VA health services. This label may not resonate with the individual veteran's experiences, as here, where there appears to be a mismatch in the institutional definition and personal context. The subjective nature of personal context makes it difficult to navigate institutionalized policies and practices that force veterans to disclose sexual trauma, for example. Due to distress of disclosure many veterans recall:

In the beginning I just didn't want to talk about it. And it automatically gave me flashbacks and I think I had an anxiety event where I just freaked out and start[ed] sweating and [pause] got nervous and I just blocked on every other question she wanted to ask me. I just didn't say anything else at all. 
Here we see the potential impact of surprising a veteran with questions about MST, leading them to shut out the stimulus altogether and shut down in the interaction. When veterans were asked if they recalled being screened for MST at the VA point of care they describe being surprised by discussions of military sexual harassment and sexual assault which caused the veteran's difficulties and an array of emotional symptoms or disturbances.

Lasting Effects of Abuse in Total Institutions

Of the veterans with MST+/all 4 SEQ+ domains suggest that they were "at a loss" in how to deal with the military sexual assault and harassment when it occurred, so they "kind of shut it away" (female, MST+/SEQ+). Roger, a male veteran shared his experienced of retaliation for reporting sexual harassment or assault during military service and suggested a widespread conspiracy of sexual violence in the military was inherent in the institution: "I used to think that this was the military's best kept secret" (male, MST+/SEQ+). Jo, a female veteran shared, "There's a lot of things you just put up with in the ... I felt like the stuff that I experienced was crap that I just had to put up with as part of the culture" (female, MST+/SEQ+).

I was even afraid to go to my appointment. I thought about cancelling it, and I was like no, it's the law. They have to ask. And you need to talk, we need to learn, Veterans need to learn to talk and share it. We don't share it. We just don't because it's painful. But some of it's because our families had this great picture of our experience in the military . . . cause your family is proud of you, you served your country. So, you don't want to tell them, 'horrible things happened to me!' For some soldiers, some of it was just so horrible that they just wanna, they think they are forgetting it . . . but you don't. They just feel like, 'If I don't talk about it, I'm leaving it behind.' Really we don't, we carry it with us. (MST+/SEQ+)

Another veteran discussed the unlikelihood of accurate reporting: 
I felt uncomfortable because throughout my military career I was never asked that question. Just towards the end, and then now that I'm out, they were asking. I felt like why wait nine years to ask that question. I was already having problems. So, I didn't feel like the VA could help me. (female, MST-/SEQ+)

Participants reported: “You can't fix anything that you don't even know is broken. If you don't know about it, how can you address it" (male, MST-/SEQ+). Female veterans with MST-/SEQ+ scores noted they were not asked similar questions about military sexual harassment or assault while serving in the military—although they were being asked about sexual trauma history in the VA medical center:

Regina, a female veteran summed it up: "Why are you asking me this shit?" Similarly, another veteran said, "Why are you asking ... do you know something I don't know?" (male, MST-/SEQ+). These findings also indicate a clear reluctance on the part of military personnel and veterans to self-identify as victims. Unsurprising, as "evidence has surfaced that doctors employed by the VA have been discouraged from properly diagnosing veterans with PTSD and were told to instead consider a diagnosis of Adjustment Disorder, a less chronic disorder that offers fewer benefits and inappropriate treatment for veterans with PTSD" (Schweitzer 2016). Clearly, this type of unethical behavior and tacit compliance among VA clinicians further demonstrates a spectrum of causes and manifestations of why sexual abuse is not reported to authorities (King 2000). The hierarchical structure and rank of the military, required further interaction with perpetrators, potential for future abuse, disruption of unit cohesion, scrutiny of ability to serve, institutional retaliation, questioning of the individual's masculine identity (Shira Maguen et al. 2012), lack of anonymity of reporting, lesser likelihood of VA benefit 
award, and implications for identity as a military veteran are all factors that result in adverse reactions of the screening (as noted above), at the VA point of care.

Subsequently, these factors demonstrate how reporting of military sexual abuse history disrupts the interdependence conferred by, and for the goals of the total institution, as evidenced by covert and overt institutional acceptance of military sexual abuse.

\section{DISCUSSION}

Given the above potential areas of confusion in the current MST screening process and the large discrepancy between the current rates of MST to the two-question VA clinical screening mandate compared to other sources, it appears very likely that the existence of the MST in its current iteration offers the form, but not substance of compliance with the VA's own guidelines. Most notably, it should be apparent that the potential harm and emotional costs of failing to provide effective therapeutic, beneficiary, legal interventions, as well as social support for veterans with military sexual abuse histories. Potentially, these shortcomings could move well beyond the personal/medical and into the public/legal domain. Therefore, it seems vital to the interests of the US military and VA to ensure approaches are focused on 1) preventing sexual harassment and assault in the US military, 2) creating anonymous sources for reporting, 3) creating anonymous health care services related to military sexual abuse, 4) evaluation of current therapeutic interventions, 5) and further review and determination of specific institutional interventions (i.e. VA benefits and entitlements) that may provide justice for veterans with military sexual abuse histories. 
Although the SEQ is Not Perfect, It Provides a Useful Alternative

Among others, Gutek, Murphy, Douma, and Noone, critique, in detail, a myriad of issues with the SEQ (Noone 1999; Uggen \& Blackstone 2004). While characterizing all these concerns is beyond the scope of this paper, the most important issue as it pertains to this paper is that the SEQ "over reports prevalence of sexual harassment" and "overestimates the gap between reported harassment and its identification" - though they hasten to add that these stated weaknesses are" not mean[t] to imply ... that the SEQ is useless, or that there are other superior measures that researchers should use."

The potential over-reporting problem emanates from the SEQ's scoring approach, which counts as sexual harassment and assault a positive answer (e.g., more than "never") to any item from the twenty-plus scenarios. We agree with Gutek et al. and Noone that this is likely to have strongly informed the size of the discrepancies between current measure MST reporting and studies using the SEQ. It seems clear that while one measure may result in over-reporting; the other produces the opposite result. Additional reasons include the "severe or pervasive" standard that is often applied to legal definitions for harassment (and accepted, at least at face value, by the federal definition), whereby harassment (as assessed by the SEQ) may be established not by a pattern of repeated low-severity behaviors but by a single serious incident (Uggen et.al. 2004) Thus, not all SEQ events that occurred "once or twice" can be discounted.

As noted above, the current 2-item screening test does not provide veterans or clinicians a clear understanding of how the VA interprets Congress's definition. Rather, the questions rely on individual veteran and clinician interpretation. The two MST 
screening questions don't incorporate federal definitions at all or do so very narrowly.

For example, the first question doesn't incorporate the aspect of "repeated" or "threatening" sexual attention and the second question asks only about "hav[ing had] sex" without any definition of what it means to "have sex."

Furthermore, the questions appear to curtail the possibility of a variety of other sexual interactions that may not have been overtly forced or threatening but were perceived as such by one party because of military rank or other status imbalance between the parties, shaped by the social norms of the total institution. In addition, the venue for the MST screen as part of a battery of questions during the course of a routine visit to a primary care provider does not seem ideally conducive to either the veteran's willingness to self-identify as a victim of MST or for the primary care clinicians and VA institution to respond in a way that is helpful to the veteran.

The confusion and lack of understanding about the purpose of the screen and the meaning of the screening, on the part of the veteran and clinicians using the current MST screening questions appears to be very high. Even if the MST screening questions elicit a positive response, the validity of that response is questionable given that most veterans and clinicians are not likely to be familiar with the underlying definitions of sexual harassment and sexual assault on which it is supposed to be based. Most importantly, the current MST screening protocol provides no guidance or education for VA clinicians to respond to a positive screen. Consequently, there is a lack of congruence in the MST screening question language and the Congressional and VA definitions; for example, "sexual harassment and sexual assault" vs. "sexual trauma." Furthermore, it is not clear if 
the clinician would be able or qualified to offer any guidance on the subject should questions regarding semantics arise.

Despite the congressional mandated screen to detect veterans with histories of military sexual abuse, identifying individuals who need care following military sexual abuse, as opposed to other types of exposures (e.g., smoking, radiation), is problematic because MST is not "a syndrome, diagnosis, or construct associated with clear treatment indications" (Kimerling 2004). Further complicating screening efforts is whether the purpose of screening should be to identify individuals' self-perceptions that they have experienced sexual trauma (i.e., personally labeling the experience as trauma) or whether the purpose is to identify actual sexual abuse histories (i.e., behaviorally specific experiences), even if individuals do not label their experience(s) as traumatic or themselves sexual abuse victims. Numerous studies demonstrate that individual perceptions about what constitutes harassment varies by one's sex, race, position in the organization, and whether one perceives the environment as 'typical' or 'normal' (Kimberling 2004).

We believe the SEQ remains the better available option for research purposes, as the SEQ can offer: 1) another means - other than MST screening protocols; and Goffman's concept of total institution can better 2) serve as a different framework from which to understand responses from participants about their perceptions on what types and frequencies of behaviors constitute sexual harassment and assault within a military context, and insights to better address military sexual abuse as a public health concern (Dahlberg and Mercy, 2009). In addition, concern over the validity of instruments due to 
veteran non-remembrance of MST and distress expressed by veterans screened in the VA clinical setting indicates a dire need for anonymity of veterans disclosing military sexual harassment and assault histories to authorities in-service and post-service. Our findings suggest alternatives outside the US military and VA institutions must be made for veterans reporting military sexual abuse histories, and for veterans seeking related health care, VA benefits, and/or legal resolve.

In conclusion, our study offers insight concerning the significant underreporting of sexual abuse among military veterans in the VA clinical setting, and markedly lower rates of MST reporting among VA users (Rock, 2013; Namrow \& Rock, 2013; Hoyt, Rielage, \& Williams, 2011; Rheinhardt, 2016). Due to US military and VA failure to further commit reducing military sexual abuse conduct or providing relief for veterans with military sexual abuse histories, it is of vital necessity that alternative approaches be created for our nation's veterans outside of these institutions. Otherwise, past and current mandates fall short in prevention, relief, or justice for those who report military sexual abuse, remaining largely burdensome for our nation's veterans. Our findings indicate that VA's unsuccessful and extremely ineffective... or nonexistent approaches to addressing military sexual harassment and assault and related health sequelae in the VA clinical setting resembles condoning of military sexual abuse (Knoer, 2016). In our study, the distress expressed among veterans, and lack of evidentiary therapeutic benefit of disclosure at the VA point of care suggest VA's approach to screening is ineffective and potentially harmful (Schweitzer, 2015). Therefore, it is incumbent upon these institutions to first do no harm, and make justice a priority for our nation's veterans. 


\section{Acknowledgements}

The author would like to express gratitude and appreciation to the individuals who participated in this study.

\section{Funding}

This material is the result of work supported with resources and the use of Department of Veterans Affairs facilities. The views expressed in the article are those of the authors and do not necessarily reflect the position or policy of the Department of Veterans Affairs or the United States Government.

\section{REFERENCES}

American College of Obstetricians and Gynecologists. (2011). Committee opinion No. 499: Sexual assault. Obstetrics and Gynecology, 118 (2, Part 1), 396399. http://dx.doi.org/10.1097/AOG.0b013e31822c997c

Castro, C. A., Kintzle, S., Schuyler, A. C., Lucas, C. L., \& Warner, C. H. (2015). Sexual assault in the military. Current Psychiatry Reports, 17 (54), 1-

13. http://cir.usc.edu/wp-content/uploads/2015/06/Sexual-Assault-in-theMilitary.pdf

Coxell, A., King, M., Mezey, G., \& Gordon, D. (1999). Lifetime prevalence, characteristics, and associated problems of non-consensual sex in men: Cross sectional survey. BMJ, 318, 846-850. http://dx.doi.org/10.1136/bmj.318.7187.846

Cunradi, C., Ames, G., \& Moore, R. (2005). Prevalence and correlates of interpersonal violence victimization in a junior enlisted Navy cohort. Violence and Victims, 20(6), 679-694. http://dx.doi.org/10.1891/0886-6708.20.6.679 
Dahlberg, L. L., \& Mercy, J. A. (2009). History of violence as a public health problem. Virtual Mentor, 11(2), 167-

172. http://dx.doi.org/10.1001/virtualmentor.2009.11.2.mhst1-0902

de Boinville, M. (2013). Screening for domestic violence in health care settings. ASPE Policy Brief. Retrieved from https://aspe.hhs.gov/sites/default/files/pdf/76931/pb screeningDomestic.pdf Department of Defense. (2015). 2015 demographics: Profile of the military community. Retrieved from http://download.militaryonesource.mil/12038/MOS/Reports/2015Demographics-Report.pdf

Firestone, J. M., \& Harris, R. J. (1994). Sexual harassment in the U.S. military: Individualized and environmental contexts. Armed Forces \& Society, 21(1), 2543. http://dx.doi.org/10.1177/0095327x9402100103

Fitzgerald, L. F., Drasgow, F., \& Magley, V. J. (1999). Sexual harassment in the armed forces: A test of an integrated model. Military Psychology, 11(3), 329343. http://dx.doi.org/10.1207/s15327876mp1103 7

Fitzgerald, L. F., Gelfand, M. J., \& Drasgow, F. (1995). Measuring sexual harassment: Theoretical and psychometric advances. Basic and Applied Social Psychology, 17(4), 425-445. http://dx.doi.org/10.1207/s15324834basp1704_2

Fitzgerald, L. F., Magley, V. J., Drasgow, F., \& Waldo, C. R. (1999). Measuring sexual harassment in the military: The Sexual Experiences Questionnaire (SEQDoD). Military Psychology, 11(3), 243-

263. http://dx.doi.org/10.1207/s15327876mp1103_3 
Frayne, S. M., Phibbs, C. S., Saechao, F., Maisel, N. C., Friedman, S. A., Finlay, A. ... Haskell, S. (2014). Sourcebook: Women veterans in the Veterans Health Administration. Volume 3. Sociodemographics, utilization, costs of care, and health profile. Women's Health Evaluation Initiative, Women's Health Services, Veterans Health Administration. Washington DC: Department of Veterans Affairs.

Freyd, J. J. (1994). Betrayal trauma: Traumatic amnesia as an adaptive response to childhood abuse. Ethics and Behavior, 4(4), 307-329.

Freyd, J. J., \& Barrell, P. (2013). Blind to betrayal. Why we fool ourselves we aren't being fooled. Hoboken, NJ: John Wiley and Sons.

Freyd, J. J., DePrince, A. P. \& Gleaves, D. H. (2007). The state of betrayal trauma theory: Reply to McNally_Conceptual issues and future directions. Memory, 15(3), 295-311.

Goldsmith, R. E., Freyd, J. J., \& DePrince, A. P. (2012). Betrayal trauma: Associations with psychological and physical symptoms in young adults. Journal of Interpersonal Violence, 27, 547-567.

Gutek, B. A., Murphy, R. O., \& Douma, B. (2004). A review and critique of the Sexual Experiences Questionnaire (SEQ). Law and Human Behavior, 28(4), 457482. http://dx.doi.org/10.1023/B:LAHU.0000039335.96042.26

Hoyt, T., Rielage, J. K., \& Williams, L. F. (2011). Military sexual trauma in men: A review of reported rates. Journal of Trauma \& Dissociation, 12(3), 244260. http://dx.doi.org/10.1080/15299732.2011.542612 
Kang, H., Dalager, N., Mahan, C., \& Ishii, E. (2005). The role of sexual assault on the risk of PTSD among Gulf War veterans. Annals of Epidemiology, 15(3), 191195. http://dx.doi.org/10.1016/j.annepidem.2004.05.009

Katz L, Bloor L, Cojucar G, Draper T. (2007). Women who served in Iraq seeking mental health services: relationships between military sexual trauma, symptoms, and readjustment. Psychol Serv, 4(4), 239-249.

Kimerling, R., Gima, K., Smith, M. W., Street, A., \& Frayne, S. (2007). The Veterans Health Administration and military sexual trauma. American Journal of Public Health, 97(12), 2160-2166. http://dx.doi.org/10.2105/AJPH.2006.092999

Kimerling, R., Street, A. E., Gima, K., \& Smith, M. W. (2008). Evaluation of universal screening for military-related sexual trauma. Psychiatric Services, 59(6), 635640. http://dx.doi.org/10.1176/ps.2008.59.6.635

Kimerling, R., Street, A. E., Pavao, J., Smith, M. W., Cronkite, R. C., Holmes, T. H., \& Frayne, S. M. (2010). Military-related sexual trauma among Veterans Health Administration patients returning from Afghanistan and Iraq. American Journal of Public Health, 100(8), 1409-1412. http://dx.doi.org/10.2105/AJPH.2009.171793

Konrad, A. M., \& Gutek, B. A. (1986). Impact of work experiences on attitudes toward sexual harassment. Administrative Science Quarterly, 31(3), 422438. http://dx.doi.org/10.2307/2392831

Krug, E. G., Mercy, J. A., Dahlberg, L. L., \& Zwi, A. B. (2002). The world report on violence and health. The Lancet, 360(9339), 10831088. http://dx.doi.org/10.1016/S0140-6736(02)11133-0 
Layman, M. J., Gidycz, C. A., \& Lynn, S. J. (1996). Unacknowledged versus acknowledged rape victims: Situational factors and posttraumatic stress. Journal of Abnormal Psychology, 105(1), 124-131. http://dx.doi.org/10.1037/0021$\underline{843 X .105 .1 .124 .}$.

Lipari, R. N., Lancaster, A. R., \& Jones, A. M. (2005). 2004 Sexual Harassment Survey of Reserve Component Members. Report 2005-010. Retrieved from http://www.sapr.mil/public/docs/research/2004-Sexual-Harassment-Surveyof-Reserve-Component-Members.pdf.

McDonald, P. (2012). Workplace sexual harassment 30 years on: A review of the literature. International Journal of Management Reviews, 14(1), 117. http://dx.doi.org/10.1111/j.1468-2370.2011.00300.x.

McIntyre, L. M., Butterfield, M. I., Nanda, K., Parsey, K., Stechuchak, K. M., McChesney, A. W., . . Bastian, L. A. (1999). Validation of a Trauma Questionnaire in veteran women. Journal of General Internal Medicine, 14(3), 186-189. http://dx.doi.org/10.1046/j.1525-1497.1999.00311.x.

McMullin, D., \& White, J. W. (2006). Long-term effects of labeling a rape experience. Psychology of Women Quarterly, 30(1), 96105. http://dx.doi.org/10.1111/j.1471-6402.2006.00266.x.

Mengeling, M. A., Booth, B. M., Torner, J. C., \& Sadler, A. G. (2014). Reporting sexual assault in the military: Who reports and why most servicewomen don't. American Journal of Preventive Medicine, 47(1), 17-

25. http://dx.doi.org/10.1016/j.amepre.2014.03.001. 
Mengeling, M. A., Booth, B. M., Torner, J. C., \& Sadler, A. G. (2015). Post-sexual assault health care utilization among OEF/OIF servicewomen. Medical Care, 53(4 Supplement), S136-

S142. http://dx.doi.org/10.1097/MLR.0000000000000267.

Morral, A. R., Gore, K. L., \& Schell, T. L. (2016). Sexual assault and sexual harassment in the U.S. military: Volume 2. Estimates for Department of Defense service members from the 2014 RAND Military Workplace Study. Retrieved from http://www.rand.org/pubs/research_reports/RR870z2-1.html.

Murdoch, M., \& Nichol, K. L. (1995). Women veterans' experiences with domestic violence and with sexual harassment while in the military. Archives of Family Medicine, 4, 411-418. http://dx.doi.org/10.1001/archfami.4.5.411.

Murdoch, M., Polusny, M. A., Hodges, J., \& O'Brien, N. (2004). Prevalence of in-service and post-service sexual assault among combat and noncombat veterans applying for Department of Veterans Affairs posttraumatic stress disorder disability benefits. Military Medicine, 169(5), 392-

395. http://dx.doi.org/10.7205/MILMED.169.5.392.

Murdoch, M., Pryor, J. B., Polusny, M. A., \& Gackstetter, G. D. (2007). Functioning and psychiatric symptoms among military men and women exposed to sexual stressors. Military Medicine, 172(7), 718-

725. http://dx.doi.org/10.7205/MILMED.172.7.718.

National Defense Research Institute (NDRI). Sexual assault and sexual harassment in the military: top-line estimates for active duty service members from the 2014 RAND 
military workplace study. Washington, D.C.;

2014. http://www.sapr.mil/public/docs/reports/FY14_POTUS/FY14_DoD_Report to_POTUS_Annex 1_RAND.pdf.

Namrow, N., \& Rock, L. (2013). 2012 Workplace and Gender Relations Survey of Reserve Component Members (2013-002). Retrieved from http://www.sapr.mil/public/docs/research/2012 Workplace and Gender Re lations_Survey_of_Reserve_Component_MembersSurvey_Note_and_Briefing.pdf.

Reddy, M. K., \& Murdoch, M. (2010). Sex differences in the factor structure of a modified Sexual Experiences Questionnaire. Psychological Reports, 107(3), 773783. http://dx.doi.org/10.2466/03.08.16.pr0.107.6.773-783.

Reinhardt, K.M., Smith, C.P., \& Freyd, J.J. (2016). Came to serve, left betrayed: MST and the trauma of betrayal. In L. S. Katz (Ed.), Understanding and treating military sexual trauma. New York: Springer.

Smith, C. P. \& Freyd, J. J. (2013). Dangerous safe havens: Institutional betrayal exacerbates sexual trauma. Journal of Traumatic Stress, 26, 119-124.Rock, L. (2013). 2012 Workplace and Gender Relations Survey of Active Duty Members (2013-007). Retrieved from http://www.sapr.mil/public/docs/research/2012 Workplace and Gender Re lations Survey of Active Duty Members-Survey Note and Briefing.pdf. 
Rosen, L. N., \& Martin, L. (1998). Incidence and perceptions of sexual harassment among male and female U.S. Army soldiers. Military Psychology, 10(4), 239257. http://dx.doi.org/10.1207/s15327876mp1004_2.

Sadler A, Booth B, Cook B, Doebbeling B. (2003). Factors associated with women's risk of rape in the military environment. Am J Ind Med, 43(3):262-73.

Shale, J. H. (2014). A proposal to refine the definition of military sexual trauma for purposes of treatment and research. The Journal of Clinical Psychiatry, 75(10), 1190-1191. http://dx.doi.org/10.4088/JCP.14com09537.

Street, A., Gradus, J. L., Stafford, J., \& Kelly, K. (2007). Gender differences in experiences of sexual harassment: Data from a male-dominated environment. Journal of Consulting and Clinical Psychology, 75(3), 464474. http://dx.doi.org/10.1037/0022-006X.75.3.464.

Street, A. E., Gradus, J. L., Giasson, H. L., Vogt, D., \& Resick, P. A. (2013). Gender differences among veterans deployed in support of the wars in Afghanistan and Iraq. Journal of General Internal Medicine, 28(2), 556-

562. http://dx.doi.org/10.1007/s11606-013-2333-4.

Street, A. E., Stafford, J., Mahan, C., \& Hendricks, J. (2008). Sexual harassment and assault experienced by reservists during military service: Prevalence and health correlates. Journal of Rehabilitation Research and Development, 45(3), 409420. http://dx.doi.org/10.1682/JRRD.2007.06.0088. 
Suris, A. \& Lind, L. (2008). Military sexual trauma: A review of prevalence and associated health consequences in veterans. Trauma, Violence, \& Abuse, 9(4), 250-269. http://dx.doi.org/10.1177/1524838008324419.

Tjaden, P., \& Thoennes, N. (2000). Full report of the prevalence, incidence, and consequences of violence against women. NCJ 183781. Retrieved from www.ncjrs.gov/pdffiles1/nij/183781.pdf.

Tjaden, P. G., \& Thoennes, N. (2006). Extent, nature, and consequences of rape victimization: Findings from the National Violence Against Women Survey. NCJ 210346. Retrieved from https://www.ncjrs.gov/pdffiles1/nij/210346.pdf.

Turchik, J. A., \& Wilson, S. M. (2010). Sexual assault in the U.S. military: A review of the

literature and recommendations for the future. Aggression and Violent Behavior, 15(4), 267-277. http://dx.doi.org/10.1016/j.avb.2010.01.005.

Turner, C. \& Frayne, S. (2004). Military sexual trauma. Department of Veterans Affairs employee education system (Independent study course).

Retrieved from https://www.publichealth.va.gov/docs/vhi/military_sexual_trauma.pdf. U.S. Department of Veterans Affairs. (2010). VHA Directive 2010-033. Military Sexual Trauma (MST) Programming. Retrieved from www.va.gov/vhapublications/publications.cfm?pub=1.

U.S. Department of Veterans Affairs. (2015). Military Sexual Trauma (MST) screening report fiscal year 2015. Patient Care Services, Office of Mental Health Services, MST Support Team. 
U.S. Department of Veterans Affairs. (May 2015). Mental Health: Conditions: Military Sexual Trauma: Articles \& Fact Sheets. Retrieved from http://www.mentalhealth.va.gov/docs/mst_general_factsheet.pdf.

U.S. Department of Veterans Affairs. (2016). Mental Health: Conditions: Military Sexual Trauma. Retrieved from www.mentalhealth.va.gov/msthome.asp.

U.S. Department of Veterans Affairs Product Development. (2015). The Military Sexual Trauma Clinical Reminder Referral Question and Re-Deployment Activation Patch PXRM 2.0 43 Installation and Setup Guide. Retrieved from www.va.gov/vdl/documents/Clinical/CPRSClinical_Reminders/pxrm_2 0 _ 43 _ig.pdf.

U.S. Government Publishing Office. (2000). Veterans Millennium Health Care and Benefits Act, Public Law 106-117. Retrieved from www.gpo.gov/fdsys/pkg/PLAW-106publ117/content-detail.html. Veterans Health Care Act of 1992, 38 U.S.C., Pub. L. No. 102-585. Retrieved from https://www.govtrack.us/congress/bills/102/hr5193, (1992).

Veterans Health Programs Extension Act of 1994, 38 U.S.C., Publ. L. 103-452. Retrieved from https://www.govtrack.us/congress/bills/103/hr3313, (1994).

Veterans Health Programs Improvement Act of 2004, 38 U.S.C., Publ. L. No. 108-422. Retrieved from https://www.govtrack.us/congress/bills/108/hr3936, (2004).

Zinzow, H. M., Grubaugh, A. L., Monnier, J., Suffoletta-Maierle, S., \& Frueh, B. C. (2007). Trauma among female veterans: A critical review. Trauma, Violence, \& Abuse, 8(4), 384-400. http://dx.doi.org/10.1177/1524838007307295. 


\title{
CHAPTER 5: COMBATING GENDER BIAS IN VA DISABILITY AWARD
}

Authors: Sarah Aktepy, JaDee Carathers, and Paul Sorenson

\begin{abstract}
This study examines self-reported military exposures (i.e., exposure to combat/war, death/dying/wounded, and environmental hazards) and Department of Veterans Affairs Disability Compensation award and 50\%-or-greater rating level (VADC) by gender, prior to DODs 2014 policy reform for the inclusion of women in combat military occupational specialties utilizing data from a subset of 8,710 respondents of the 2010 National Survey of Veterans. Results of logistic regression models predicting VADC award indicate the moderating effect of gender on the relationship between military exposures and VADC award and rating. Findings reveal gender bias in VADC award, and VADC rating percent. Women veterans suffer the burden of proof in their military exposures claims for due compensation by the VA. This disparity is informed by inequality regimes in the institutional organization that create and maintain cultural gender norms that devalue the service of women veterans by limiting their benefits and entitlements.
\end{abstract}

\section{INTRODUCTION}

In 2018, Bipartisan representatives from New York and Florida introduced a bill to modify the wording of the VA motto, "To care for him who shall have borne the battle and for his widow, and his orphan.” The VA motto, adopted about 60 years ago, is a quote from President Abraham Lincoln's second inaugural address in 1865 and greets every veteran seeking care in a VA facility. The updated language would omit the universal masculine to reflect the reality that servicemembers and their families have 
various genders. The revised motto would read: “To fulfill President Lincoln's promise to care for those 'who shall have borne the battle' and for their families, caregivers, and survivors." Republicans blocked the bill, first introduced through the efforts of Iraq and Afghanistan Veterans of America (IAVA), and the VA later rejected the suggestion of modifying the language. According to IAVA, this debate is symbolic of the gendered barriers that plague women veterans as they seek VA benefits and entitlements, including VA health care. In this study, we consider the impact of gender bias in an institutional setting where the labor of women veterans is marginalized and made invisible, such that cultural norms frame only men as war heroes who have earned the right to health care and other benefits.

Since 2001, more than 150,000 U.S. military women have been deployed overseas; combined this is the largest wartime deployment for U.S. military servicewomen (Department of Defense [DOD], 2010). One important way the VA can recognize veterans for their service is by granting benefits and entitlements to veterans who had military exposures (e.g., hazards, war) with disability compensation for functional limitations incurred or aggravated during military service (Schweitzer 2013). However, gendered cultural norms about women's labor continue to shape health and quality-of-life outcomes that disadvantage women veterans in meaningful ways (e.g. service-connected status, unequal access to benefits, such as VA health care), in part, through policies and practices disallowing women combat Military Occupational Specialty (MOS) and reinforcing the notion that combat exposure is dependent on combat MOS. Gender inequality is embedded within the policies and practices of the VA such 
that women veterans are less likely to receive VA benefits than men veterans, despite having wartime exposures. The gendered logic of MOS reinforces masculine privilege through combat-bias in VA award and distribution of benefits and entitlements, thus creating and maintaining gender inequalities among servicemembers.

The veteran health literature has primarily focused on individual level factors to explain health outcomes among military veterans. Most of these studies have excluded women veterans, and adopted rigid definitions of combat that have conflated military exposures with outdated combat policy or combat MOS, "jobs" previously excluded to women. We explore gender inequality in VA benefits by applying Acker's (2006) theoretical framework on inequality regimes: "All organizations have inequality regimes, defined as loosely interrelated practices, processes, actions, and meanings that result in and maintain class, gender, and racial inequalities within particular organizations” (p. 443). By examining the organizational processes that produce inequality, we can better interpret the individual and institutional dimensions of complex social interaction that occur inside organizations, such as the VA. We consider self-reported military exposures to empirically assess the impact of policies and practices such as MOS restrictions and combat-bias are part of inequality regimes that disadvantage women veterans. To address gaps in the current literature we adopt Acker's (2006) conceptualization of inequality regimes and examine exposures unique to military contexts, including self-reported exposure to combat/war, death/dying/wounded, and environmental hazards prior to DODs 2014 policy reform for the inclusion of women in combat military occupational specialties utilizing data from a subset of 8,710 respondents of the 2010 National Survey 
of Veterans. To our knowledge, we are the only study that has examined self-reported military exposures, and Department of Veterans Affairs Disability Compensation award and 50\%-or-greater rating level (VADC) by gender.

\section{BACKGROUND}

Today women veterans are among the fastest-growing segments of the veteran population and new Department of Veterans Affairs (VA) health care users (Department of Veterans Affairs [DVA], 2016). Among VA health care patients, roughly 19 percent of women served in $\mathrm{OEF} / \mathrm{OIF}$, a higher percentage when compared to only nine percent of men veteran patients who deployed with at least one OEF/OIF tour (DVA, 2016). In addition, 51.3 percent of OEF/OIF women veterans were enrolled in VA health care, with 88 percent having used VA health care more than once, a sharp contrast compared to only 11 percent of women from all other previous eras (Batuman et al., 2011). Most women veterans report good to excellent health, despite military service being associated with increased odds of having a variety of conditions and illnesses that negatively impact postservice quality-of-life. (Murdoch et al., 2006; Harris \& Associate, 1985).

"Women have carried arms or engaged the enemy in virtually every conflict ever

fought by the U.S., including and beginning with the War of Independence" (Murdoch et al., 2006). Officially, women have been serving on active duty since 1901, with increasingly participation in the US military over time (Prokos \& Cabage 2015). Women experience military exposures (Carney et. al. 2003), although they have been excluded from combat jobs until 2013. Servicewomen's military experiences historically include combat exposures and service in theatre (Mulhall 2009; SWAN 2009; Grunden 2014; 
Hassija, Jakupca, Maguen, \& Shipherd 2012; Mattocls et al. 2012), regardless of job type. For example, Margaret Corbin was wounded in action after taking over the cannon of her fallen husband during the Battle of Fort Washington in the American Revolution and was the first woman to be awarded disability compensation from Congress for injuries sustained during her military service (SWAN 2015). Dr. Mary Walker is the only woman ever awarded the Congressional Medal of Honor for her role as a physician during the Civil War. Clara Barton founded the American Red Cross and served at the siege of Petersburg, and several other women disguised themselves as men to serve for North or South, including Harriet Tubman who was a volunteer scout, spy, and nurse for the Army of the North (SWAN 2015). It has also been documented that five African American women provided medical care onboard the USS Red Rover, serving on one of the Navy's first hospital ships in 1862 (SWAN 2015). During World War I, three women were awarded the Distinguished Service Cross, and many military nurses serving near enemy lines during combat operations were gassed or wounded (SWAN 2015).

A total of 543 service women died during World War II, 16 from enemy fire, 200 nurses whose deaths occurred serving overseas in a combat zone, and eighty-five POWs. On the day of the at Inchon and in Pusan, Korea, Army nurses were treating casualties, 17 military women who died primarily in aircraft during the Koran War. Eight US military service women died in theater during the Vietnam War and their names are inscribed on the Vietnam War Memorial. Almost 41,000 women served in theater during the Gulf War, 15 killed, and two taken as POWs. Integration of women in the US military has occurred slowly over time; however, women's military contributions can no longer 
remain invisible. Military women have sustained injury and functional limitations (disability) and have been killed; labeled as "non-combatants," historically nurses have accounted for a majority of female POWs (Murdoch et al., 2006).

Since 2001, more women are experiencing combat exposures (Prokos and Cabage 2013) with the presence of military women serving in war zones a common sight in worldwide media (SWAN 2015). According to SWAN, as of 2015:

Fifty American servicewomen died and 383 were wounded in action during Operation Enduring Freedom [OEF] (Afghanistan), which ended in December 2014. One hundred and ten women were killed and 627 were wounded in action during Operation Iraqi freedom [OIF], which ended on 31 August 2010. One woman died and 12 were wounded in action in Operation New Dawn (Iraq), from September 2010 to December 2011. As of now, five women have died and 68 have been wounded in action in Operation Inherent Resolve (Iraq and Syria), which began in 2014; and to date four women have died and 12 have been wounded in action in Operation Freedom's Sentinel (Afghanistan), which began in 2015. Two women, both enlisted, have received the Silver Star for heroismone in Operation Iraqi Freedom and on in Operation Enduring Freedom.

In short, women have always experienced varying levels of combat exposure during wartime. It is a gendered fallacy to assume that women have not done this work historically, and faulty biological essentialism to suggest that they are incapable of performing combat duties.

Previous DOD policies prohibited women from frontline combat military occupational specialties, such as ground infantry. Nevertheless, women have been working in nearly every capacity alongside servicemen, with clear war zones or battle lines lacking in most conflicts. Roadside bombs known as improvised explosive devices (IEDs), mortars, small arms fire, and missile attacks increase the likelihood of injury or death among deployed military personnel in the most recent conflicts (Mulhall, 2009). "Since 2001, women service members have performed more than 22,000 jobs in battle, 
making 'combat support roles' some of the most dangerous jobs in theater, including military police, intelligence, pilots, medics, mechanics, convoy transportation, and neighborhood patrols through Iraqi cities like Baghdad" (Mulhall, 2009, p.11). The wars in Iraq and Afghanistan made it increasingly challenging for military policy and officials to divide combat and combat support roles. Consequently, in Washington on January 24, 2013, the Joint Chiefs of Staff Defense Secretary Leon E. Panetta announced the end of the direct ground combat exclusion rule for women service members. The decision opened about 237,000 positions to women, 184,000 in combat arms professions (Kimerling 2006). This policy change represents a shift in the gendered dynamics of occupational designation that potentially impacts the interpretation of service-connected disability status among women veterans seeking VA benefits and entitlements.

Military service has been shown to erode health (MacLean and Edwards, 2010). Roughly 15 percent of servicemembers returning from OIF and 11 percent of service members returning from OEF experience challenges, including major depression, generalized anxiety, and PTSD (Mattocks et al., 2012; Baker et. al., 2009; Cohen et al., 2010; Erbes, Westermeyer, Engdahl, \& Johnsen, 2007; Jakupcak et. al., 2009; McDevittMurphy et. al., 2010; Schurr, Lunny, Bovin, \& Marx, 2009; Seal et. al., 2010, 2009). However, there have been incongruent findings in the literature when examining militaryrelated exposures among OEF/OIF veterans by gender, and even less is understood about women from previous eras.

Of the studies that have examined gender differences among OEF/OIF veterans enrolled in VA health care, studies find women veterans share a range of military 
experiences similar to men veterans, including combat exposure, environmental exposures, and other stressors (Kimberling, 2006). For example, in one study, 94 percent of men and 30 percent of women experienced at least some combat exposure (DVA, 2008). However, little is known about PTSD associated with combat exposure among women veterans, since combat has typically been associated with men, and in a military setting, PTSD with combat. Women are also less likely to receive a diagnosis of PTSD associated with combat exposure and service-connected disability compensation for PTSD (Kimerling, 2007; Suris, 2008; SWAN, 2016; Murdoch, 2015). Two recent studies support these findings, suggesting a combat-bias in service-connected disability compensation award, with combat definitional criteria exclusionary of women's wartime experiences due to policy restrictions (SWAN, 2016; Murdoch, 2015). In this way, cultural norms about gendered labor interact with gender inequalities structurally through military policies, practices, and ideologies that create and maintain inequality regimes in the US military that transfer to VA.

The number of veterans who can be enrolled in VA health care is determined by the amount of money Congress gives the VA each year. Since funds are limited, the VA sets up priority groups to make sure that certain groups of veterans can be enrolled before others. Once veterans apply for enrollment, their eligibility is verified, with enrollment priority groups that range from one to eight, with one being the highest priority. The VA determines the highest priority group the veteran is eligible for based on several factors, including a VADC (Department of Veterans Affairs Service Connected Disability) award and rating percentage with service-connected conditions along a continuum ranging from 
$0 \%$ (non disabling) to $100 \%$ (total disability); combat or war exposure; military medal awards related to combat and injury; exposure to environmental hazards, such as depleted uranium, sarin gas, burn pit smoke, diesel fuel; and other considerations (Murdoch, Hodges, Cowper, \& Sayer, 2005). VADC is defined by the VA as follows: "a condition or disability that the VA has determined...was incurred in or aggravated by military service" (DVA, 2016). Subsequently, VADC rating and percent of rating is a determinant of eligibility for enrollment in VA health care, and other earned benefits and entitlements post- military service (DVA, 2016). Veterans may be eligible for more than one VA health care priority group, and some veterans may have to agree to pay co-pays to be placed in priority groups. This evaluation system privileges men through combat-bias in assessment of military exposures (Murdoch et. al., 2003; Murdoch et. al., 2005; Schweitzer, 2013; Service Women's Action Network, 2013), informed by inequality regimes in the institutional context that systematically minimize and make invisible the labor of women veterans. Because greater exposures increase the likelihood of VADC award, there this systemic gender bias to examine in this rating process.

VADC represents the difference between access to VA health care and no access (Murdoch et al., 2005). In this way, VADC is an important benefit to mitigate poverty among veterans who sustain physical and mental health injuries because of military exposures (Murdoch, Hodges, Cowper, \& Sayer, 2005). Therefore, we investigate the potential effect of gender bias to address interlocking social inequalities. We conceptually consider inequality regimes through the gendered effect of institutional policies, practices, and ideologies that maintain gender difference and shape cultural norms about 
the labor of women veterans. Gender inequality is created and maintained within the military through the cultural ideologies that shape ideas about women not being exposed to combat (as a masculine MOS), practices that filter women into non-combat service positions and evaluate their service as non-exposure, and through policies that prior to 2014 restricted gendered labor formally. In these ways, we see the structural components of Acker's (2006) inequality regimes reinforcing a work culture where gender neutral language in policies, for example, creates and maintains masculine privilege, as manifest in combat bias and the related impact on service award benefits and entitlements.

In the analysis, we demonstrate how military exposures and gender more generally relate to the dependent variables, and then specifically address the research questions using logistic regression models predicting each dependent variable: VADC award and VADC-50\%-or-greater by gender. We analyze data from the 2010 National Survey of Veterans to investigate these research questions: 1a) How does exposure to combat/war zone, dead/dying/wounded, and/or environmental hazards relate to the odds of VA Disability Compensation (VADC) award? 1b) How does gender moderate this relationship? 2a) How do military exposures relate to veterans' odds of being at a VADC rating of 50\%-or-greater? 2b) How does gender moderate this relationship? 


\section{METHOD}

Data

This study analyzes a subset of data from the 2010 National Survey of Veterans (NSV) survey conducted by the National Center for Veterans Analysis and Statistics through the DoD Defense, Manpower Data Center. Initiated in response to Public Law 108-454 Section 805, the NSV Final Weighted Report, issued on October 2010 is the sixth in a series of national surveys to help plan for future programs and services for Veterans. The 2010 NSV used a list-based address-sample design from 50 states and the District of Columbia to obtain a nationally representative sample of active duty service members, demobilized National Guard and reserve members, family members, and surviving spouses. The analytic sample for this study consists of 8,710 respondents, including 7,987 men and 595 women. The primary variables analyzed for this study come from the following measurement content areas: "Military-Duty Exposures" and "VA Benefits and Entitlements." Table 1 provides descriptive statistics on all variables in the study.

Table 1. Descriptive Statistics Based on Weighted Data

\begin{tabular}{|c|c|c|c|c|}
\hline \multirow[b]{2}{*}{ Variables } & \multicolumn{2}{|c|}{ Men } & \multicolumn{2}{|c|}{ Women } \\
\hline & $N$ & $\%$ & $N$ & $\%$ \\
\hline Gender & 7987 & 91.7 & 595 & 6.8 \\
\hline Age (mean) & 65.1 & & 52.1 & \\
\hline \multicolumn{5}{|l|}{ Race } \\
\hline White & 7113 & 91.8 & 460 & 79.9 \\
\hline Black & 494 & 6.4 & 98 & 17.0 \\
\hline Hispanic & 325 & 4.4 & 44 & 7.9 \\
\hline Other & 138 & 1.8 & 19 & 3.3 \\
\hline \multicolumn{5}{|l|}{ Education } \\
\hline Less than diploma & 480 & 6.1 & 14 & 2.4 \\
\hline Diploma or GED & 2089 & 26.6 & 78 & 13.3 \\
\hline Some college & 2258 & 28.7 & 193 & 32.8 \\
\hline & 104 & & & \\
\hline
\end{tabular}




\begin{tabular}{lcccc} 
AA/AS & 673 & 8.6 & 81 & 13.8 \\
BA/BS & 1372 & 17.5 & 148 & 25.2 \\
MA/MS & 633 & 8.1 & 56 & 9.5 \\
MD/JD/PhD & 356 & 4.5 & 18 & 3.1 \\
Income (mean) & 287 & & & \\
Married & 5931 & 75.3 & 296 & 50.3 \\
Military branch & & & & \\
Army & 3857 & 100.0 & 262 & 100.0 \\
Navy & 1809 & 23.0 & 125 & 21.5 \\
Air Force & 1508 & 80.8 & 165 & 28.4 \\
Marine Corps & 753 & 9.6 & 32 & 5.5 \\
Coast Guard & 111 & 1.4 & 8 & 1.4 \\
Service Era & & & & \\
September 2001 or later & 589 & 7.5 & 159 & 27.4 \\
Persian Gulf War & 931 & 11.9 & 193 & 33.2 \\
May 1975 to July 1990 & 1530 & 19.5 & 249 & 42.9 \\
Vietnam War & 3518 & 44.8 & 111 & 19.1 \\
February 1955 to July 1964 & 1579 & 20.1 & 33 & 5.7 \\
Korean War & 1088 & 86.1 & 554 & 95.4 \\
January 1947 to June 1950 & 162 & 2.1 & 3 & 0.5 \\
World War II & 821 & 10.5 & 34 & 5.9 \\
November 1941 or earlier & 32 & 0.4 & 0 & 0.0 \\
OEF/OIF Participation & 455 & 6.0 & 101 & 17.7 \\
\hline Note. Vals are numbrs & & &
\end{tabular}

Note. Values are numbers and percentages unless otherwise noted

\section{Variables}

The first dependent variable is a veteran's VA disability compensation award, that is, whether they are in receipt of veteran benefits for a disability. We retain the original dichotomous response category, $1=$ "Yes" VA disability compensation award, and $0=$ "No". The second dependent variable is VA disability compensation 50\%-or-greater, indicating the level of benefits the veteran is receiving. The original response categories were 0 percent, 10 to 20 percent, 30 to 40 percent, 50 to 60 percent, or 70 percent or higher. To facilitate logistic regression modeling and address small cell sizes, we construct a dichotomous variable by collapsing the first three categories into 
$0=$ Compensation below $50 \%$, and the last two categories into $1=$ Compensation $50 \%$-orgreater

The predictors of interest include three military duty exposures and gender. Exposures are measured through three dichotomous variables: a) served in combat or war zone $1=$ "Yes, $0=$ "No" b) ever exposed to dead/dying/wounded, $1=$ "Yes", $0=" N o "$, and c) ever exposed to environmental hazards $1=$ "Yes", and $0=" N o "$. Gender kept its original dichotomous structure, with $0=$ male and $1=$ female.

To improve estimates of how our predictors, relate to the dependent variables, we control for important demographic characteristics, including: age, race/ethnicity, income, and level of education.

\section{Analytic Plan}

Descriptive statistics are provided for all variables in the analysis. We use logistic regression models to predict each dependent variable. The first model focuses on the baseline relationship between gender and VADC award. The second model includes all controls discussed in the previous section to improve the estimate of how gender relates to VADC award. To investigate RQ 1a (how exposures relate to VADC award), the third model adds the measures of military exposure. To investigate RQ $1 \mathrm{~b}$ (whether gender moderates how exposures relate to VADC award), the fourth model adds statistical interactions between gender and each measure of military exposure (Figure 1). Therefore, we theorize that the positive relationship between military exposures and VADC award will be smaller for women than men because of gender bias in the military. We expect the same moderating effect of gender for the positive relationship between military exposures and VADC-rating-50\%-or-greater.

In the next set of analyses, the first model focuses on the baseline relationship between gender and VADC-rating-50\%-or-greater. The second model includes all 
controls discussed in the previous section to improve the estimate of how gender relates to VADC rating 50\%-or-greater. To investigate RQ 2a (how exposures relates to VADCrating-50\%-or-greater), the third model adds the measures of military exposure. To investigate RQ 2b (whether gender moderates how exposures relate to VADC-rating$50 \%$-or-greater), the fourth model adds statistical interactions between gender and each measure of military exposure.

Figure 1: Gender Moderating Relationship between Military Exposures and VADC Award and Rating

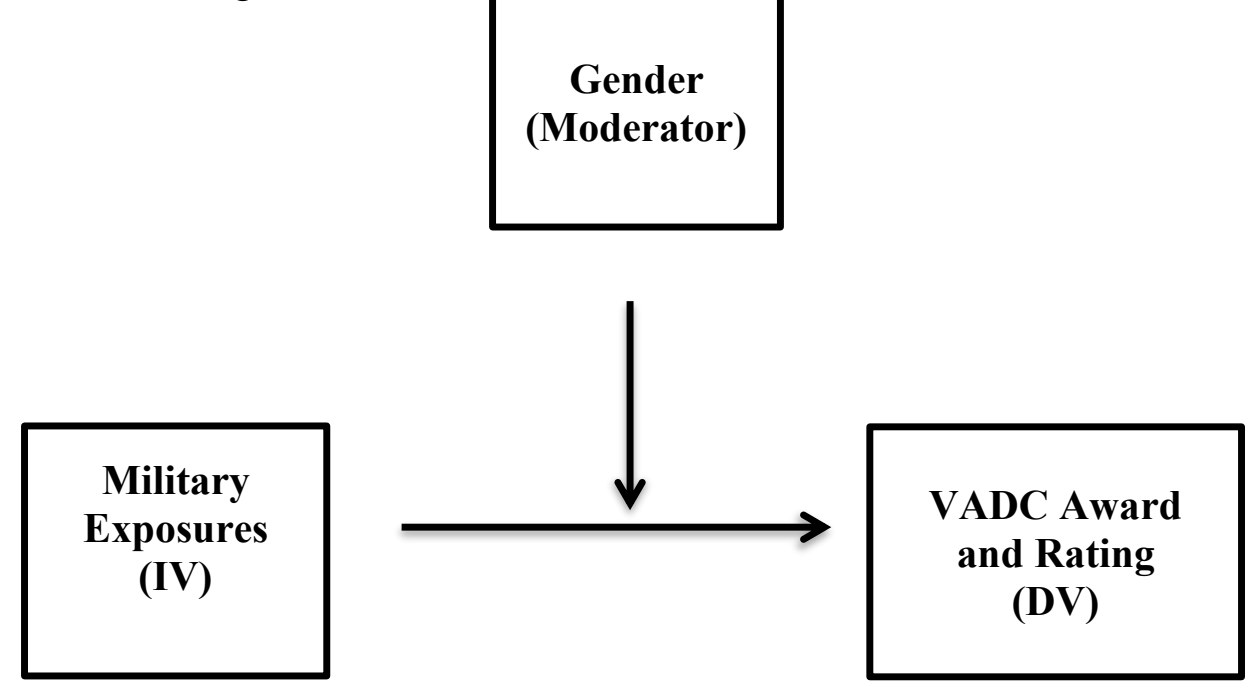

\section{FINDINGS}

Results indicate the moderating effect of gender on the relationship between military exposures and VADC award and rating. Table 2 presents log odds from logistic regression models predicting $\mathrm{VADC}$ award $(0=$ Not connected, $1=$ Connected $)$. The $\log$ odds of VADC award are 0.232 higher on average for women veterans relative to men veterans (Table 2, Model 1). This suggests women may experience more exposures than men overall. The log odds of VADC are 0.180 higher on average for veterans exposed to 
combat/war relative to veterans not exposed to combat/war, adjusting for other measures in the model (Table 2, Model 3). This difference is not statistically significant which is likely due to small cell sizes. Exposure to dead/dying/wounded is statistically significant $(\mathrm{p}<.05)$, with the log odds of VADC award 0.393 higher on average, when adjusting for other measures (Model 3). The log odds of VADC award are 0.021 higher for veterans with environmental exposures relative to veterans without such exposure, net of controls (Model 3). Consistent with the small size of this coefficient, this difference is not statistically significant. The findings in this model provide support for part one of the first hypothesis that exposures would relate positively to VADC award - particularly in the case of death/dying/wounded exposures.

Model 4 in Table 2 narrows in on part two of research question one: gender moderates exposures relative to VADC. All estimates are adjusted based on the other variables included in the model. The interaction between female and exposure to combat is -0.286 , which suggests the positive relationship between exposure to combat $(0.197)$ and VADC is smaller on average for women veterans $(0.197+(-0.286)=-0.089)$ than for men veterans (0.197). The interaction between female and exposure to death/dying/wounded is -0.434 (Table 2, Model 4), which suggests the positive relationship between exposure to death/dying/wounded (0.422) and VADC-50\%-orgreater is smaller on average for women veterans $(0.422+(-0.434)=0.012)$ than for men veterans $(0.422)$. The interaction between female and exposure to environmental hazards is -0.407 (Table 2, Model 4), which suggests the positive relationship between environmental exposures (0.056) and VADC-50\%-or-greater is smaller on average for women veterans $(0.056+(-0.407)=-0.351)$ than for men veterans $(0.056)$. This supports our hypothesis that gender moderates the relationship between military exposures and VADC-50\%-or-greater, with women veterans exposed to combat, death/dying/wounded, 
and environmental hazards less likely on average to be awarded VADC compensation $50 \%$-or-greater compared to men veterans with combat, death/dying/wounded, and environmental exposures.

Table 2. Log Odds from Logistic Regression Models Predicting VADC Award

\begin{tabular}{|c|c|c|c|c|c|c|c|c|}
\hline \multirow[b]{2}{*}{ Independent Variable } & \multicolumn{2}{|c|}{ Model 1} & \multicolumn{2}{|c|}{ Model 2} & \multicolumn{2}{|c|}{ Model 3} & \multicolumn{2}{|c|}{ Model 4} \\
\hline & B & SE & B & SE & B & SE & B & SE \\
\hline Female & 0.232 & 0.253 & 0.138 & 0.273 & 0.283 & 0.277 & 0.695 & 0.384 \\
\hline Age & & & -0.007 & 0.005 & -0.008 & 0.005 & -0.008 & -0.005 \\
\hline \multicolumn{9}{|l|}{ Race (ref=white) } \\
\hline Black & & & -0.259 & 0.202 & -0.254 & 0.204 & -0.250 & -0.204 \\
\hline Hispanic & & & $0.655 \pm$ & 0.369 & 0.575 & 0.372 & 0.623 & 0.373 \\
\hline Income & & & $0.005^{*}$ & 0.002 & $0.005^{*}$ & 0.002 & 0.005 & 0.002 \\
\hline Married & & & $0.287 \pm$ & 0.158 & $0.299 \pm$ & 0.160 & 0.300 & 0.160 \\
\hline \multicolumn{9}{|l|}{$\begin{array}{l}\text { Education (ref=not high } \\
\text { school graduate) }\end{array}$} \\
\hline High School graduate & & & -0.341 & 0.342 & -0.355 & 0.346 & -0.357 & 0.346 \\
\hline Some college & & & 0.271 & 0.177 & 0.240 & 0.179 & 0.234 & 0.179 \\
\hline College graduate & & & 0.212 & 0.210 & 0.184 & 0.212 & 0.201 & 0.212 \\
\hline \multicolumn{9}{|l|}{ Exposures } \\
\hline Combat/War Exposure & & & & & 0.180 & 0.175 & .0197 & 0.183 \\
\hline $\begin{array}{l}\text { Death/dying/Wounded } \\
\text { Exposure }\end{array}$ & & & & & $0.393 *$ & 0.176 & 0.422 & 0.182 \\
\hline \multicolumn{9}{|l|}{$\begin{array}{l}\text { Environmental } \\
\text { Exposure }\end{array}$} \\
\hline $\begin{array}{l}\text { Female X Combat/War } \\
\text { Exposure }\end{array}$ & & & & & & & -0.286 & 0.619 \\
\hline $\begin{array}{l}\text { Female X } \\
\text { Death/Dying/Wounded } \\
\text { Exposure }\end{array}$ & & & & & & & -0.434 & 0.669 \\
\hline $\begin{array}{l}\text { Female X Environmental } \\
\text { Exposure }\end{array}$ & & & & & & & -0.407 & 0.626 \\
\hline Constant & 1.212 & 0.071 & 0.982 & 0.374 & 0.713 & 0.388 & 0.652 & 0.389 \\
\hline -2 Log likelihood & \multicolumn{2}{|c|}{1314.31} & \multicolumn{2}{|c|}{1280.61} & \multicolumn{2}{|c|}{1266.92} & \multicolumn{2}{|c|}{1263.982} \\
\hline
\end{tabular}


Table 3. Logistic Regression Models Predicting VA Disability Compensation 50\%-OrGreater

\begin{tabular}{|c|c|c|c|c|c|c|c|c|}
\hline \multirow[b]{2}{*}{ Independent Variable } & \multicolumn{2}{|c|}{ Model 1} & \multicolumn{2}{|c|}{ Model 2} & \multicolumn{2}{|c|}{ Model 3} & \multicolumn{2}{|c|}{ Model 4} \\
\hline & B & SE & $\mathrm{B}$ & SE & B & SE & B & SE \\
\hline Female & 0.143 & 0.233 & 0.072 & 0.256 & 0.412 & 0.269 & 0.770 & 0.359 \\
\hline Age & & & -0.001 & 0.005 & -0.004 & 0.005 & -0.004 & 0.005 \\
\hline \multicolumn{9}{|l|}{ Race (ref=white) } \\
\hline Black & & & .041 & 0.218 & 0.016 & 0.224 & 0.016 & 0.224 \\
\hline Hispanic & & & 0.319 & 0.288 & 0.166 & 0.295 & 0.225 & 0.297 \\
\hline Income & & & -0.004 & 0.002 & -0.004 & 0.002 & -0.004 & 0.002 \\
\hline Married & & & -0.216 & 0.168 & -0.199 & 0.171 & -0.200 & 0.172 \\
\hline \multicolumn{9}{|l|}{$\begin{array}{l}\text { Education (ref=not high } \\
\text { school graduate) }\end{array}$} \\
\hline High School graduate & & & -0.777 & 0.431 & $-0.855^{*}$ & 0.440 & -0.859 & 0.441 \\
\hline Some college & & & -0.225 & -0.186 & -0.303 & 0.191 & -0.309 & 0.191 \\
\hline College graduate & & & -0.409 & 0.212 & $-0.456^{*}$ & 0.218 & -0.445 & 0.218 \\
\hline \multicolumn{9}{|l|}{ Exposures } \\
\hline Combat/War Exposure & & & & & 0.284 & 0.183 & 0.369 & 0.197 \\
\hline $\begin{array}{l}\text { Death/dying/Wounded } \\
\text { Exposure }\end{array}$ & & & & & $0.415^{*}$ & 0.184 & 0.409 & 0.194 \\
\hline $\begin{array}{l}\text { Environmental } \\
\text { Exposure }\end{array}$ & & & & & $0.472 * *$ & 0.173 & 0.474 & 0.183 \\
\hline $\begin{array}{l}\text { Female X Combat/War } \\
\text { Exposure }\end{array}$ & & & & & & & -0.761 & 0.571 \\
\hline $\begin{array}{l}\text { Female } X \\
\text { Death/Dying/Wounde } \\
\text { d }\end{array}$ & & & & & & & -0.014 & 0.663 \\
\hline $\begin{array}{l}\text { Exposure } \\
\text { Female X Environmental } \\
\text { Exposure }\end{array}$ & & & & & & & -0.095 & 0.589 \\
\hline Constant & -0.459 & 0.071 & 0.248 & 0.381 & -0.323 & 0.402 & -0.348 & 0.403 \\
\hline -2 Log likelihood & \multicolumn{2}{|c|}{1226.442} & \multicolumn{2}{|c|}{1206.921} & \multicolumn{2}{|c|}{1165.161} & \multicolumn{2}{|c|}{116.5285} \\
\hline
\end{tabular}


Table 3 presents logistic regression models predicting VA disability ratings $50 \%$ or greater. The log odds of VADC rating 50\%-or-greater are 0.143 higher on average for female veterans relative to male veterans (Table 3, Model 1). The log odds of VADC ratings $50 \%$ or greater is 0.284 higher on average for veterans exposed to combat relative to veterans not exposed to combat, adjusting for other measures in the model (Table 3, Model 3). Exposure to dead/dying/wounded was statistically significant $.03(\mathrm{p}<.05)$, with 0.415 higher on average likelihood of VADC rating 50\%-or-greater, when adjusting for other measures in the model. The log odds of environmental exposures were statistically significant $(\mathrm{p}<.005)$, with 0.472 higher than average likelihood of VADC rating 50\%-or-greater, even with controls. The interaction between female and exposure to combat is -0.761 (Table 3, Model 4), suggests the positive relationship between exposure to combat (0.369) and VADC rating 50\%-or-greater is less likely on average for female veterans $(0.369+(-0.761)=-0.692)$ than for male veterans $(0.369)$, adjusting for other measures in the model (Table 3, Model 3). The interaction between female and exposure to death/dying/wounded is -0.014 (Table 3, Model 4), which suggests the statistically significant and positive relationship between exposure to death/dying/wounded (0.409) and VADC rating 50\%-or-greater is less likely on average for female veterans $(0.409+(-0.014)=0.395)$ than for male veterans $(0.409)$, adjusting for other measures in the model (Table 3, Model 3). The interaction between female and exposure to environmental hazards is -0.095 (Table 3, Model 4), which suggests the statistically significant and positive relationship between exposure to environmental hazards (0.472) and VADC rating 50\% or greater is less likely on average for female 
veterans $(0.472+(-0.095)=0.351)$ than for male veterans $(0.472)$. This supports my hypothesis that gender moderates the relationship between military exposures and VADC rating 50\%-or-greater, with women veterans exposed to combat, death/dying/wounded, and environmental hazards less likely on average to be awarded VADC rating 50\% -orgreater compared to male veterans exposed combat, death/dying/wounded, and environmental hazards (e.g. the same military exposures).

\section{DISCUSSION}

Results indicate that military exposures are associated with greater likelihood for VADC award for veterans as a group, and that women veterans with military exposures are less likely on average to be awarded VADC than men veterans with military exposures. Similarly, veterans with military exposures have a higher likelihood of a 50\%-or-greater VADC rating than veterans without military exposures, but that positive relationship is smaller for women veterans than for men veterans. This confirms our hypothesis that gender moderates how exposures relate to VADC, with women essentially receiving fewer VA benefits and entitlements than men with the same exposures. A few previous studies have demonstrated that a combat bias exists in VADC award (Murdoch et. al 2003; Murdoch et. al. 2005; Schweitzer 2013; Service Women's Action Network 2013). Our findings support these previous studies, and empirically confirm that gender $i s$ an important predictor for VADC award and rating award 50\%-or-greater.

Our research suggests gender inequalities can be made visible but not consistently viewed as legitimate since previous combat exclusion policies have been a key mechanism of gender inequality in the US military. The eradication of this type of overt 
sexism through gender neutralizing policies and practices concerning labor (MOS) makes gender inequality appear less legitimate. However, we find systemic gender bias in the VADC rating process that can be understood as a consequence entrenched binary gender ideologies within the military and VA that continue to shape ideas about "women's work." Such policies are part of institutional inequality regimes that often invisibilize gender inequalities and make them difficult to change (Acker 2006). Notably, women veterans have faced historical marginalization in the military as an institution shaped by hegemonic masculinity through policies, practices, and ideologies that have consistently minimized women's efforts in military service. The difficulty in dismantling inequality regimes within institutions can be seen here, where policies and practices restricting women from combat continue to influence ideologies about the value of women veterans' service, such that practices to restrict VADC award and benefits among women can be understood as systemic gender inequality. Further, VADC award and award-rating 50\%or-greater determine veterans' access to health care, economic resources, education, and other VA benefits and entitlements post- military. Our findings indicate gender bias exists in VADC award, and VADC rating percent. This is especially troubling considering the increasing number of women veterans who live in poverty, and the positive relationship researchers have demonstrated between socioeconomic status and health outcomes (MacLean \& Edwards 2010).

To examine VADC award among veterans is to attend to the gendered dimensions of inequality that are shaped by the structural facets of the military institution. By examining the interlocking policies and practices that reproduce complex inequalities 
from the military into the VA, we can interpret the implications of VADC award as a gendered outcome of inequality regimes perpetuated by the military institution. Adopting Acker's concept of inequality regimes provides a framework for theorizing inequalities, such as policies and practices that create and recreate inequalities, and the invisibility of them. In this study, we focused on the organizational logic, that is, the policies and practices relevant to the US military and VA, as central to the reproduction of gender and health inequalities. In our analysis of VADC award, we find evidence of gender bias demonstrating that sexism is visible when specific policies and practices are observed within the organization related to combat bias and MOS reinforcing masculine privilege and structurally disadvantaging women veterans by defining their work differently, as inherently not combat service.

This analysis documents, that on the surface, VBA and VHA appear to provide equal access programs, but in practice, disadvantage women veterans. As Acker (2006) finds, this is a consequence of gender neutral policies that create and maintain gender inequality. We propose that adopting an inequality regimes framework could better inform policy and clinical interventions. Addressing gender and health disparities only on an individual level basis maintains systemic inequalities. We must address inequalities at the structural level rather than individual level; this is a requirement for fundamental changes to these organizations, and a requirement to improve the health and quality-oflife for 'she who has borne the battle' (Mulhall 2009 p.13).

Our study is limited in identifying the nuances of practices and ideologies within the military and VA that differentiate VADC award by gender for veterans with 
exposures. For example, future work could explore what sexist elements of organizational culture and more subtle forms of discrimination at the VA Regional Office and Board of Veterans Appeals levels, as well as, enrollment procedures at VHA facilities. Age at the time of injury and age at the time of VADC benefit award should be further explored, since aging may impact the progression of functional limitations (disability) and VADC award rating percent. The gendered dimensions of age may also be relevant for such research. As gender also, often informs the types of occupational positions that are available and accessible within military service, we further recommend cultural shifts in occupational environment that allow ideological change within the institution related to the implicit sex-typing of the US military as a total institution and military type jobs. As ideologies are deeply entrenched within the institution, we recommend attention to ending gender bias as a priority goal for shifting occupational environment, for example, through mechanisms that address cultural gender norms, such as rectifying the universal masculine in the VA motto (as discussed in this introduction).

\section{Policy Recommendations}

Our findings demonstrate an urgent need for several changes in how VA handles VADC award for women veterans (Table 1). Specifically, regulatory reform as well as improved training, oversight, transparency, and record keeping are necessary to resolve the overall discrimination and gender bias in the adjudication of VA claims for disability compensation. VADC is of vital importance to women veterans with health sequelae due to military exposures, not only because VA provides monetary assistance necessary for veterans in difficult financial situations, but because VADC award secures and 
determines priority enrollment in VHA services, securing access to critical medical attention (Schweitzer, 2013).

Changes in the U.S. Military. The US military still faces challenges in recruitment, integration, and retention of women. Our findings indicate transference of military challenges for women seeking VA benefits and entitlements under the law. Consistent with suggestions provided for other occupations, we support US military policy reforms for women's inclusion in all military occupational specialties across all branches of service, since increasing gender diversity could have a positive impact on the US military overtime (SWAN, 2019). Furthermore, regulatory reform as well as improved training, oversight, transparency, and record keeping within the US military are necessary to resolve the overall discrimination and gender bias post-service for women veterans.

Changes in VA Treatment and Benefits Procedures. It is well documented that structural and fiscal problems plague the VA, making it functionally incapable of adequately meeting the needs of veterans seeking benefits and services to which they are entitled by law (Schweitzer, 2013). Schweitzer 2013 note "a backlog of 756,000 claims at the Board of Veterans' Appeals is a product of understaffing, underfunding, and undertraining" (p. 653). Currently, the burden of proof is placed on the veteran for development of VBA claims seeking VADC.

First, the VA must help bear the burden of proof for the veteran by doing a better job of evaluating the evidence recorded in the woman veteran's DOD personnel and medical records, and consider evidence outside of the veteran's military records in 
determining VADC award (Schweitzer 2013). Second, similarly to the adjudication of military sexual harassment and military sexual assault claims, the VA should relax the evidentiary standard that applies to VADC award based on combat regulations, and treat women veteran's testimony of military exposures as evidence for functional limitations on the basis to re-adjudicate denied claims as it did following the July 2010 PTSD regulatory reforms. Our findings make it abundantly clear that systemic regulatory reform is necessary to remove gender bias from the practices, policies, and ideologies in order to put women with military exposures who served prior to the reform of combat exclusion policies on equal footing with men veterans. Thirdly, VA must improve oversight and target training of VA staff exhibiting apparent gender discrimination of VADC award, and the practices of VA doctors who are not sufficiently informed of military exposures among women veterans, nor equipped in appropriate diagnostics needs of women veterans with these military exposures (Schweitzer 2013; Carney 2003; Prokos 2015). Fourthly, the VA should be required to release data annually on the award rates for VADC for women veterans more generally, and justification by type of military exposure. Lastly, Congress should act swiftly to pass regulatory reform for VADC award for women veterans, as well as improved training, oversight, transparency, and record keeping to resolve the overall discrimination and gender bias in the adjudication of VA claims for disability compensation.

In summary, the study documents gender bias in VADC award, and VADC rating percent. Our nation's women veterans have a uniquely different task in realizing the burden of proof in their military exposures claims for due compensation by the VA. This 
disparity is informed by inequality regimes in the institutional organization that create and maintain cultural gender norms that shape ideas about the military service of women veterans. As a step towards improving health and quality-of-life for women veterans, we must address gender inequalities at the structural level, a requirement for fundamental change to these organizations.

\section{Acknowledgements}

The authors would like to express gratitude and appreciation to the individuals who participated in this study, as well as, Drs. Matthew Carlson and Hyeyoung Woo for their support during earlier stages of the analysis.

\section{Funding}

This material is the result of work supported with resources and the use of Department of Veterans Affairs facilities. The views expressed in the article are those of the authors and do not necessarily reflect the position or policy of the Department of Veterans Affairs or the United States Government.

\section{REFERENCES}

American Civil Liberties Union. (2013). Battle for benefits: VA discrimination against survivors of military sexual trauma. Retrieved fromhttps://www.aclu.org/sites/default/files/assets/lib13-mst-report-11062013.pdf Batuman, F., Bean-Mayberry, B., Goldzweig, C., Huang, C., Miake-Lye, I. M., Washington, D. L.,...Shekelle, P. G. (2011). Health effects of military service on women veterans. Retrieved from https://www.ncbi.nlm.nih.gov/books/NBK56370/ 
Breslau, N. (2001). Gender differences in trauma and posttraumatic stress disorder. The Journal of Gender-Specific Medicine: JGSM: The Official Journal of the Partnership for Women's Health at Columbia, 5(1), 34-40.

Brownson, C. (2014). The battle for equivalency: Female US Marines discuss sexuality, physical fitness, and military leadership. Armed Forces \& Society. doi:10.1177/009527X14523957

Brownson, C. (2016). Rejecting patriarchy for equivalence in the US military: A response to Anthony King's "Women warriors: Female accession to ground combat." Armed Forces \& Society, 42(1), 235-242.

Burdett, H., Woodhead, C., Iversen, A. C., Wessely, S., Dandeker, C., \& Fear, N. T. (2012). Are you a veteran? Understanding of the term "veteran" among UK exservice personnel: A research note. Armed Forces \& Society. doi:10.1177/0095327X12452033

Hogan, P. F., \& Seifert, R. F. (2009). Marriage and the military: Evidence that those who serve marry earlier and divorce earlier. Armed Forces \& Society.

Hoggatt, K. J., Jamison, A. L., Lehavot, K., Cucciare, M. A., Timko, C., \& Simpson, T. L. (2015). Alcohol and drug misuse, abuse, and dependence in women veterans. Epidemiologic reviews. doi:10.1093/epirev/mxu010

Kelly, Ursula A., et al. (2011). More than military sexual trauma: Interpersonal violence, PTSD, and mental health in women veterans. Research in Nursing \& Health 34(6): 457-467. 
Klein, R. E. (2005). Women veterans: Past, present and future. Department of Veterans Affairs. Retrieved from http://www1.va.gov/womenvet/docs/womenvet_history.pdf

King, A. C. (2015). Women warriors: Female accession to ground combat. Armed Forces \& Society, 41(2), 379-387.

MacLean, A., \& Edwards, R. D. (2010). The pervasive role of rank in the health of US veterans. Armed Forces \& Society, 36(5), 765-785.

Maguen, S., Luxton, D. D., Skopp, N. A., \& Madden, E. (2012). Gender differences in traumatic experiences and mental health in active duty soldiers redeployed from Iraq and Afghanistan. Journal of Psychiatric Research, 46(3), 311-316.

Mattocks, K. M., Haskell, S. G., Krebs, E. E., Justice, A. C., Yano, E. M., \& Brandt, C. (2012). Women at war: Understanding how women veterans cope with combat and military sexual trauma. Social Science \& Medicine, 74(4), 537-545.

McClam, E. (2008). New generation of homeless vets emerges in wake of Afghanistan and Iraq: New generation of homeless war veterans emerges. ABC News.

Murdoch, M., Hodges, J., Hunt, C., Cowper, D., Kressin, N., \& O’Brien, N. (2003). Gender differences in service connection for PTSD. Medical Care, 41(8), 950961.

Murdoch, M., Hodges, J., Cowper, D., Fortier, L., \& van Ryn, M. (2003). Racial disparities in VA service connection for posttraumatic stress disorder disability. Medical care, 41(4), 536-549. 
Murdoch, M., Hodges, J., Cowper, D., \& Sayer, N. (2005). Regional variation and other correlates of Department of Veterans Affairs Disability Awards for patients with posttraumatic stress disorder. Medical care, 43(2), 112-121.

Murdoch, M., Nelson, D. B., \& Fortier, L. (2003). Time, gender, and regional trends in the application for service-related post-traumatic stress disorder disability benefits, 1980-1998. Military medicine, 168(8), 662.

Prokos, A., \& Cabage, L. N. (2015). Women military veterans, disability, and employment. Armed Forces \& Society. doi:10.1177/0095327X15610743

Sheehan, C. M., Hummer, R. A., Moore, B. L., Huyser, K. R., \& Butler, J. S. (2015). Duty, honor, country, disparity: Race/ethnic differences in health and disability among male veterans. Population Research and Policy Review, 34(6), 785-804.

Street, A. E., Vogt, D., \& Dutra, L. (2009). A new generation of women veterans: Stressors faced by women deployed to Iraq and Afghanistan. Clinical Psychology Review, 29(8), 685-694.

Tolin, David F., \& Edna B. Foa. "Sex differences in trauma and posttraumatic stress disorder: a quantitative review of 25 years of research."Psychological bulletin 132.6 (2006): 959.

Winslow, D. (2010). Gender and military sociology. Stockholm: Försvarshögskolan, Sociology at the Department of Leadership and Management.

Zinzow, H. M., Grubaugh, A. L., Monnier, J., Suffoletta-Maierle, S., \& Frueh, B. C. (2007). Trauma among female veterans: A critical review. Trauma, Violence, \& Abuse, 8(4), 384-400. 


\section{CHAPTER 6: DISCUSSION}

The fact that we are here and that I speak these words is an attempt to break that silence and bridge some of those differences between us, for it is not difference which immobilizes us, but silence. And there are so many silences to be broken.

-Audre Lorde

This three-paper dissertation project examined pervasive gender inequalities across two institutions: the US military and VA. In the following sections, I first explain why I conducted this research and my veteran feminism, then I discuss in some detail the key findings across all three papers, including varying characteristics of the US military, a total institution, and VA as inequality regimes. I conclude with recommendations to reduce gender inequalities to advance the lives of women veterans who are "outsiders within inequality regimes."

\section{Learning from Black Feminist Thought and Veteran Feminism}

Gender is a fundamental aspect of feminist research which focuses on challenging neutrality and objectivity in the historically male-dominate academy and research strategies that contribute to subordination based on gender (e.g. a socially constructed difference between men and women and the beliefs and identities that support difference and inequality in all organizations) that shape class relations (enduring and systematic differences in access to and control over resources for provisioning and survival) (Acker, 2006; Nelson, 1993). Feminist scholars have provided long standing arguments to seek research approaches that challenge gender bias, account for gender diversity, and provide a more rich and accurate account of people's lives. Therefore, this work aimed to challenge "truth claims and the disembodied scientific objectivity of traditional inquiry" (Haraway, 1988:576) by emphasizing the lived experiences of women veterans and other veterans themselves as the source of inquiry (Naples, 2013). In doing so, I transcend the limited and limiting approaches found in majority of studies 
about women veterans (Collins, 2000) and investigated the lives of women veterans at the site of marginalization since it provides a vantage point not otherwise accessible to nonmarginalized groups (Collins, 2000). As a woman veteran, I know that women veterans have a clearer view of their own subordination (Collins, 1986) as 'outsiders within' the US military and VA institutions, and an awareness of the gendered and sexualized beliefs and oppressive class practices entrenched in these institutions that result in differing access to resources (Acker, 2006).

Feminists have long unveiled the use of "science to control women, whether through medicine and psychiatry, or through social scientific theories of family, work, sexuality, and deviance" (DeVault, 1996 p. 30). As a feminist scholar, military veteran, and VA user, I acknowledge that we must highlight the differences among veterans as a group (Ramazanoglu, 2002; DeVault, 1996) to challenge previous studies that represent the veteran experience as universal, or assume equal access of VA benefits and entitlements. Much of knowledge produced in this substantive area is the product of research from medicine, psychiatry, psychology, and social work disciplines. The representation of these experiences is often constructed in a bias view which shape the beliefs, identities, interactions, and institutions and deeply embedded in all social structures with implications for the lives of the veteran community. Our findings indicate that these claims of impartiality and objectivity have dominated the women veteran literature and is "like the god trick, this eye fucks the world" (Haraway, 1998 p. 581) rendering invisible the diversity of veteran experiences, and misrepresents the lived experiences of military and veteran women, and men veterans with little attention to their location in a military type class system, i.e. military status(s) (Haraway, 1998 p. 581). In addition, I acknowledge that differing feminism(s) is deliberately diverse in addressing various forms of oppression, including its ability for "consciousness raising" 
(Haraway, 1998; DeVault, 1996 p. 31). A strength and defining characteristic of this work is the diversity of its methodology and the ability to produce knowledge from lived experience and its connection to political activism. Intentionally, I chose a multi-study mixed methods design for the dissertation project to better highlight descriptive accounts and self-reported data from women and other disadvantaged veteran groups. In doing so, I emphasize what individuals use themselves in thinking, speaking, and in acting in relation to specific types of institutional oppression within US military and VA contexts. As a benefit to the larger body of literature, our approach minimizes preconceived notions about women as a veteran group, with majority of these studies ignoring the responsibility institutions have for the quality of life outcomes of women veterans. In contrast, our work adopts categories that members of society (veterans) themselves use, drawing from important word building to better create the knowledge that is produced. Across these studies, social meanings of experiences were highlighted during the research construction process from the individuals themselves from self-reported accounts of military and VA experiences (Haraway, 1998; Naples, 2013). In these studies, I drew on differing locations, experiences, and perspectives of veterans to better address the broader issue of social change needed in two organizations: US military and VA (DeVault, 1996).

Contrary to traditional perspectives, I embrace marginalization as a "potential source of strength" (Collins, 1998) and engage with it, not as a rhetoric of victimhood, rather as a "site of radical possibility, a space of resistance" (Hooks, 1990). For example, the concept of gender as class is conceptualized as a site of engaging with marginalized and disadvantaged groups as source of feminism(s), feminist solidarity and active struggle not dependent on sameness (Mohanty, 2003). This dissertation work seeks to engage in "consciousness raising" (Haraway, 1998; DeVault, 1996 p. 31) as a type of political activism (Mohanty, 2003). For example, I show that sameness is not a 
prerequisite for active struggle in the lives of veterans, since I identify reporting of military sexual abuse in both military and VA contexts as problematic for all veteran VA users. Instead, common interests are the foundation for solidarity in the fight against class situations of women and men in different ways (Acker, 2006) when I assess veteran's remembrance of VA screening for MST. Consequently, my findings bring to the forefront a new discourse of gendered experiences of two historically male-dominant institutions where hegemonic masculinity and warrior ideologies characterize both institutions.

In addition, this work advances knowledge about gender categories that have been previously excluded from the veteran discourse, such as gender (women and men) and class (access to and control over resources) as dependent on context. Thus, this study disrupts the dominant processes of social categorizing in which hierarchies are created in relation to gender, combat and military exposures, perpetrator and victim, and the experiences and challenges of reporting military sexual abuse to authorities as solely a woman veteran issue (Crenshaw, 1989). This work also dismantles the assumption that VA benefit award is seemingly an equal access programs for all veterans with histories of military exposures, i.e. combat, death/dying/wounded, and environmental.

I further illustrate the nature of oppression, and embrace the idea of veteran feminism as a deliberate act, a social movement for equality by way of accessing the 'outsider within' status as a lived experience of the veterans who participated in these studies (Collins, 1986). The personal is political (Lorber, 2012 p. 507), a term that demonstrates the connection between personal experience and political arrangements. This assumption underlies this dissertation work and in its very nature seeks to demonstrate this connection, research that embodies the idea that women veterans and some men veterans offer a unique standpoint by, and for veterans as 'outsiders within' US military and VA, and in my case, as a veteran and feminist scholar. By drawing from 
Black feminist thought (Collins, 1986) this work is a change effort, a political act, created over time in my doctoral program with the hope to challenge externally defined negative images and stereotypes perpetuated by the total institution designed to control veteran's behavior, and maintain subordination of women veterans and some men veterans as members of the US military, a total institution (Collins, 1986). Contrary to the work produced by the dominant group that seeks to justify their position or institutional authority, I provide an alternative process of interpretation and documentation in this substantive area, emphasizing institutional processes and the responsibility they have for the lives of veterans rather than adopting pathologizing, stigmatizing, and dehumanizing discourse that fails to acknowledge the elements of social structures which work simultaneously. My veteran feminism aims to challenge not only what has been said about women veterans, and some men veterans as traumatized, victims, or needing to be managed, but gives credibility and power to a community of veterans who are aware of the lower status assigned to them by VA and US military institutions (Collins, 1986).

This is a necessary redirection of analytic categories and focus on structural patterns in research, most of which have ignored inequalities within broader contexts normally unrecognized as forms of inequality and misrecognized disadvantaged social locations (Fieldmen, 1991). As such, I propose that further work should follow suit and aim to offer a distinctly sociological perspective which highlights structural factors and power relations that move beyond individual-level factors to reframe how everyone's understanding of differing quality of life outcomes for some veteran groups. As a point of departure, all of us must challenge ourselves as researchers, clinicians, and authorities to understand lived experiences within broader organizational contexts, reveal existing complexities of inequalities, and the controls that prevent protest against them (Acker, 2006). This work has been an "evolving science," it is "collective critique and 
transformation" of my life and the lives of members of the veteran community - it is activism (DeVault, 1996 p. 31)-it is, in part, my veteran feminism.

\section{Key Findings Across All Three Studies}

In the first study I examined experiences and perceptions of gender-based violence in the US military reported by participants who are OEF/OIF women veterans and VA health care providers who serve them. All participants descried experiences of gender-based violence in the US military, including discrimination, harassment, sexual violence, and rape. Participants perceived gender-based violence as institutional betrayal through the lens of isolation, exclusion, and marginalization, demonstrated through mistrust and retaliation of the reporting process in the military and the VA health system. Notably, rather than only describing interpersonal violence, women veterans and VA providers alike described factors of the military as a total institution that contribute to this prevalent public health concern. In addition, although sexual violence within the military has been formally designated as MST by the VA, this terminology was not used by women veteran participants at the time of this study. Findings also indicate a need to critically evaluate the MST-designation as a mechanism that potentially influences access to VA benefits.

In the second study, I found markedly lower rates of MST reporting among VA users (Rock, 2013; Namrow \& Rock, 2013; Hoyt, Rielage, \& Williams, 2011; Rheinhardt 2016), low remembrance and distress among veterans screened for MST at the VA point of care. Due to US military and VA failures to further commit reducing military sexual abuse or provide relief for veterans with military sexual abuse histories, it is of vital necessity that alternative approaches be created for veterans outside of these institutions. Otherwise, current mandates fall short in prevention, relief, or justice for those who 
report military sexual abuse, with the burden placed on our nation's veterans. Our findings indicate that VA's unsuccessful and extremely ineffective... or nonexistent approaches to addressing military sexual harassment and assault and related health sequelae in the VA clinical setting are characteristics of the military as a total institution, specifically institutional avoidance of potential for disruption to meeting the institutional goals of the US military.

In the third study results indicate that military exposures are associated with greater likelihood for VADC award for veterans as a group, but women veterans with military exposures are less likely on average to be awarded VADC than men veterans with military exposures. Similarly, veterans with military exposures have a higher likelihood of a 50\%-or-greater VADC rating than veterans without military exposures, but that positive relationship is smaller for women veterans than for men veterans. Our findings support few previous studies that demonstrated a combat bias exists in VADC award (Murdoch et. al., 2003; Murdoch et. al., 2005; Schweitzer, 2016; Service Women's Action Network, 2013). Study results support these previous findings, and I empirically confirm that gender is also an important predictor for VADC award and rating award $50 \%$-or-greater.

Women veterans have faced historical marginalization in the military as an institution shaped by hegemonic masculinity through policies, practices, and ideologies that have consistently minimized women's efforts in military service. The difficulty in dismantling inequality regimes within institutions can be seen here, where practices and previous policy's restricting women from combat jobs (MOS) continue to influence 
ideologies about the value of women veterans' service, such that practices to restrict VADC award and benefits among women can be understood as systemic gender inequality. To examine VADC award among veterans is to attend to the gendered dimensions of inequality that are shaped by the structural facets of the military institution. By examining the interlocking policies and practices that reproduce complex inequalities from the military to the VA administration, we can interpret the implications of VADC award as a gendered outcome of inequality regimes perpetuated by the military institution.

The conclusions of these studies do not examine all the diverse experiences of veterans because the data are limited. Few studies have examined race/ethnicity, sexual and gender identity, and disability/health status and experiences with VA and US military institutions. These veteran subpopulations may experience these institutions very differently. Future research should seek to further explore and understand veteran experiences not covered in our analyses.

Conceptualizing the US military as a total institution (Goffman, 1961) and adopting Ackers (2006) concept of inequality regimes provides a framework for understanding the pervasive inequalities in the US military and VA. Although these institutions appear to provide equal access opportunities to veterans, findings from these three empirical studies demonstrate that policies, practices, and ideologies of the institutions perpetuate gender inequalities. Understanding the military as a total institution, including the loss of autonomy where veterans and other members within the institutions are "shaped and coded into an object that can be fed into the administration or 
establishment" (Goffman, 1961 p.16) is useful to better understand the processes that reproduce these inequalities, including characteristics of the military as a total institution as causative mechanisms of such gendered disparities. For example, Acker (2006) identified mechanisms that continue the perpetuation of inequality in work organizations. In these studies, we identified organizational logic, challenges in retention, supervisory practices, and formal and informal interactions as key mechanisms. Specifically, I found 1) a military culture that is hostile to women with women leaving military service to avoid further abuse, evidenced by narratives of gender-based violence experiences during military service and retaliation for reporting, 2) non-anonymous and therefore harmful VA screening of veterans for histories of military sexual abuse, and 3) gender bias in VA benefit award that disadvantage women veterans, with known implications for quality of life outcomes, such as loss of earnings and lack of access to health care.

These findings raise ethical concerns related to gender-based violence prevention and intervention strategies for US military and VA alike with implications for military officials, policymakers, researchers, and health care professionals. Given the results, I find that the US military and VA is an improper setting for gender-based violence reporting processes, investigations, and prosecution of perpetrators and accessing related health care considering the hierarchical structure of the military as total institution, the US military's rack record concerning cases of sexual abuse (Cernak, 2015), and VA's failure to address the social problem and health sequelae of military sexual abuse for veterans (Cernak, 2015; SWAN, 2016). I further suggest that the effect of the military as a total institution situates the MST-label (as reflected in VA health records) as one that is 
reified through the interplay of individual and institutional processes, such as reporting, prosecuting, and VA benefit award. As such, I recommend veterans, clinicians, authorities alike assess the potential impact of internalization of MST as an institutionalized label within the VA EMR and implications for veterans seeking VA health care services.

In sum, this dissertation project contributes to our understanding of how organizational policies, practices, and ideologies reproduce gender inequality across two institutions: the US military and VA. I demonstrate usefulness for the processes identified by Acker (2006) in this research, and Goffman's (1961) concept of the total institutions when applying the concept of the total institution to the military and its transferability to the VA. Findings highlight tacit acceptance of gender inequalities and resistance of institutional authorities to prevent and address military sexual abuse, disparities in benefit award, as well as retaliation and harmful organizational practices that prevent veteran reporting and recovery. Future military-related studies and policy initiatives should consider adopting these concepts to better avoid further harm and emotional costs of efforts that fail to offer effective therapeutic, beneficiary, and legal intervention, as well as social support for our nation's veterans since these shortcomings could move well beyond the personal/medical and into the public/legal domain.

I also demonstrate an urgent need for several changes in how VA handles VADC award for women veterans. Specifically, regulatory reform as well as improved training, oversight, transparency, and record keeping and accountability necessary to resolve the overall discrimination and gender bias in the adjudication of VA claims for disability 
compensation related to military exposures (Table 1). VADC is of vital importance to women veterans with health sequelae secondary to military exposures, not only because VA provides monetary assistance necessary for veterans in difficult financial situations, but because VADC award secures and determines priority enrollment in VHA services, securing access to critical medical attention (Schweitzer, 2013).

The US military still faces challenges in recruitment, integration, and retention of women. Our findings indicate transference of military challenges for women seeking VA benefits and entitlements under the law. Consistent with suggestions provided for other occupations, I support US military policy reforms for women's inclusion in all military occupational specialties across all branches of service since increasing gender diversity could have a positive impact on the US military overtime (SWAN, 2019). Furthermore, regulatory reform as well as improved training, oversight, transparency, and record keeping within the US military are necessary to resolve the overall discrimination and gender bias post-service for women veterans. As a step towards improving health and quality of life for women veterans, we must address gender inequalities at the structural level, a requirement for fundamental change to these organizations. 
Table 1. Recommendations

Changes in the US Military

Policy reforms for women's inclusion in all military occupational specialties across all branches of service

Release data annually on the military sexual assault and harassment rates

Release data annually on conviction rates of perpetrator and review of justification for legal outcomes

Accountability for training, oversight, transparency, and record keeping

\section{Changes in VA Treatment and Benefits Procedures}

Thoroughly evaluate evidence recorded in all personnel and medical records

Accept and review evidence outside of the veteran's military and VA records

Relax the evidentiary standard that applies to VADC award

Accept veteran testimony in VADC award and access to medical care

Improve oversight and target educational training of VA staff and clinicians of military

exposures and diagnostics needs of women veterans

Release data annually on the award rates for VADC for women veterans and justification by type of military exposure

Congress should pass regulatory reform for combat policies and VADC award for women veterans with service prior to combat inclusion

Congress should pass reform to terminate mandatory screening of veterans for MST by VA

\section{REFERENCES}

Acker, Joan. 2006. "Inequality Regimes: Gender, Class, and Race in Organizations.”

Gender \& Society 20(4):441-464.

Bettie, Julie. 2003. Women without Class: Girls, Race, and Identity. Berkeley CA:

University of California Press. 
Braswell, Harold., and Kushner, Howard. 2010. "Suicide, Social Integration, and Masculinity in the US Military” Social Science Medicine 2010:1-7.

Charmaz, Kathy. 1983. "The Grounded Theory Method: An Explication and Interpretation." Pp.109-126 in Contemporary Field Research, edited by R. Emerson. Prospect Heights, IL: Waveland Press.

Cohen, Philip N., and Matt L. Huffman. 2003. “Individuals, Jobs, and Labor Markets: The Devaluation of Women's Work." American Sociological Review 68:443-463. Collins, Patricia Hill. 2000. Black Feminist Thought: Knowledge, Consciousness, and the Politics of Empowerment. New York: Routledge.

Crenshaw, Kimberlé Williams. 1991. "Mapping the Margins: Intersectionality, Identity Politics, and Violence against Women of Color." Stanford Law Review 43(6):1241-1299.

DeVault ML. 1990. Talking and listening from women's standpoint: feminist strategies for interviewing and analysis. Soc. Probl. 37(1):96-116.

DeVault ML. 1996. Talking back to sociology: distinctive contributions of feminist methodology. Annu. Rec. Socio.. 22:29-50.

Doucet, Andrea and Natasha S. Mauther. 2002. "Knowing Responsibility: Ethics, Feminist Epistemologies and Methodologies." Pp. 123-45 in Ethics in Qualitative Research, edited by M. Mauthner, M. Birch, J. Jessop, T. Miller. London, England: Sage.

England, Paula, 1993. "The Separative Self: Androcentric Bias in Neoclassical Assumptions.” Pp. XX in Beyond Economic Man: Feminist Theory and 
Economics, edited by M. A. Farker and J. A. Nelson. Chicago: University of Chicago Press.

England, Paula. 2010. “The Gender Revolution: Uneven and Stalled." Gender \& Society 24(2):149-166.

Glaser, Barney G., and Anselm L. Strauss. 1967. The Discovery of Grounded Theory. Chicago, IL: Aldine.

Haraway D. 1988. Situated knowledges: the science question in feminism and the privilege of partial perspective. Fem. Stud. 14(3):575-99.

Harding S. 1986. The Science Question in Feminism. Ithaca, NY: Cornell Univ. Press Harding S, ed. 1987. Feminism and Methodology: Social Science Issues. Bloomington, IN: Ind. Univ. Press.

Harding S. 1991. Whose Science? Whose Know- ledge? Ithaca, NY: Cornell Univ. Press Harding S. 1992. Rethinking standpoint epistemology: what is "strong objectivity?" Centen. Rev. 36(3):437-70.

Huebner, Angela. Mancini, Jay., Wilcox, Ryan., Grass, Saralyn., and Grass, Gabriel.2007. "Parental Deployment and Youth in Military Families: Exploring Uncertainty and Ambiguous Loss." Family Relations. 56:112-122.

Ibarra, P. R. and J. L. Kitsuse. 1993. "Vernacular Constituents of Moral Discourse: An Interactionist Proposal for the Study of Social Problems.” Pp. 25-28 in Reconsidering Social Constructionism, edited by J. Holstein and G. Miller. New York: Aldine de Gruyter. 
Kane, Emily W. 2012. The Gender Trap: Parents and the Pitfalls of Raising Boys and Girls. New York: New York University Press.

Kanter, Rosabeth Moss. 1977. Men and Women of the Corporation. New York: Basic Books.

Lorber, Judith. 2012. Gender Inequality: Feminist Theories and Politics, fifth edition. New York: Oxford University Press.

McKelvey,T. 2007. One of the Guys: Women as Aggressors and Torturers. Emeryville, CA: Seal Press.

MacKinnon, Catharine A. 1982. "Feminism, Marxism, Method, and the State: An Agenda for Theory.” Signs 7(3):515-544.

Maguen, Shira., Luxton, David., Skopp, Nancy., and Maddin, Erin. (2012). Gender differences in traumatic experiences and mental health in active duty soldiers redeployed from Iraq and Afghanistan. Journal of Psychiatric Research 46:311316.

Mason, Katherine. 2012. "The Unequal Weight of Discrimination: Gender, Body Size, and Income Inequality.” Social Problems 53(3).

Mattocks, Kristin., Haskell, Sally., Krebs, Erin., Justice, Amy., Yano, Elizabeth., and Brandt, Cynthia. 2012. "Women at war: Understanding how women veterans cope with combat and military sexual trauma." Social Science Review 75:537545.

McCall, Leslie. 2005. "The Complexity of Intersectionality." Signs: Journal of Women in Culture and Society 30(3):1771-1800. 
Naples, Nancy. 2003. Feminism and Method: Ethnography, Discourse Analysis, and Activist Research. New York: Routledge.

Ramazanoglu, Caroline, and Janet Holland. 2002. “Chapter 1: Introduction.” Pp. 1-16 in Feminist Methodology: Challenges and Choices. Thousand Oaks, CA: Sage Publications.

Ridgeway, Cecilia L. 2011. Framed by Gender: How Gender Inequality Persists in the Modern World. New York: Oxford University Press.

Risman, Barbara J., and Georgiann Davis. 2013. "From Sex Roles to Gender Structure." Current Sociology 61(5-6):733-55.

Sandra Harding, ed., 2004. The Feminist Standpoint Theory Reader New York and London: Routledge.

Shaw, R., Lee, S. \& Lee, J. (2015). Women's Voices, Feminist Visions: Classic and Contemporary Readings, sixth edition. Boston: McGraw Hill.

Shilt, Kristen. 2010. Just One of the Guys: Transgender Men and the Persistence of Gender Inequality. Chicago: University of Chicago Press. 